\title{
Cellular adaptation to dehydration stress: Molecular adaptations for dehydration tolerance in the African clawed frog, Xenopus laevis
}

\author{
Amal I. Malik
}

B.Sc. University of Oregon, 2003

\begin{abstract}
A Thesis Submitted to the Faculty of Graduate Studies and Research in partial fulfillment of the requirements for the degree of
\end{abstract}

\author{
Doctor of Philosophy \\ Department of Biology
}

Carleton University

Ottawa, Ontario, Canada

(C) copyright 2009

Amal I Malik 
Library and Archives

Canada

Published Heritage

Branch

395 Wellington Street

Ottawa ON K1A 0N4

Canada
Bibliothèque et

Archives Canada

Direction du

Patrimoine de l'édition

395, rue Wellington

Ottawa ON K1A 0N4

Canada
Your file Votre reférence

ISBN: 978-0-494-60109-9

Our file Notre reference

ISBN: 978-0-494-60109-9

\section{NOTICE:}

The author has granted a nonexclusive license allowing Library and Archives Canada to reproduce, publish, archive, preserve, conserve, communicate to the public by telecommunication or on the Internet, loan, distribute and sell theses worldwide, for commercial or noncommercial purposes, in microform, paper, electronic and/or any other formats.

The author retains copyright ownership and moral rights in this thesis. Neither the thesis nor substantial extracts from it may be printed or otherwise reproduced without the author's permission.
AVIS:

L'auteur a accordé une licence non exclusive permettant à la Bibliothèque et Archives Canada de reproduire, publier, archiver, sauvegarder, conserver, transmettre au public par télécommunication ou par l'Internet, prêter, distribuer et vendre des thèses partout dans le monde, à des fins commerciales ou autres, sur support microforme, papier, électronique etlou autres formats.

L'auteur conserve la propriété du droit d'auteur et des droits moraux qui protège cette thèse. $\mathrm{Ni}$ la thèse ni des extraits substantiels de celle-ci ne doivent être imprimés ou autrement reproduits sans son autorisation.
In compliance with the Canadian Privacy Act some supporting forms may have been removed from this thesis.

While these forms may be included in the document page count, their removal does not represent any loss of content from the thesis.
Conformément à la loi canadienne sur la protection de la vie privée, quelques formulaires secondaires ont été enlevés de cette thèse.

Bien que ces formulaires aient inclus dans la pagination, il n'y aura aucun contenu manquant.

\section{Canadä}


The undersigned hereby recommend to the Faculty of Graduate Studies and Research acceptance of this thesis

\title{
Cellular adaptation to dehydration stress: molecular adaptations for dehydration tolerance in the African clawed frog, Xenopus laevis
}

\author{
submitted by \\ Amal I. Malik, B.Sc. \\ in partial fulfillment of the requirements for the degree of Doctor of Philosophy
}

Chair, Department of Biology

Thesis Supervisor

External Examiner

Carleton University 


\begin{abstract}
The thesis addressed multiple questions about the signal transduction mechanisms that trigger gene expression responses to dehydration signals, and about the role of antioxidant defenses in combating dehydration stress in the African clawed frog, Xenopus laevis.
\end{abstract}

In the first part of the thesis the responses to dehydration stress by the three main MAPK cascades were traced by measuring both total protein levels, and the relative amounts of active phosphorylated proteins for multiple intermediates in the p38 MAPK, stress-activated protein kinase (SAPK), and extracellular signal-regulated kinase (ERK) cascades. The data documented a major activation of the ERK pathway in most organs of $X$. laevis during dehydration. Selected upstream activator and downstream targets of the ERK pathway also showed pronounced tissue specific regulation in response to dehydration. The SAPK was activated in skeletal muscle, lung, and skin whereas the p38 MAPK was activated in the lung and kidney of $X$. laevis.

The second part of the thesis focused on antioxidant defenses that are known to be contributors to cell preservation under various types of stress. Two main transcription factors that regulate antioxidant genes were activated in response to dehydration in $X$. laevis organs: NF-E2 related factor (Nrf2) and forkhead box, class $\mathrm{O}$ (FoxO). Immunoblotting showed a significant increase in their nuclear translocation, and enzymelinked immunosorbant assays showed increased DNA binding activity by FoxO1 under dehydration stress. Expression of downstream target genes controlled by these transcription factors was enhanced during dehydration. Six family members of the glutathione S-transferase (GST) and three family members of the aldo-keto reductase 
(AKR) showed tissue specific expression, correlated with Nrf2 activation. Manganesedependent superoxide dismutase (MnSOD) and catalase expression were also elevated under FoxO1 control. Improved antioxidant defenses may be critical to dealing with variations in tissue oxygenation and reactive oxygen species generation that are one consequence of large changes in body hydration that affect oxygen delivery to tissues.

This thesis showed for the first time that the MAPKs family members are selectively activated in response to two levels of dehydration stress in $X$. laevis. Also, antioxidant defenses play a critical protective role during dehydration stress in these frogs. 


\section{ACKNOWLEDGEMENTS}

First and foremost, I would like to express my appreciation and gratitude to my Mom for all her continuous help and support throughout the years. She has furnished my pathway with better educational opportunities to excel in my studies and attain higher academic degrees. Without her love and support I could have not accomplished what I have. I would also like to convey my great thanks to my husband for being there for me, and for all his support and encouragement.

I would like to thank my thesis supervisor Dr. K.B. Storey. I express my gratitude to Dr. Storey for providing me the opportunity to join his lab, and for his continuous guidance and constructive advice. Also, I extend my appreciation to J.M. Storey for her enduring cooperation and assistance in reviewing and editing my work. Furthermore, many thanks to the Storey lab members for their help and support especially Anastasia for always being there.

Last, but not least, I would like to thank my committee members Dr. T.W. Moon and Dr. J.J. Cheetham for their valuable comments and suggestions, and, many thanks to Dr. R. Liversage and Mr. N. White for providing the animals for this study. 


\section{TABLE OF CONTENTS}

Title Page

Acceptance Sheet $\quad$ ii

$\begin{array}{ll}\text { Abstract } & \text { iii }\end{array}$

Acknowledgements $\quad$ V

Table of Contents vi

List of Abbreviations

List of Figures $\quad x$

List of Tables $\quad$ xii

Chapter 1 General Introduction 1

Chapter 2 Activation of extracellular signal-regulated kinases during $\quad 12$ dehydration in the African clawed frog, Xenopus laevis.

Chapter 3 Transcription regulation via the activation of mitogenactivated protein kinases during dehydration in the African clawed frog, Xenopus laevis.

Chapter 4 Activation of antioxidant defense via Nrf2 transcription factor in the dehydrated African clawed frog.

Chapter 5 Transcriptional regulation of antioxidant enzymes by FoxO1 in the dehydrated Xenopus laevis.

Chapter 6 General Discussion

$\begin{array}{ll}\text { Publication List } & 99\end{array}$

$\begin{array}{lr}\text { References } & 102\end{array}$

Appendixes $\quad 113$ 


\section{LIST OF ABBREVIATIONS}

AA

AFAR

AKT

AKR

AP-1

ATP

ARE

BLAST

bZip

cDNA

CREB

DEPC

DTT

ETC

ECL

EDTA

ELISA

$\mathrm{EtBr}$

ERK

FoxO

GST

HEPES
Amino acid

Aflatoxin aldehyde reductases

Protein kinase B

Aldo-keto reductase

Activator protein 1

Adenosine triphosphate

Antioxidant response element

Basic Local Alignment Search Tool

Basic leucine zipper

Complementary deoxyribonucleic acid

cAMP response element binding protein

Diethylpyrocarbonate

Dithiolthreitol

Electron transport chain

Enhanced chemiluminescence

Ethylenediamine tetraacetic acid

Enzyme-linked immunosorbent assay

Ethidium bromide

Extracellular signal regulated kinase

Forkhead box, class $\mathrm{O}$ proteins

Glutathione $S$-transferase

N- (2-hydroxyethyl) piperazine-N'- (2-ethanesulfonic acid) 
JNK

$\mathrm{kb}$

$\mathrm{kDa}$

Keap 1

Maf

MAPK

Mcl-1

MOPS

mRNA

NCBI

Nrf2

PAGE

PCR

PMSF

PVDF

ROS

rRNA

RT

RT-PCR

SAPK

SDS

MnSOD
c-Jun N-terminal kinases

Kilobase

Kilodalton

Kelch-like ECH-associated protein 1

v-maf musculoaponeurotic fibrosarcoma (avian) oncogene family, protein

Mitogen-activated protein kinase

Myeloid cell factor-1

2- (N-morpholine) propanesulfonic acid

Messenger RNA

National Center for Biotechnology Information

Nuclear factor-erythroid 2 related factor -2

Polyacrylamide gel electrophoresis

Polymerase chain reaction

Phenylmethanesulfonyl fluoride

Polyvinylidine fluoride

Reactive oxygen species

Ribosomal RNA

Room temperature $\left(\sim 21^{\circ} \mathrm{C}\right)$

Reverse-transcriptase polymerase chain reaction

Stress activated protein kinase

Sodium dodecyl sulfate

Manganese superoxide dismutase 
TAE Tris-acetate-ethylenediamine tetraacetic acid buffer

TEMED N,N,N',N'-tetramethylethylenediamine

Tris Tris (hydroxymethyl) aminomethane 


\section{LIST OF FIGURES}

Fig. 2.1 Progress of body water loss by $X$. laevis over 6-7 days. 30

Fig. 2.2 Schematic of the ERK pathway members analyzed. 31

Fig. 2.3 Effect of medium and high dehydration on the activation of c-Raf 32 and MEKK.

Fig. 2.4 Effect of medium and high dehydration on MEK 1/2 total protein levels and phosphorylation status.

Fig. 2.5 Effect of medium and high dehydration on ERK2 total protein level and phosphorylation status.

Fig. 2.6 Effect of medium and high dehydration on the activation of STAT3 and RSK.

Fig. 2.7 Effect of medium and high dehydration on S6 ribosomal protein and phosphor-S6 ribosomal protein.

Fig. 3.1 Western blots analysis of total (A) JNK protein and (B) phosphorylated JNK protein expression in tissues from control, medium, and high dehydrated $X$. laevis.

Fig. 3.2 Effect of medium and high dehydration on the protein levels of

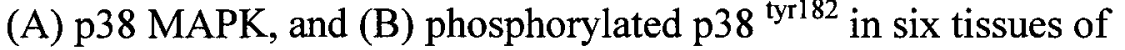
$X$. laevis.

Fig. 3.3 Western blots analysis of total (A) c-Jun, and (B) phosphorylated

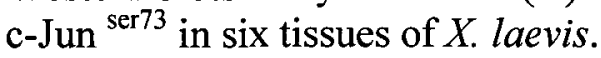

Fig. 3.4 Effect of medium and high dehydration on phospho-c-Myc protein expression in five tissues of $X$. laevis.

Fig. 3.5 Western blots analysis of total of (A) CREB, and (B)

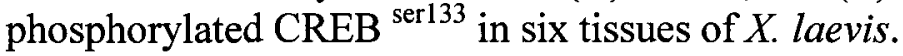


Fig. 4.1 Effect of dehydration on $X$. laevis $\mathrm{Nrf2}$ (A) protein expression, (B) representative bands on agarose gels showing OCR product levels, and (C) representative western blots showing levels of Nrf2 protein in nuclear extracts.

Fig. 4.2 Effect of dehydration on the expression of GST pi and mu family members in six tissues of $X$. laevis: (A) GSTP1, (B) GSTM1, (C) GSTM3.

Fig. 4.3 Effect of dehydration on the expression of GST kappa, alpha and theta family members in tissues of $X$. laevis: (A) GSK1, (B) GSTA3, (C) GSTT1.

Fig. 4.4 Effect of dehydration on the expression of AKR family members in X. laevis: (A) AFAR1, (B) AKR1B4, (C) AKR1A3.

Fig. 5.1 Effect of dehydration on X. laevis FoxO1: (A) relative protein distribution in nuclear extracts of muscle and liver from control and dehydrated frogs, (B) expression of phospho-FoxO $1^{\text {ser245 }},(\mathrm{C})$ expression of phospho-FoxO1 ${ }^{\text {thr28 }}$.

Fig. 5.2 Effect of dehydration on the expression of MnSOD: (A) total protein level, (B) mRNA level in the muscle and liver of $X$. laevis.

Fig. 5.3 Effect of dehydration on the expression of catalase: (A) total protein level, (B) mRNA level in the muscle and liver of $X$. laevis. 


\section{LIST OF TABLES}

Table 2.1 Total body water lost by experimental groups of $X$. laevis, blood hematocrit. Plasma urea and plasma glucose concentrations. 


\section{CHAPTER 1}

\section{General Introduction}




\section{INTRODUCTION}

Water availability in the environment has major influence on the distribution, activity, and behavior of amphibians. As consequences of their highly water permeable skin, most amphibians (a) live in moist or wet environments where they can keep themselves well-hydrated by absorbing water across their skin, and (b) show the widest tolerance among vertebrate groups for variation in body water content and body fluid ionic strength and osmolality. Hence, they are good models for studies of dehydration effects because of their unique abilities to survive dehydration levels that would be lethal to other vertebrates (Hillman et al., 2009). A variety of species that live in seasonally arid environments can withstand long periods of dehydration (especially while estivating) through applying one or more of these strategies: 1) conserving water by forming waterproof cocoons that minimize evaporative water loss, 2) accumulating urea to increase the osmolality of body fluids (Feder and Burggren, 1992), 3) oxidizing lipid reserves as fuels during estivation, which results in metabolically produced water. In addition, during dehydration, water in extra-organ fluid spaces and in the bladder is used first to help stabilize the water of vital organs, but as the stress progresses and dehydration levels become severe, organs experience water loss too (Churchill and Storey, 1993).

In sub-Saharan Africa, the clawed frog Xenopus laevis is known to occupy swamps, lakes, rivers and human-established bodies of water like dams and wells (Tinsley and Kobel, 1996). These environments can change rapidly during the dry season. As these bodies of water dry up, the absence of water affects the vegetation and wild life in the area making it hard for Xenopi to survive, so they estivate and rely on adaptive mechanisms to help them survive their harsh environment. Estivation in lower 
vertebrate is poorly studied except for lungfish (Dunn et al., 1983; Fishman et al., 1992; Frick et al., 2008; Ferreira da Silva et al., 2008). The fact that $X$. laevis leads an almost totally aquatic life but still shows a substantial tolerance to dehydration and salinity change made it an attractive model for the studies of dehydration responsive signal transduction and gene expression presented in this thesis.

In order to survive long periods of stress, animals have to decrease their metabolic demands. This occurs in a coordinated manner in a process known as metabolic rate depression (MRD). This adaptation has been reported in animals experiencing different types of environmental stressors including anoxia, estivation, dehydration, freezing, and hibernation. To date, many metabolic pathways that assist in stress resistance have been identified. All these pathways are regulated by processes that involve stress activated signal transduction cascades. Controlling the activity of enzymes and functional proteins via reversible protein phosphorylation is considered the most powerful mechanism of MRD. The process involves the addition or removal of a phosphate group, via the action of protein kinases and protein phosphatases, resulting in a change in enzyme/protein conformation that can affect multiple parameters including activity, sensitivity to efforts, binding to other proteins, etc (Storey, 2004). One of the best-studied families of protein kinases is the mitogen-activated protein kinases (MAPKs). MAPK cascades begin at the cell membrane where an external signal causes the activation of a receptor kinase, typically a receptor protein tyrosine kinase (RPTK). This then triggers a three-tier regulatory cascade of kinases that provide a huge amplification of signal through the serial activation of the MAPK kinase kinase (MAPKKK), MAPK kinase (MAPKK) and finally the MAPK, increasing its activity by about 1000-fold (Cowen and Storey, 2003). The role of many members of this superfamily of kinases in regulating stress responses in 
cells has been identified in a number of animal species (Greenway and Storey, 2000a; Greenway and Storey, 2000b; Cowan and Storey, 2003; MacDonald and Storey, 2005; Larade and Storey, 2006). This made them a good potential target of study when analyzing $X$. laevis responses to dehydration. As part of $\mathrm{MRD}$, reversible protein phosphorylation also contributes to regulating gene transcription via inhibiting or activating a number of transcription factors (TFs). Gene transcription is an energy expensive process that costs cells about $1-10 \%$ of their energy budget; protein synthesis is even more expensive and can consume up to $40 \%$ cellular ATP turnover in some tissues. As a consequence, one part of MRD must include strong global suppression of transcription and translation. In general, cells respond by shutting down the synthesis of most proteins but production of selected proteins is continued and/or up-regulated. This is particularly true of proteins that play roles in stabilizing and protecting other macromolecules (Storey and Storey, 2004). Antioxidant defense enzymes are one class of protective proteins that are typically up-regulated under stress conditions. For example, they play a protective role during anoxia stress in freshwater turtle, garter snakes, and the leopard frogs and also aid natural freezing survival in wood frogs and garter snakes (Hermes-Lima and Storey, 1993a; Hermes-Lima and Storey, 1993b; Hermes-Lima and Storey, 1996; Willmore and Storey, 1997a; Willmore and Storey, 1997b; Joanisse and Storey, 1996). Since dehydration stress in X. laevis leads to an increase in blood viscosity and a decrease in blood volume causing a decrease in oxygen circulation and generalized tissue hypoxia (Hillman, 1978), rehydration in this species might cause an increase in reactive ROS in a manner similar to that seen in mammalian organs during post-ischemic reperfusion. Hence, I reasoned that the activation pattern of two transcription factors (Nrf2 and FoxO1) might play a protective role during dehydration in $X$. laevis by 
increasing the production of a number of antioxidant enzymes.

\section{LIFE HISTORY AND PREVIOUS STUDIES}

Xenopus is a genus of frogs that was described in 1803 by Daudin. The bestknown species is Xenopus laevis from southern Africa. The scientific names Xenopus (meaning peculiar foot) and laevis (meaning smooth) were given to the frog by Wagler and Daudin, respectively, during the $19^{\text {th }}$ century (Deuchar, 1975). Platanna, flat hand, is the popular name of the species in South Africa. However, X. laevis is mostly known as the African clawed frog because of the presence of keratinous claws on the inner toes of its hind legs (Cannatella and De Sa, 1993). The Xenopus genus is known for its bizarre flattened body, clearly designed for swimming. The body includes fairly long and muscular hind legs that extend sideways and have webbed toes for swimming and short lateral forelegs with no webbing and long flexible toes that play no significant role in supporting the body but guide food to the mouth. Xenopus also has a small head relative to its body size with dorsally pointed eyes since the frogs spend much of their time on the bottom of bodies of water watching for prey or predators to approach from above. The eyes lack an eyelid but have a highly convex cornea to improve the range of vision overhead. The middle ears of Xenopus are fully developed but concealed by skin, and the tongue is absent (Cannatella and De Sa, 1993; Deuchar, 1975). Even though Xenopus does not have a visible ear drum, which is considered a primitive feature in aquatic vertebrates that is not adapted to receiving airborne vibration, the presence of a cartilaginous disc under the skin behind the eyes in Xenopus is implicated in providing the same functions as an ear-drum in terrestrial frogs. This may also give it an advantage 
since the disc could better analyze vibrations carried through water because it has greater robustness than an ear-drum (Deuchar, 1975).

The sudden appearance of Xenopi in newly formed ponds at the beginning of the rainy season gave indirect evidence of their ability to estivate. Direct evidence followed when drought conditions were simulated in the lab, and the frogs were observed to disappear into the mud. $X$. laevis can survive eight months of estivation with no food or water (Tinsley and Kobel, 1996). Estivation is a state of torpor used by anurans that inhabit areas with limited water supply during the dry season (Feder and Burggren, 1992). Even though estivating species show a high level of dehydration and starvation tolerance, retaining water and maintaining cellular energy reserves represent the most critical elements for their long term survival. Thus, survival during estivation is strongly constrained by the starvation and desiccation conditions that the animals have to face. As mentioned before estivators are not the only animals known to use MRD as a strategy to endure environmental stress conditions; rather it is a common strategy for dealing with many types of environmental stress (Storey and Storey, 1990). For example, by suppressing metabolic rate to $25 \%$ of normal, animals gain a 4 -fold extension of the time that they can survive using their stored reserves of internal fuels. Also, according to Feder and Burggren (1992), MRD in estivators is temperature dependent.

$X$. laevis can survive long term starvation (Merkle and Hanke, 1988a). When starved, the frog goes through two distinct phases. The first one starts within about 2 weeks and lasts for about 4-6 months. This phase is marked by a decrease in oxygen consumption to about $30 \%$ of normal resting values within a few days of starvation. The frogs switch gradually from metabolizing protein, provided from the frogs' normal diet, to relying on lipid and glycogen consumption. The first phase ends with the beginning of 
an energy crisis caused by the depletion of carbohydrates and lipid reserves after 4-6 months of starvation (Hanke and Merkle, 1988a, b). The second phase starts with an increase in oxygen consumption, an increase in nitrogen excretion and a decrease in muscle protein mass indicating a switch to protein catabolism for energy. This phase lasts for about 40 weeks and is then followed by yet another diminished metabolic rate. After 12 months of starvation a $30-40 \%$ decrease in blood glucose was evident (Hanke and Merkle, 1988a) whereas plasma electrolyte levels seemed to be well-controlled with a 10$30 \%$ decline only.

$X$. laevis have a very small bladder and so cannot rely on it to store water during estivation like many other estivating frog species do. Hence, their main option seems to be the metabolic strategy of minimizing water loss by increasing body fluid osmolality via urea accumulation. To do this, the frogs reduce ammonia excretion, increase the activities of urea cycle enzymes and convert ammonia to urea that accumulates in plasma and tissues (Balinsky et al., 1961; Janssens, 1964; Seiter et al., 1978). Carbamoyl phosphate synthetase (CPS) is the rate-limiting step in urea production, because it provides the initial substrate used in the urea cycle. CPS uses bicarbonate, ammonia, and phosphate (derived from ATP) to produce carbamoyl phosphate (Horton et al., 1996). With respect to $X$. laevis, researchers have analyzed both natural and experimental conditions where the animals are under water stress (ie. dehydration in air or immersion in hypersaline water). Balinsky et al. (1967) analyzed a group of X. laevis that had been naturally estivating for 2-3 months; they found small variations in tissue amino acid levels but plasma amino acid levels doubled or tripled and urea rose 15-20 fold during estivaiton. Liver CPS activity also increased $\sim 6$-fold. Effects of dehydration were also directly analyzed in frogs that were held out of water for 1-3 weeks with results showing 
that urea levels increased in $X$. laevis liver, blood and muscle proportional to the extent of water loss (Balinsky et al., 1961). Exposure of these freshwater frogs to hypersaline external medium ( $0.9 \%$ saline) also led to urea accumulation in $X$. laevis tissues (Janssens, 1964).

$X$. laevis has been widely studied for about 50 years, both as a convenient adult amphibian model for various physiological studies and, much more extensively, as a model of embryonic development. However, the molecular mechanisms that help $X$. laevis to survive long periods of dehydration have not been investigated in depth. Dehydration is one form of environmental stress that cells can adapt to by regulating different pathways that are central to an animal's metabolism. Other stress models showed the ability to regulate powerful biochemical mechanisms to achieve a much lower metabolic rate. These mechanisms are usually quickly reversed upon arousal. There is little known about the regulation of gene expression in estivating animals, therefore more research is needed in that area (Storey, 2002). One aspect of estivation is explored in this thesis - selected gene responses to dehydration. From other stress models it has been established that conserving fuel reserves is a key component of long-term survival, and animals achieve this using MRD. Indeed, estivators typically lower metabolic rate to levels that are just $20-30 \%$ of normal resting rate (Storey, 2002). Similarly, dehydration stress is known to cause a significant decline in $X$. laevis active metabolic rate reaching values similar to that of resting metabolic rate at $30 \%$ water loss (Hillman, 1978). 


\section{OBJECTIVES AND HYPOTHESES}

\section{Objective 1: Dehydration stress and mitogen activated protein kinases (MAPKs)}

For dehydrating animals, reducing energy expensive processes is essential for long term survival. Protein modification via phosphorylation is ATP-inexpensive and quickly reversible upon removal of the stress. The mitogen-activated protein kinase (MAPK) superfamily encompasses major conserved signaling cascades that lead to the control of diverse physiological processes by phosphorylating a number of proteins and transcription factors that play an essential role in cell differentiation, mobility, energy metabolism and apoptosis. I predicted that dehydration stress would disturb the balance of these processes and that stress-induced MAPK signaling will be important in implementing responses to dehydration.

Hypothesis: MAPK family members are activated during dehydration in $X$. laevis tissue and exert their activity via induction of proteins and transcription factors that play protective roles.

Chapter 2 tests this hypothesis by assessing the protein levels and activation status of different components in the ERK pathway using western blotting. Tissue specific activation was seen for the ERK pathway components c-Raf, MAPK ERK Kinase (MEK1/2), and MEK Kinase. The activation of ERK upstream activators and downstream targets showed similar patterns to that of ERK. Two known downstream targets of the ERK pathway were also tested: the signal transducer and activators of transcription (STAT) and the p90 ribosomal S6 kinase (RSK). Furthermore, the total 
protein levels and activation status of one of the RSK downstream targets, ribosomal S6 protein (S6RP), was measured in response to medium and high dehydration in $X$. laevis.

Chapter 3 further investigates two other MAPK modules by measuring protein levels and phosphorylation status of JNK and p38. In this chapter significant activation of the p38 MAPK pathway was demonstrated in lung and kidney whereas JNK-mediated signaling was important in muscle, lung and skin. Total protein levels and the phosphorylation status of three known downstream targets of this pathway were further assessed: c-Jun, c-Myc, and the cAMP responsive element binding protein (CREB). All showed tissue specific regulation in response to dehydration in $X$. laevis.

\section{Objective 2: Dehydration stress and antioxidant defense}

One effect of dehydration is an increase in blood viscosity and a decrease in blood volume that, as dehydration progresses, impairs proper oxygen delivery to tissues and causes hypoxia. During rehydration, oxygen will again rise but a rapid increase in oxygen levels also causes oxidative stress that must be dealt with by cellular antioxidant defenses. Elevated antioxidant defenses have been proven to be a widespread component of hypometabolism in multiple animal systems suggesting their beneficial effects in long term cell protection under conditions where energy/fuel limitation does not allow normal levels of protein turnover (synthesis, degradation) to eliminate oxidatively damaged macromolecules.

Hypothesis: Tissue response to dehydration stress in $X$. laevis includes the activation of antioxidant transcription factors such as NF-E2 related factor (Nrf2) 
and forkhead box, class $\mathrm{O}$ (FOXO) and leads to the up-regulation of antioxidant enzymes under their control.

Chapter 4 tests this hypothesis by measuring Nrf2 protein expression in six tissues of $X$. laevis. Tissue specific regulation of $\mathrm{Nrf} 2$ in response to dehydration stress included a significant increase in Nrf2 protein level in the lung, heart, skin and liver. RT-PCR also demonstrated an increase in $n r f 2$ mRNA expression in liver. Studies of Nrf2 downstream targets, glutathione $S$-transferases and the aldo-keto reductases, showed organ specific patterns of expression during dehydration.

Chapter 5 further investigates antioxidant responses by examining the activation status of FoxO1 transcription factors in $X$. laevis muscle and liver. Total protein and mRNA levels of two FoxO1 downstream targets, catalase and $\mathrm{Mn}^{2+}$-dependent superoxide dismutase (MnSOD), were also analyzed. In the liver, FoxO1 showed a significant increase in nuclear translocation and DNA binding activity under dehydrating conditions. The activation pattern of this transcription factor was similar to that seen in the two downstream targets studied. Western blotting showed a significant increase in catalase and MnSOD protein levels in $X$. laevis liver. RT-PCR confirmed that the increases in both enzymes were due to elevated catalase and MnSOD mRNA levels in liver. 


\section{CHAPTER 2}

\section{Activation of extracellular signal- regulated kinases during dehydration in the African clawed frog, Xenopus laevis}




\section{INTRODUCTION}

The African clawed frog is native to southern Africa, and lives in areas where water is limited (Tinsley and Kobel, 1996). The frog is largely aquatic, but it has the ability to survive through the dry season. The molecular signaling mechanisms that allow adult $X$. laevis to deal with environmental dehydration stress have not been explored. This chapter explores one of the signal transduction cascades that mediate external stress signals to coordinate metabolic and gene expression responses by cells. This is the extracellular signal-regulated kinase (ERK) cascade, one family of the mitogen-activated protein kinase (MAPK) superfamily. This superfamily encompasses major conserved signaling cascades that lead to the control of diverse physiological processes (Roux and Blenis, 2004; Krishna and Narang, 2008). MAPKs have been classified into six distinct pathways in mammals based on their preferential response to selected signals (Krishna and Narang, 2008). The three most studied groups of vertebrate MAPKs are: 1) the p38 MAPKs, that were originally described as a $38 \mathrm{kDa}$ protein that is phosphorylated under endotoxin treatment or osmotic shock, 2) the stress activated protein kinases (SAPKs), also known as JNKs, because they were first discovered by their role in the phosphorylation of the c-jun transcription factor, and 3) the ERKs (Cowan and Storey, 2003; Krishna and Narang, 2008).

The regulation of the three main MAPK members in response to different stressors has been well characterized in mammalian cell lines but until recently the role of this superfamily in regulating adaptive responses in stress tolerant animals has received little attention (Cowan and Storey, 2003). Recent work in our lab has examined the responses of the three MAPK families to whole body freezing in wood frogs, anoxia 
exposure in turtles and snails, and hibernation in ground squirrels (Greenway and Storey, 2000a; Greenway and Storey, 2000b; Cowan and Storey, 2003; MacDonald and Storey, 2005; Larade and Storey, 2006). In wood frogs (Rana sylvatica), for example, natural freezing survival was associated with the activation of $\mathrm{p} 38$ and JNK in different tissues, whereas the ERK pathway was unaffected (Greenway and Storey, 2000a). Studies have also explored the activation of MAPK family members in another frog species (Rana ridibunda) by diverse stimuli, including oxidative stress (Aggeli et al., 2001; Gaitanaki et al., 2003). In the present study I hypothesized that the ERK2 pathway would be activated in response to dehydration stress leading to subsequent activation of downstream ERK targets. Among the targets of ERK are various transcription factors and protein kinases whose actions could play roles in cellular responses to dehydration including enhanced expression of genes encoding protective proteins as well as protein kinase mediated readjustment and/or suppression of energy-expensive cellular processes under stress. This chapter examines the effect of dehydration on the expression of the ERK2 pathway in $X$. laevis including the upstream regulators of ERK2 and some of its downstream targets. The data show a strong coordinated activation of the entire cascade providing good evidence of a significant role for ERK signaling in regulating both metabolic and gene expression responses to dehydration in the frogs.

\section{MATERIAL AND METHODS}

\section{Animals}

Animal holding and experimental procedures received prior approval of the Carleton University Animal Care Committee. Female X. laevis (Daudin), 80-128 g body mass, were a donation from the Department of Zoology, University of Toronto. Animals 
were held in tanks of dechloraminated water at $22^{\circ} \mathrm{C}$. Dehydration experiments were similar to those described by Churchill and Storey (1993). Animals were divided into three groups: (1) controls maintained as above, (2) medium dehydration, and (3) high dehydration. For medium dehydration, frogs were placed in closed containers and were allowed to air dry over time. For high dehydration, frogs were placed in the same types of containers but these had a layer of silica gel desiccant in the bottom which resulted in a more rapid rate of dehydration; a perforated divider prevented frogs from touching the desiccant. Water loss was monitored at intervals over 6-7 days by removing the animals at intervals and quickly weighing them. Six frogs were monitored at frequent intervals (Fig. 2.1) and the others less often. The change in mass was used to calculate the percentage of total body water lost via the following equation:

$\%$ water lost $=\left[\left(\mathrm{W}_{\mathrm{i}}-\mathrm{W}_{\mathrm{d}}\right) /\left(\mathrm{W}_{\mathrm{i}} * \mathrm{BWC} \mathrm{i}\right)\right] * 100$

where $\mathrm{W}_{\mathrm{i}}$ is the initial mass of an individual, $\mathrm{W}_{\mathrm{d}}$ is the mass during experimental dehydration, and $\mathrm{BWC}_{\mathrm{i}}$ is the initial body water content of frogs before dehydration. $\mathrm{BWC}_{\mathrm{i}}$ was determined from measurements of the wet and dry masses of 7 euthanized frogs; the value was $0.741 \pm 0.019 \mathrm{~g}$ water per $\mathrm{g}$ body mass. Medium and high dehydration groups of frogs were sampled when they reached predetermined levels of water loss. For tissue sampling, frogs were quickly pithed, blood samples were retrieved (see below), and then tissues were quickly dissected out and frozen in liquid nitrogen prior to transfer to $-80^{\circ} \mathrm{C}$ for long term storage.

\section{Blood sampling, hematocrit and metabolic assays}

Blood was sampled as follows. The aorta was snipped and two $50 \mu \mathrm{l}$ aliquots of blood were quickly withdrawn into heparinized micropipettes. These were plugged at one 
end with miniseal (Dade), centrifuged for $1 \mathrm{~min}$ and then total sample length and packed red blood cell length in the tubes were measured and used to calculate hematocrit. Remaining blood was pipetted into $2 \mathrm{ml}$ microcentrifuge tubes with a aliquot $(\sim 0.1 \mathrm{vol})$ of anticoagulant solution added (10 mM EDTA in $0.9 \% \mathrm{w}: \mathrm{v} \mathrm{NaCl})$. Samples were centrifuged for $5 \mathrm{~min}$ at $5^{\circ} \mathrm{C}$ and then plasma was removed and frozen at $-80^{\circ} \mathrm{C}$. Plasma glucose levels were measured using a commercial glucose analyzer (Freestyle). Initial tests with known amounts of glucose added to aliquots of $X$. laevis plasma showed that there were no detection problems when using frog plasma with this commercial analyzer.

Plasma urea was measured by the method Price and Harrison (1987) with some modification. The working reagent was made fresh by combining 2 vol stock reagent $\mathrm{A}$ (600 ml double-distilled water [DDW], $300 \mathrm{ml} \mathrm{H}_{2} \mathrm{SO}_{4}, 100 \mathrm{ml} 85 \% \mathrm{H}_{3} \mathrm{PO}_{4}, 0.1 \mathrm{~g} \mathrm{FeCl}_{3}$ ) with 1 volume stock reagent $\mathrm{B}(500 \mathrm{ml} \mathrm{DDW}, 0.05 \mathrm{~g}$ thiosemicarbazide, $2.5 \mathrm{~g}$ diacetylmonoxime). Samples (1-50 $\mu$ l plasma) and standards (from $1 \mathrm{mM}$ urea stock) were added to polypropylene Falcon tubes and adjusted to $1 \mathrm{ml}$ total volume with DWW. A $0.5 \mathrm{ml}$ aliquot of the working reagent was then added, mixed and the tubes were boiled in a covered bath for $10 \mathrm{~min}$. After cooling for a few minutes in a fume hood, $200 \mu \mathrm{l}$ aliquots of samples were pipetted into wells of a microplate and absorbance at $525 \mathrm{~nm}$ was measured using a microplate reader. Urea concentrations in plasma samples were determined by comparison with the standard curve.

\section{Preparation of crude tissue extracts}

Frozen tissue samples were homogenized 1:10 w:v in buffer containing $20 \mathrm{mM}$ Hepes, $0.1 \mathrm{mM}$ EDTA, $1 \mathrm{mM} \mathrm{Na} \mathrm{VO}_{4}, 200 \mathrm{mM} \mathrm{NaCl}, 10 \mathrm{mM} \mathrm{NaF}, 10 \mathrm{mM} \beta-$ glycerophosphate, and Sigma protease inhibitor mix. After centrifugation for $15 \mathrm{~min}$ at 
$11,000 \mathrm{rpm}$, the supernatant was removed. Soluble protein concentration was measured by the Coomassie blue dye-binding method using Bio-Rad prepared reagent and bovine serum albumin as the standard. Samples were adjusted (if needed) to constant concentrations by the addition of small amounts buffer and were then mixed 1:1 v/v with SDS-PAGE sample buffer (100 mM Tris-HCl, pH 6.8, 4\% w:v SDS, $20 \%$ v:v glycerol, $0.2 \mathrm{w}: \mathrm{v}$ bromophenol blue, $10 \% \mathrm{v}: \mathrm{v} 2$-mercaptoethanol) and boiled for $5 \mathrm{~min}$. Final soluble protein concentrations for the preparations from different tissues were $5 \mu \mathrm{g} / \mu \mathrm{l}$ for heart and kidney, $4 \mu \mathrm{g} / \mu \mathrm{l}$ for skeletal muscle, $2 \mu \mathrm{g} / \mu \mathrm{l}$ for lung and liver, and $1 \mu \mathrm{g} / \mu \mathrm{l}$ for skin.

\section{Immunoblotting}

Aliquots containing equal amounts of protein for samples from each tissue (10-30 $\mu \mathrm{g}$ depending on the protein being analyzed) were loaded into wells of 10 or $12 \%$ SDS polyacrylamide gels. Electrophoresis was carried out on a Bio-Rad mini-gel apparatus at room temperature using $1 \mathrm{X}$ running buffer $(3.02 \mathrm{~g}$ Tris base, $18.8 \mathrm{~g}$ glycine, $1 \mathrm{~g}$ SDS per litre, $\mathrm{pH} \sim 8.3$ ). Proteins were then transferred onto PVDF membrane by wet transfer with transfer buffer containing $25 \mathrm{mM}$ Tris $\mathrm{pH} 8.5,192 \mathrm{mM}$ glycine, $20 \% \mathrm{v} / \mathrm{v}$ methanol. Membranes were washed in TBST (Tris buffered saline containing 0.1\% v:v Tween-20, $20 \mathrm{mM}$ Tris base, $140 \mathrm{mM} \mathrm{NaCl}$ ) for $5 \mathrm{~min}$ and were then blocked with $2.5 \%$ non-fat dried milk for 10-30 min in TBST prior to washing twice with TBST. Membranes were then incubated with primary antibodies overnight at $4^{\circ} \mathrm{C}$ followed by washing for $3 \times 5$ min in TBST and then incubation with secondary antibody (1:1000 or 1:2000 dilution) for $1-2 \mathrm{~h}$ at $22^{\circ} \mathrm{C}$, and final washes of $3 \times 5 \mathrm{~min}$ with TBST. Immunoreactive bands were visualized by enhanced chemiluminescence (Millipore Corporation). PVDF membranes 
were then stained for 20 min with Coomassie blue $(0.25 \% \mathrm{w}$ :v Coomassie Brilliant Blue $\mathrm{R}, 50 \% \mathrm{v}: \mathrm{v}$ methanol, $7.5 \% \mathrm{v}: \mathrm{v}$ acetic acid) and destained for $\sim 7 \mathrm{~min}$ with destaining solution ( $50 \mathrm{ml}$ distilled water, $50 \mathrm{ml}$ acetic acid, $150 \mathrm{ml}$ methanol). Antibodies were purchased from Cell Signalling Technology except for MEK kinase and MEK1/2 which were from Transduction Laboratories; all were used according to manufacturer's instructions (for more information see appendix 1). Where possible the synthetic peptide sequence of the source used is compared to $X$. laevis protein sequence at the specific residues where the immunogen is synthesized. Also, ground squirrel samples are used as control.

\section{Normalization and Statistics}

Both immunoblot and Coomassie stained bands were visualized using a ChemiGenius Bio-imaging System (Syngene, Frederick, MD, USA) and densitometric analysis was performed using the associated Gene Tools software. A group of three Coomassie blue stained bands that showed constant density in all samples from a given tissue were quantified and immunoblot band densities in each lane were normalized against the summed density of these bands in the same lane in order to correct for any minor variations in sample loading. Mean normalized band densities \pm SEM for control and dehydrated samples ( $n=3-6$ independent samples) were calculated and then statistical testing was performed using analysis of variance followed by the Student-Newman-Keuls test.

\section{RESULTS AND DISCUSSION}

\section{Metabolic responses to dehydration}


Initial studies determined the limit to body water loss for $X$. laevis; frogs died at values just above $30 \%$, the mean percentage of total body water loss for frogs that died being $32.4 \% \pm 0.98 \mathrm{SEM}(\mathrm{n}=7)$. Based on this value, two groups of frogs were set up and monitored as they underwent experimental dehydration to medium or high levels. Frogs lost water at near-linear rates and the final mean percentages for the medium and high dehydration groups were $16.6 \pm 1.6 \%(n=9)$ and $28.0 \pm 1.6 \%(n=10)$, respectively, of total body water lost over 6-7 days (Fig. 2.1). Hence, the high dehydration group represents frogs whose water loss was close to the lethal limit whereas the medium dehydration group reached only about half of that level. Blood hematocrit values also attested to the loss of body water, the percentage of total blood volume occupied by packed red blood cells rising from $40 \%$ in control frogs to $47 \%$ in medium and $50 \%$ in high dehydration groups (Table 1).

The high cutaneous water loss rates of amphibians can be minimized by behavioral, physiological and biochemical adaptations (Hillman et al., 2009). One method to help retard water loss is to raise the osmolality of body fluids and, among anuran species that estivate or endure hypersalinity, the commonly-used osmolyte is urea. Indeed, previous studies have shown that under osmotic or water stress, $X$. laevis reduce ammonia excretion, elevate the activities of urea cycle enzymes and accumulate urea (Balinsky et al., 1961; Janssens, 1964; Seiter et al., 1978). In the present study, plasma urea concentration increased sharply when frogs were dehydrated, rising by 27- and 33fold, respectively, in the medium and high dehydration groups as compared with control values of $1.66 \mathrm{mM}$ (Table 1). As a consequence of dehydration, amphibians also experience hypoxia due to elevated blood viscosity and reduced blood volume that make it harder to fully oxygenate tissues (Hillman et al., 2009). Hypoxia stress typically 
triggers the mobilization of liver glycogen reserves and elevates plasma glucose in frog species and in the present study this also occurred. Plasma glucose levels in the high dehydration group were 2.3 -fold higher than in controls (Table 1), similar to the effects of dehydration on blood glucose levels in leopard frogs, Rana pipiens (Churchill and Storey, 1993). This is consistent with the probable development of hypoxic conditions during dehydration in $X$. laevis.

\section{The ERK pathway}

The components of the ERK signaling cascade have been well established (Roux and Blenis, 2004, May and Hill, 2008; Ramos, 2008). The classical initiation site is a RPTK in the plasma membrane. Activation of the receptor passes a signal from its phosphotyrosine-docking protein and adaptor growth factor receptor bound proteins (Grb2) to a guanine nucleotide exchange factor called SOS (son of sevenless). SOS facilitates the activation of a small $G$ protein called Ras by catalyzing the exchange of GDP to GTP. Active, GTP-bound Ras then binds to and activates one of the MAPKKKs belonging to the ERK cascade; these include Rafs (A-Raf, B-Raf, and c-Raf), Mos and MEKK. These then activate the MAPKKs (MAPK/ERK kinase or MEK1/2) and finally the MAPKs (the ERK family, ERK1 and ERK2 being the best studied) (Fig. 2.2). The activated ERK is then capable of phosphorylating cytosolic substrates or transcription factors.

\section{Activation of c-Raf and MEKK in response to dehydration}

In the present study, immunoblotting was used to measure the levels of phosphorylated c-Raf-1 because it has an equal ability to phosphorylate MEK1 and 
MEK2 (Wu et al., 1996). Different and tissue specific responses were seen in organs of medium and high dehydrated $X$. laevis (Fig. 2.3A). Medium dehydration did not significantly affect phospho-cRaf ${ }^{\text {er338 }}$ levels in any of the five tissues tested but high dehydration did. Phospho-cRaf ${ }^{\text {ser338 }}$ levels rose in skeletal muscle and lung by $2.4-2.5$ fold $(\mathrm{P}<0.01)$ compared to control levels in both organs. Similarly, levels of the phosphoprotein rose by 0.94 -fold in skin $(\mathrm{P}<0.05)$ as compared to control levels. Phospho-Raf ${ }^{\text {ser338 }}$ was not detectable in the liver.

Another MAPKKK in the ERK pathway is MEKK (Roux and Blenis, 2004) and analysis of MEKK showed that it also responded to dehydration in X. laevis tissues. MEKK total protein levels were elevated significantly in muscle and liver of medium dehydrated frogs by 0.55 and 4 -fold $(\mathrm{P}<0.01)$, respectively (Fig. 2.3B). Levels remained elevated in liver of high dehydrated frogs. MEKK protein also responded to high dehydration in lung and kidney, rising by 2 - and 2.3 -fold. However, in heart and skin, MEKK levels were reduced significantly in dehydrated frogs and MEKK levels also returned to control values in skeletal muscle of high dehydrated frogs. The activation of c-Raf and MEKK in the present study is also in line with the findings of Matsuda et al. (1995) who tested the effect of osmotic shock on these proteins using rat 3Y1 fibroblastic cells. Our data support that the proposal that c-Raf and MEKK both play important roles in the response of $X$. laevis lung and skeletal muscle to dehydration. MEKK is also important in liver and kidney whereas c-Raf responded positively to dehydration in skin.

\section{MEK1/2 activation in response to dehydration}

MEKK, c-Raf, and other activated MAPKKKs phosphorylate the dual specificity kinases MEK 1 and 2. These are highly selective for their substrates which are primarily 
ERK1 and ERK2 (English et al., 1999). They phosphorylated ERK1/2 at both tyrosine and serine/threonine residues (MacDonald and Storey, 2004) and MEK 1/2 have two other unique features that allow them to efficiently activate ERK1/2. The first is the binding site of ERK2, which is represented by an 8 residue stretch in MEK 1/2 known as the $\mathrm{D}$ domain. The second feature is the presence of a proline-rich insert in the C-terminal portion of the catalytic core of MEK $1 / 2$, which is important for intracellular stimulation of ERK1/2 (English et al., 1999).

Since upstream regulators of MEK $1 / 2$ were activated in response to dehydration in some $X$. laevis organs, I next measured total protein levels and activation status of MEK $1 / 2$. In skin and liver, total MEK $1 / 2$ protein decreased by $\sim 0.50$ and $\sim 0.60$-fold $(\mathrm{P}<0.01)$, respectively, under both medium and high dehydration conditions (Fig. 2.4A). MEK $1 / 2$ levels were also reduced in heart of medium dehydrated frogs by 0.33 -fold $(\mathrm{P}<0.01)$. However, in lung, total MEK 1/2 protein content was strongly increased by 2and 4-fold $(\mathrm{P}<0.01)$ under medium and high dehydration and MEK $1 / 2$ also increased by 2-fold $(\mathrm{P}<0.01)$ in the kidney under high dehydration.

It is the active phosphorylated form of MEK that is key to triggering ERK and so the relative levels of phospho-MEK $1 / 2^{\text {ser217/221 }}$ are important. Fig. 2.4B shows that dehydration enhanced phosphorylation of MEK in all tissues, as compared with control levels. Under medium dehydration conditions, the amount of phospho-MEK $1 / 2^{\text {ser217/221 }}$ increased by 2 -fold in lung, 2.3-fold in skin and by 0.74 -fold in liver $(\mathrm{P}<0.01)$. High dehydration further enhanced phospho-MEK $1 / 2^{\text {ser217/221 }}$ content in lung and skin to 6fold and 3-fold above the phosphoprotein content of controls $(\mathrm{P}<0.01)$. Phospho-MEK $1 / 2^{\text {ser217/221 }}$ levels were also elevated by 1.8 -fold in muscle, 2 -fold in kidney, and 2.5 -fold in heart $(\mathrm{P}<0.01)$ under high dehydration conditions. 
A strong correlation between c-Raf activation (Fig. 2.3A) and the phosphorylation of its downstream target MEK 1/2 (Fig. 2.4) occurred under high dehydration in muscle, lung and skin. Similarly, there was a good correlation between MEKK activation (Fig. 2.3B) and elevated levels of phosphorylated MEK $1 / 2$ in kidney, lung and liver. However, the elevated phospho-MEK $1 / 2^{\text {ser217/221 }}$ levels in heart under high dehydration conditions could not be related to either c-raf or MEKK so it is possible that other Raf isoforms or Mos could be involved in the pathway in heart (Roux and Blenis, 2004; Sridhar et al., 2005).

\section{ERK2 activation in response to dehydration}

Activation of MEK 1/2, the MAPKK of the ERK pathway, leads to phosphorylation of ERK at a conserved Thr-Glu-Tyr (TEY) motif of the activation loop (MacDonald and Storey, 2004). The vertebrate ERK family includes six isozymes (ERK1, 2, 3, 5, 7, 8) but ERK1 and ERK2 have received the most study. They share 83\% amino acid identity and are structurally and functionally similar (Roux and Blenis, 2004). In general, activation of the ERK pathway mediates cell growth and differentiation in response to a number of different stimuli including growth factors, cytokines, transforming agents, virus infection and carcinogens (May and Hill, 2008; Ramos, 2008). The interaction of ERK2 (the isozyme analyzed in the present study) with its substrates was better understood after using X-ray crystallography. The activation of ERK2 causes the protein to undergo conformational changes creating a proline-specific surface pocket. When inactive, this pocket is usually occupied by Arg192, so substrate access to the proline catalytic site is inhibited when ERK2 is not phosphorylated onThr183 and Tyr185. In addition to the proline specific pockets, ERK2 has the ability to regulate its 
substrates through direct binding of the C-terminal substrate binding groove of ERK to the activation site of substrates thereby restricting their interaction with other kinases (Schaeffer and Weber, 1999).

The ERK2 antibody crossreacted with a single band in X. laevis tissues at the expected molecular weight for ERK2 $(\sim 42 \mathrm{kDa})$. Under dehydration stress the total protein levels of ERK2 remained stable in muscle and lung of $X$. laevis (Fig. 2.5A) but ERK2 levels were suppressed by $0.30-0.40$-fold $(\mathrm{P}<0.05)$ in heart and skin of both medium and high dehydrated frogs. Oppositely, total ERK2 protein increased by 0.35 and 0.50-fold $(\mathrm{P}<0.01)$ in kidney and liver, respectively, under medium dehydration. Levels of the active, phosphorylated form of ERK2 showed very different responses to dehydration with a significant increase in the amount of active phospho- ERK ${ }^{\text {thr202/yr204 }}$ detected in all tissues except skin (Fig. 2.5B), mirroring the activation of MEK 1/2, the

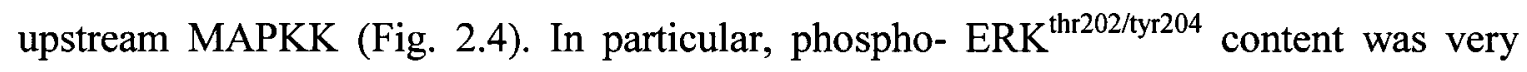
strongly enhanced in both muscle and kidney by 6- and 4.6-fold $(\mathrm{P}<0.01)$, respectively, under high dehydration conditions as compared to control levels of the phosphoprotein. Phospho-ERK ${ }^{\text {thr202/tyr204 }}$ levels also increased in lung by 2.8-3.3 fold $(\mathrm{P}<0.01)$ in dehydrated animals and heart showed a similar $\sim 2$-fold increase. This result is consistent with previous work on $R$. ridibunda heart where ERK was powerfully activated by stress stimuli (Gaitanaki et al., 2003). A 2.5-fold increase $(\mathrm{P}<0.01)$ in the amount of phosphorylated active ERK2 was also seen in liver during medium dehydration.

Overall, then, the above data for the MAPKKK, MAPKK, and MAPK components of the ERK cascade are all consistent in documenting an activation of this cascade in response to physiological dehydration stress in most tissues of $X$. laevis. The exception was skin which showed elevated levels of phosphorylated c-raf and MEK 1/2 
but not of ERK2. However, it is possible that ERK1 might be the target that is activated in skin. Activation of the ERK cascade may be responding directly to dehydration stress or may be responding to hypoxic conditions caused by dehydration effects on the circulatory system. Studies on other species have reported ERK activation by ischemia/reperfusion in rabbits (Iliodromitis et al., 2006) or by osmotic stress in animals and yeast (Kultz and Burg, 1998).

\section{ERK downstream substrates}

The activation of the ERK cascade in $X$. laevis tissues implies that activation of some downstream targets of ERK is important for dehydration resistance. ERK substrates are present in all cellular compartments (Roux and Blenis, 2004), but the best-known actions of ERKs are in the regulation of gene expression. ERKs can translocate to the nucleus and influence gene transcription by phosphorylating transcription factors or transcription factor modifying proteins (Krishna and Narang, 2008; Ramos, 2008). Therefore, I next evaluated the responses of some known ERK targets in X. laevis tissues.

The signal transducer and activators of transcription (STAT) proteins are a family of cytoplasmic transcription factors that form homo- or heterodimers upon phosphorylation prior to translocating into the nucleus. In mammals there are seven family members (STAT 1, 2, 3, 4, 5a, 5b, 6). Phosphorylation of these transcription factors occurs on a conserved tyrosine residue in the C-terminal domain (Benekli et al., 2003; Ning, et al., 2001). STAT 3 is a known substrate of ERK1/2 (Chung et al., 1997; Krishna and Narang, 2008) and so I analyzed the phosphorylation status of phospho$\mathrm{STAT}^{\mathrm{ser} 727}$ as a measure of ERK downstream action. Levels of the phosphoprotein increased significantly under high dehydration conditions in three tissues of $X$. laevis 
(Fig. 2.6A) and in all cases this correlated with elevated phospho-ERK2 in the same tissues (Fig. 2.5B). In skeletal muscle, phospho-STAT3 ${ }^{\text {ser727 }}$ showed small but significant increases of $0.24-0.30$-fold $(\mathrm{P}<0.05)$ whereas greater increases of 1.9-2.3 fold $(\mathrm{P}<0.01)$ occurred in lung. Phospho-STAT $3^{\text {ser727 }}$ levels were also 2-fold higher in kidney of high dehydrated frogs $(\mathrm{P}<0.01)$. However, phospho-STAT3 levels were suppressed in heart of medium dehydrated frogs and were unchanged in the other tissues. Activated STAT3 in muscle, lung and kidney can up-regulate a number of genes whose protein products assist in cell survival. For example, the antiapoptotic $\mathrm{Bcl}-2$ family members $\left(\mathrm{Bcl}-\mathrm{x}_{\mathrm{L}}, \mathrm{Mcl}-1\right)$ were up-regulated in multiple myeloma following STAT3 induction. Other known STAT3 target genes include c-Myc that plays a role in sensitizing cells to apoptotic stimuli (Benekli et al., 2003). The activation of STAT3 in the muscle and kidney could be a general response to dehydration stress since a significant change in the water contents of individual organs occurs (measured as a change in protein concentration) when frogs dehydrate (Churchill and Storey, 1993; Holden and Storey, 1997).

The p90 ribosomal S6 kinase (RSK) family of proteins is another known target of ERK action. The protein was originally isolated from X. laevis, and described as a protein kinase with the ability to phosphorylate the S6 protein of the $40 \mathrm{~S}$ ribosomal subunit. Although S6 is still the best-known RSK target, recent studies have identified other targets including other proteins involved in ribosomal translation, the insulin receptor, the proapoptotic protein BAD and some nuclear targets (Ruvinsky and Meyuhas, 2006). In humans, there are four RSK isoforms; each contains two distinct and functional kinase domains. In the carboxy-terminal domain, RSK autophosphorylation and activation occur and then stimulate the phosphotransferase activity of the amino-terminal kinase domain to allow RSK to phosphorylate its targets. ERK activation of RSK1 requires the 
phosphorylation of its C-terminal activation loop (Anjum and Blenis, 2008). ERK achieves that by playing one of two roles in the process. Activated ERK can directly phosphorylate RSK1 and ERK can also bring RSK1 closer to membrane-associated kinases that may phosphorylate RSK on specific residues (Richards et al., 2001).

The present study focused on the regulation of one of the essential RSK proteins, RSK1. The RSK1 activation pattern quite closely mirrored the pattern seen for $\mathrm{ERK}^{\mathrm{thr} 202 / \mathrm{tyr} 204}$. High dehydration elevated the amount of $\mathrm{p} 90^{\mathrm{RSK} \text { ser380 }}$, with levels of the phosphoprotein increasing by 7-, 5- 3- and 2-fold $(\mathrm{P}<0.01)$ in muscle, lung, kidney and liver, respectively (Fig. 2.6B). By contrast, in heart, phosphoprotein content decreased by 0.47-fold and 0.69 -fold $(\mathrm{P}<0.01)$ during medium and high dehydration, respectively, where the phospho-RSK1 content did not change in skin.

To confirm that RSK activation leads to phosphorylation of down-stream targets in tissues of dehydrated frogs, I next measured S6 ribosomal protein (S6RP) protein levels and its phosphorylation state in X. laevis organs. Phosphorylation sites on S6RP were mapped to five serine residues in the highly conserved carboxyl-terminal: Ser235, Ser236, Ser240, Ser244, and Ser 247 (Ruvinsky and Meyuhas, 2006). The effects of dehydration on total S6RP protein levels in X. laevis tissues are shown in Fig. 2.7A (note that selected samples were unavailable in 3 cases). S6 protein levels were 6.9- and 2.4fold higher $(\mathrm{P}<0.01)$ in muscle and liver during high dehydration, as compared with controls. Dehydration also had a very marked effect on lung S6RP protein levels with mean increases of 23.5- and 17.8-fold $(\mathrm{P}<0.05)$ under medium and high dehydration conditions, respectively. However, dehydration had no significant effect on S6RP protein content in kidney, heart, or skin. The phosphorylated form of the protein was assessed using an antibody that detects serine $235 / 236$ phosphorylation in the C-terminal region. A 
strong increase in phospho-S6RP content was detected in most tissues under high dehydration conditions (Fig. 2.7B); levels were 8.5-, 8.5-, 4.7-, and 6.8-fold higher in skeletal muscle, lung, kidney, and liver, respectively $(\mathrm{P}<0.01)$, compared the control content of phosphoprotein. Phospho-S6RP $\mathrm{Rer}^{\mathrm{se235/236}}$ also increased in lung by 0.70 -fold $(\mathrm{P}<0.05)$ under medium dehydration. A good correlation occurred between the increase in phospho-S6RP protein levels and the amount of activated phospho-RSK1 (Fig. 2.6B) in muscle, lung, kidney and liver of the high dehydration frogs. These findings also agree with previous studies that showed that RSKs are the kinases responsible for phosphorylating the S6RP subunit in $X$. laevis oocytes (Schwab et al., 1999).

The functional role of S6RP phosphorylation is still debatable. Initial studies proposed that S6RP has a regulatory role in translation initiation but subsequent data was conflicting as to whether a causal link existed between S6RP phosphorylation and the efficiency of protein synthesis. Indeed, a recent study used S6RP knockin (S6RP ${ }^{\mathrm{p}-/}$ ) mice to assess S6RP function with results that showed that the rate of global protein synthesis in mouse embryo fibroblasts was actually higher than in wild type cells, and, furthermore, the liver of these mice had the same proportion of ribosomes engaged in polysomes as did the wild-type. Other actions for phosphorylated S6RP have been suggested including: (a) specifically increasing the translation efficiency of a subgroup of mRNA species that contain 5'-terminal oligopyrimidine tracts (TOP mRNAs), (b) mediating an inverse regulation of cell size versus cell proliferation, and (c) involvement in glucose homeostasis (Ruvinsky and Meyuhas, 2006). Given the profound changes in S6RP levels and phosphorylation status in $X$. laevis organs, the effects of dehydration stress in this frog model might be an excellent one to exploit in order to finally identify a physiological role for S6RP. 
Table 2.1 Total body water lost by experimental groups of $X$. laevis, blood hematocrit, plasma urea and plasma glucose concentrations. Data are means \pm SEM. Statistical testing used analysis of variance followed by the Student-Newman-Keuls test. ${ }^{\text {a }}$ Significantly different from the control value, $\mathrm{P}<0.05 ;^{\mathrm{b}}-\mathrm{P}<0.005$. $^{\mathrm{c}}-$ Significantly different from the value for medium dehydration, $\mathrm{P}<0.005$.

\begin{tabular}{|l|l|l|l|}
\hline & Control & Medium Dehydration & High Dehydration \\
\hline Body water lost, \% & 0 & $16.6 \pm 1.6$ & $28.0 \pm 1.6^{\mathrm{c}}$ \\
\hline Hematocrit, \% & $40.4 \pm 1.61$ & $46.7 \pm 1.13^{\mathrm{a}}$ & $49.6 \pm 2.24^{\mathrm{b}}$ \\
\hline Plasma Urea (mmol l & \\
\hline Plasma Glucose $\left(\mathrm{mmol} \mathrm{l}^{-1}\right)$ & $1.66 \pm 0.29$ & $45.8 \pm 9.81^{\mathrm{b}}$ & $54.8 \pm 6.75^{\mathrm{b}}$ \\
\hline $\mathrm{n}$ & $2.52 \pm 0.22$ & $3.39 \pm 0.36$ & $5.81 \pm 0.75^{\mathrm{b}, \mathrm{c}}$ \\
\hline
\end{tabular}


Figure 2.1. Progress of body water loss by six $X$. laevis over 6-7 days of air drying (medium dehydration) versus drying over desiccant (high dehydration); conditions are described in detail in the Methods. For the animals shown, final \% body water loss values were $16.7,17.4$ and $19 \%$ for medium and $26.4,26.9$ and $28.8 \%$ for high dehydrated frogs. 
Figure 2.1

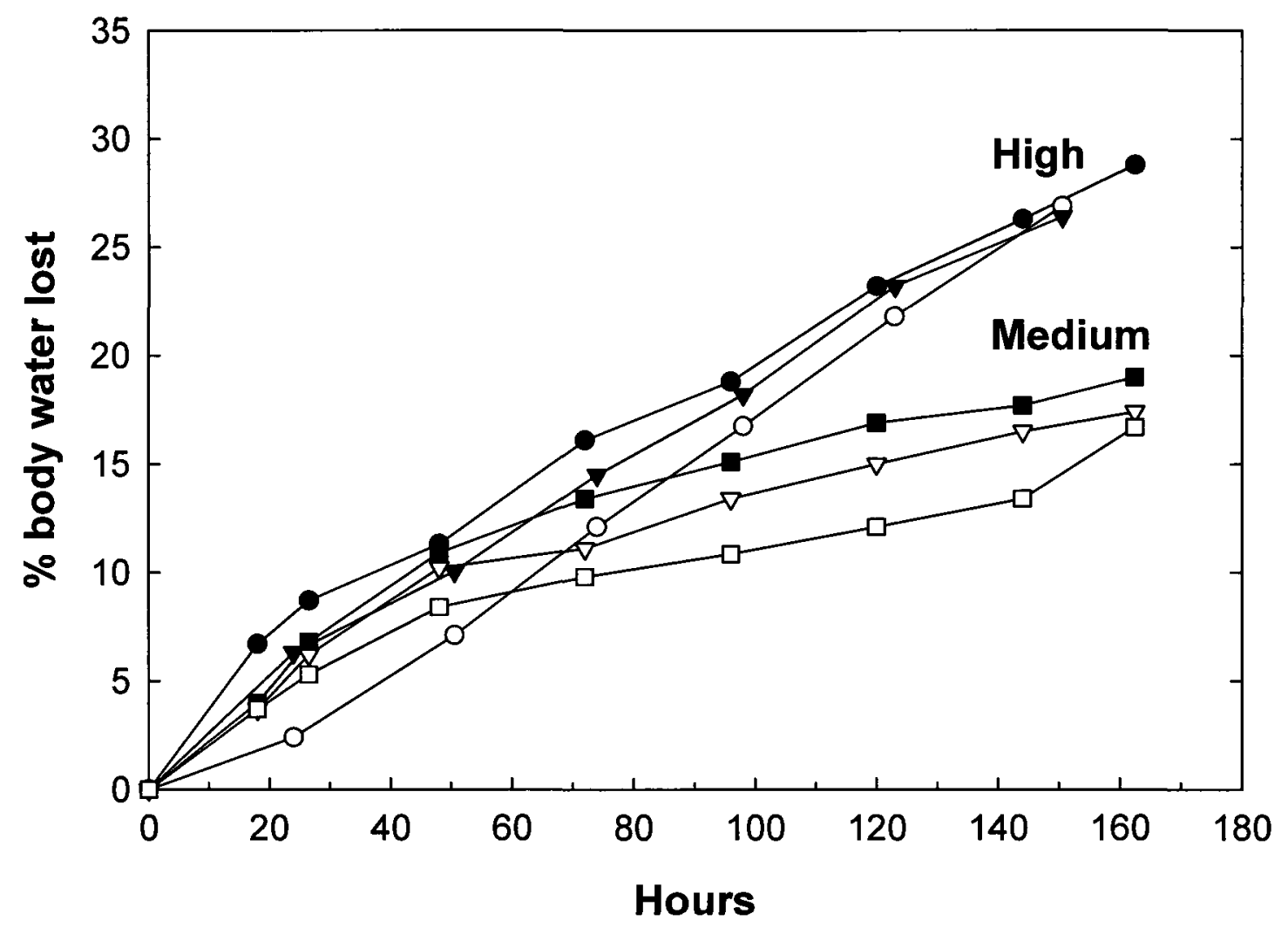


Figure 2.2. Schematic of the ERK pathway members analyzed and their relationship to the general MAPK signaling cascade. Arrows lead from activators to target proteins. 
Figure 2.2

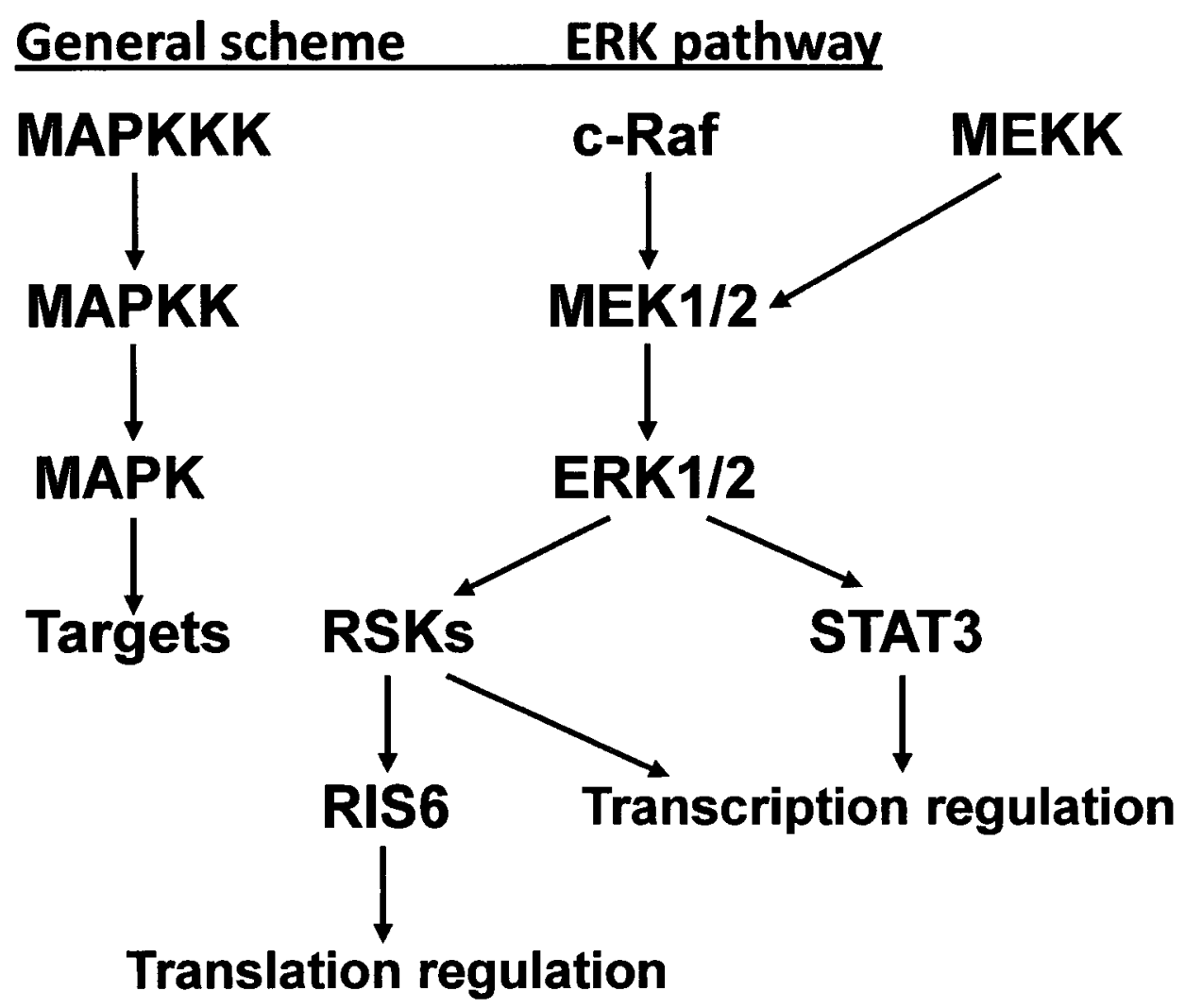


Figure 2.3. Effect of medium and high dehydration on the activation of two MAPKKKs, c-Raf and MEKK, in X. laevis tissues: (A) Expression levels of active phosphorylated cRaf. The phospho-cRaf ${ }^{\text {er } 338}$ antibody crossreacted with a single band at the expected molecular mass $\sim 74 \mathrm{kDa}$. (B) MEKK protein levels. The MEKK antibody crossreacted with a single band at the expected molecular mass of $\sim 45 \mathrm{kDa}$. Representative western blots show control (C), medium dehydration (MD) and high dehydration (HD) conditions. Histograms show mean normalized protein levels, expressed relative to control values. Kidney samples for medium dehydrated frogs were not available. Data are means \pm SEM, $n=3-6$ independent trials on tissue extracts from different animals. Letters that differ are significantly different from each other, $\mathrm{P}<0.05$. 
Figure 2.3

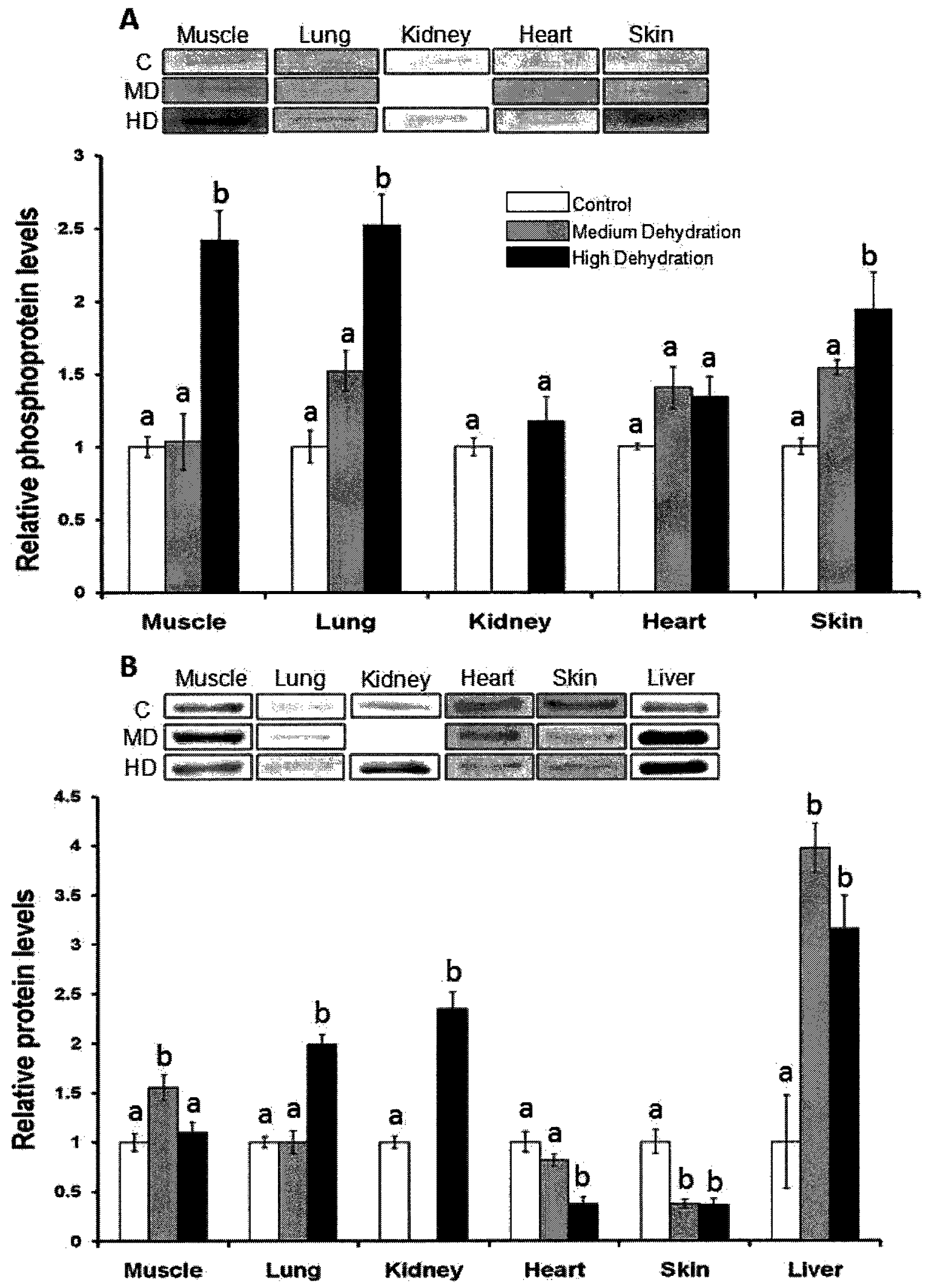


Figure 2.4. Effect of medium and high dehydration on the MAPKK of the ERK cascade in six tissues of $X$. laevis. (A) total MEK $1 / 2$ protein levels and (B) phospho-MEK $1 / 2^{\text {ser217/221 }}$ levels. The antibodies used crossreacted with single bands at the expected molecular mass of $\sim 45 \mathrm{kDa}$. Other information as in Figure 2.2. 
Figure 2.4

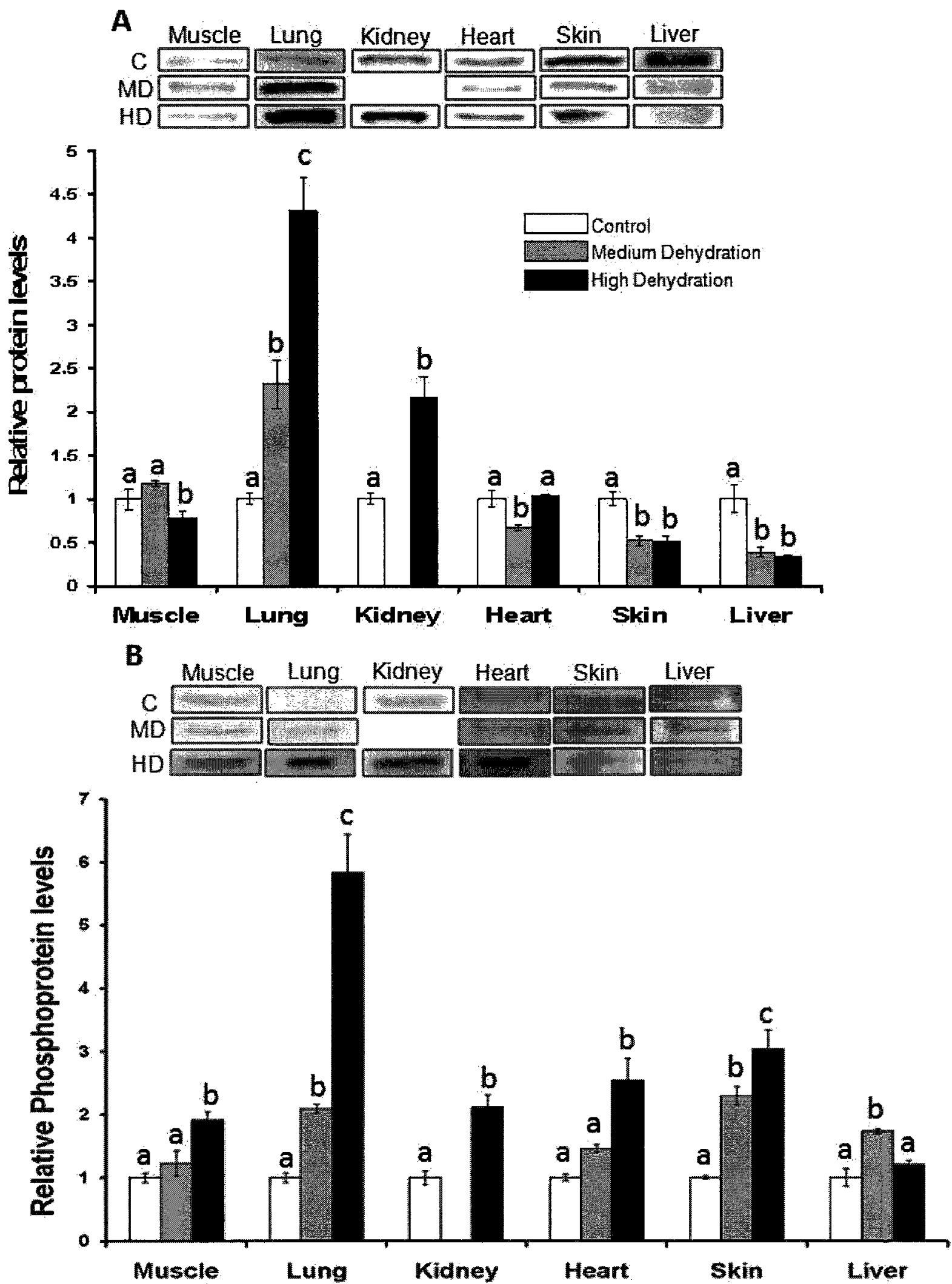


Figure 2.5. Effect of medium and high dehydration on (A) total ERK2 protein levels and (B) phospho-ERK ${ }^{\text {thr202/tyr204 }}$ content in tissues of X. laevis. The antibody used crossreacted with a single band at the expected $\sim 42 \mathrm{kDa}$. Other information as in Figure 2.2. 
Figure 2.5
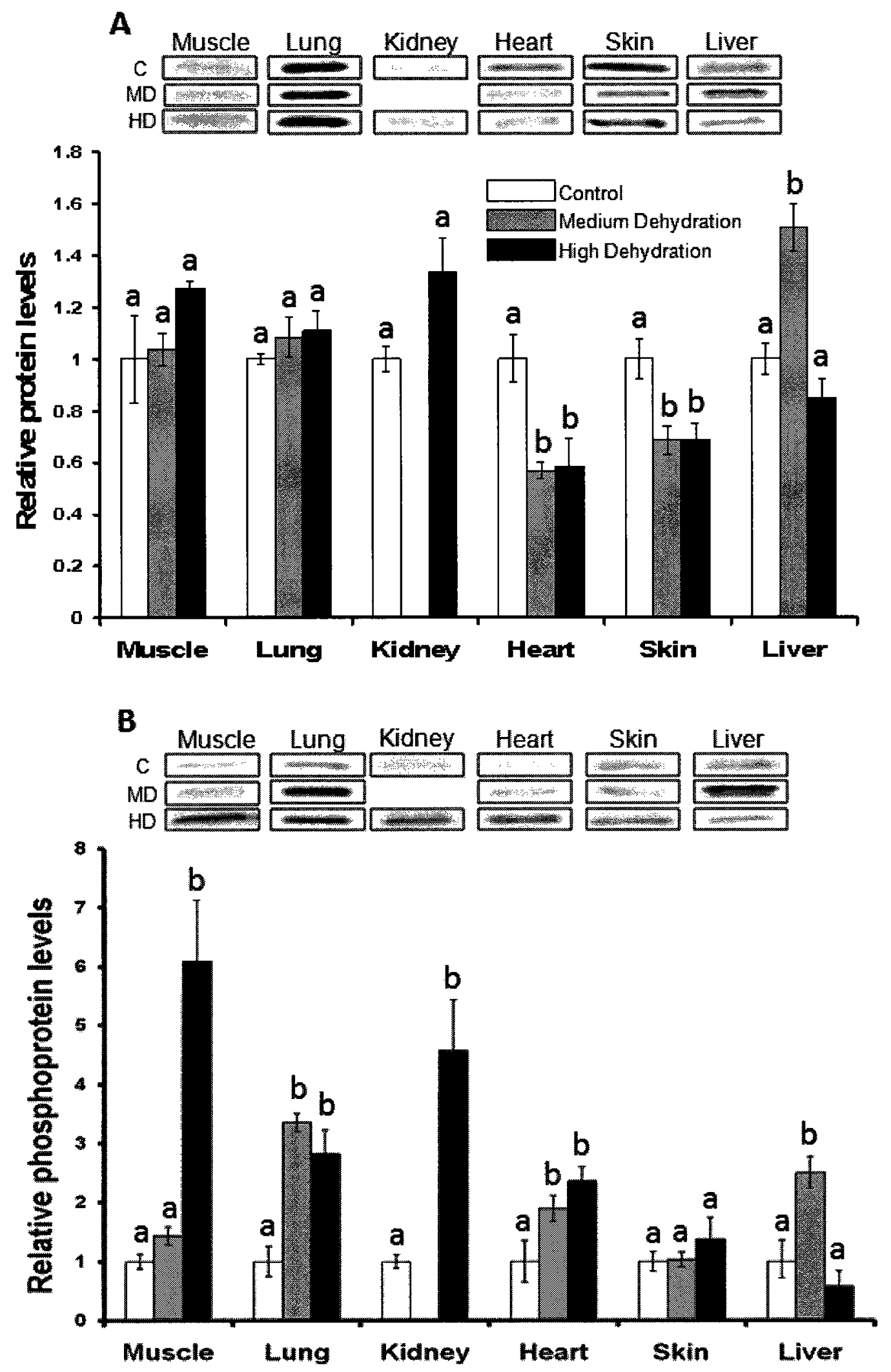
Figure 2.6. Effect of medium and high dehydration on the phosphorylation of two target substrates of ERK: (A) phospho-STAT3 ${ }^{\text {ser727 }}$ and (B) phospho-p90 $\mathrm{RSK}^{\mathrm{ser} 380}$ in X. laevis tissues. Phosphospecific antibodies each crossreacted with single bands on the blots at the expected molecular masses of $\sim 78 \mathrm{kDa}$ for phospho-STAT3 ${ }^{\mathrm{ser} 727}$ and $\sim 90 \mathrm{kDa}$ for phospho-p90 RSK ${ }^{\mathrm{ser} 380}$. Other information as in Figure 2.2. 
Figure 2.6

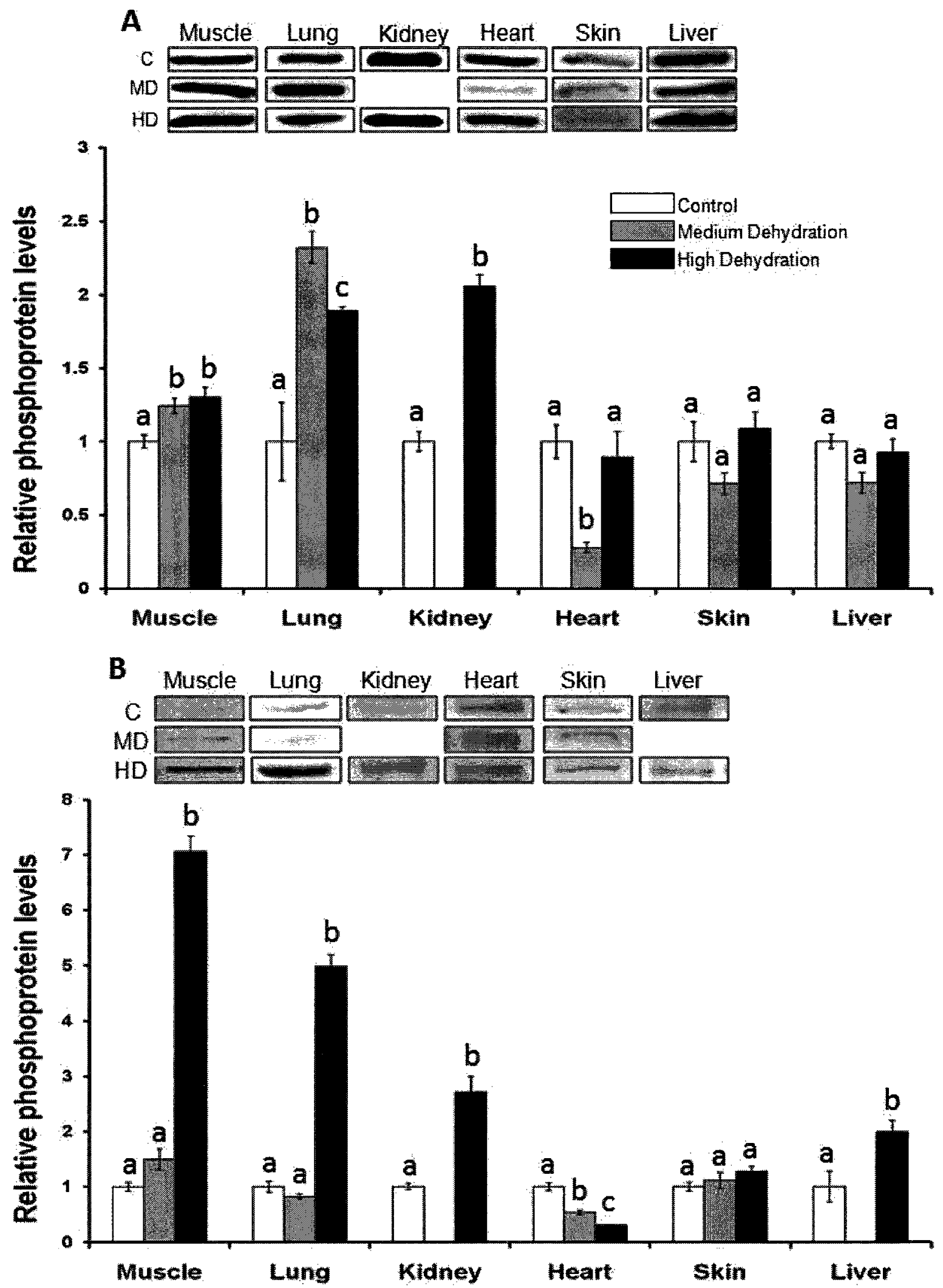


Figure 2.7. Effect of medium and high dehydration on (A) total S6 ribosomal protein and (B) phospho-S6 ribosomal ${ }^{\text {ser235/236 }}$ protein levels in six tissues of $X$. laevis. S6 antibodies crossreacted with a single band at the expected molecular weight $\sim 32 \mathrm{kDa}$. Other information as in Figure 2.2. 
Figure 2.7

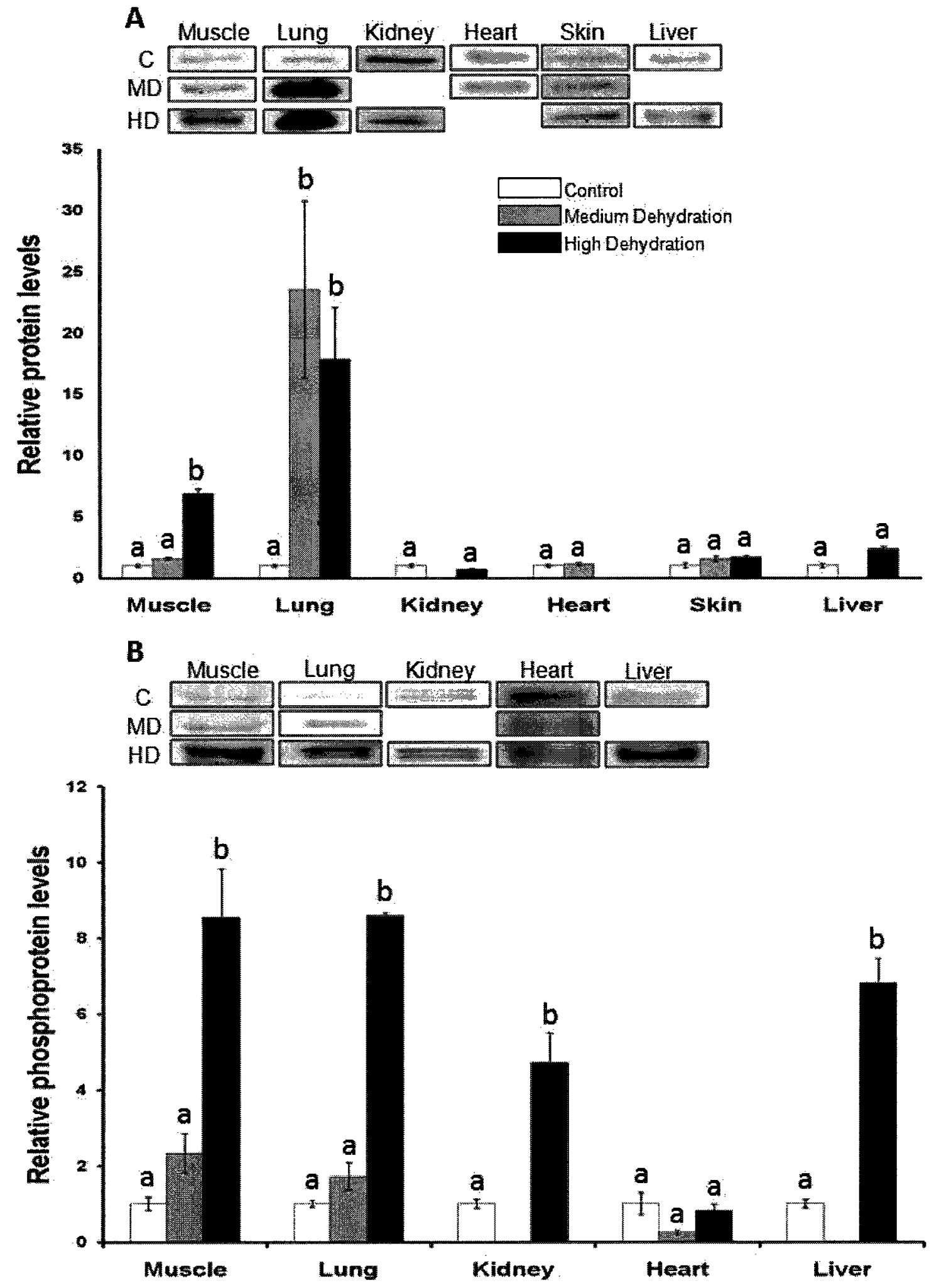




\section{CHAPTER 3}

\section{Transcription regulation via the activation of JNK and p38 mitogen- activated protein kinases during dehydration in Xenopus laevis}




\section{INTRODUCTION}

MAPKs are a superfamily of proteins that play a major role in translating cell receptor signals into biological responses within cells (Schindler et al., 2007) by covalently attaching the terminal phosphate from ATP onto specific serine (Ser), threonine (Thr) or tyrosine (Tyr) side chains of numerous target proteins in cells (Johnson and Lapadat, 2002; Biondi and Nebreda, 2003). To maintain signal specificity and efficiency this superfamily of kinases exhibits two essential properties: 1) sensitive means of regulation, and 2) high specificity for substrates, which is achieved by specific docking sites (Biondi and Nebreda, 2003). In general, the ERK pathway (examined in chapter 2) is activated mainly by mitogens or cell differentiation stimuli whereas the stress-activated protein kinase (SAPK; also known as c-Jun N-terminal kinases or JNKs) and p38 MAPK families are mostly associated with cellular responses to environmental stressors that include oxidative stress and ischemia/reperfusion (Gaitanaki et al., 2003; Cowan and Storey, 2003; Iliodromitis et al., 2006).

The SAPK/JNK and p38-MAPK pathways are well-known to respond to osmotic stress in various systems (Hohmann et al., 2007; Kultz and Burg, 1998; Tsai et al., 2007) including some rather unique forms of osmotic stress such as that caused by extracellular freezing in freeze tolerant species (Greenway and Storey, 2000). Studies analyzing osmotic stress of cells most often do so from the point of view of changes in dissolved ion or metabolite concentrations (e.g. salt loading) but osmotic stress also arises due to dehydration. Indeed, Huang and Tunnacliffe (2004) were first to report that sensing and responding to water loss caused by drying in human cells can lead to the activation of both JNK and p38 MAPKs. Many animals live in situations where they experience 
dehydration in their natural environment and they need mechanisms to defend against water loss and/or trigger adaptive responses to deal with water loss. As mentioned before the African clawed frog is one of these. Previous studies have shown that animals have to adjust many physiological, biochemical and behavioral processes in order to adapt to stresses (such as dehydration) encountered during estivation. One overriding adjustment is metabolic rate depression (MRD) which allows stored body fuel reserves to be rationed to support many months of estivation. Other adjustments include actions such as induction of urea cycle enzymes and the accumulation of urea as an osmolyte to help limit body water loss. As mentioned earlier, the powerful biochemical mechanisms used to reorganize metabolism during estivation and/or under dehydration stress should be quickly reversible and require very little metabolic reorganization upon arousal. A prime mechanism for making such adjustments is reversible protein phosphorylation. This requires only the addition or removal of a phosphate group, via the action of protein kinases and protein phosphatases, to create dramatic changes in enzyme activities (Storey, 2002). Given the involvement of the ERK pathway in the $X$. laevis response to dehydration (chapter 2), I hypothesized that whole animal dehydration would cause selective regulation and activation of other MAPK modules: the JNK and p38 MAPK pathways. Such activation could lead to differential expression and activation of selected downstream transcription factors such as c-Jun, c-Myc, and CREB.

\section{MATERIAL AND METHODS}

\section{Animals}

Animal holding and experimentation was as described in chapter 2. 


\section{Tissue extracts and Immunoblotting}

Tissue extracts were prepared from control and dehydrated $X$. laevis as described in chapter 2. JNK and phospho-JNK antibodies were purchased from Cell Signalling Technology, p38 and phospho-p38 antibodies were from New England Biolabs Inc. and all others were purchased from Santa Cruz Biotechnology. All antibodies were used according to manufacturer's instructions. Immunoblotting was conducted essentially as described in chapter 2 with minor changes. Membranes were washed in TBST before incubating with secondary antibody for $1-2 \mathrm{~h}$ at $21^{\circ} \mathrm{C}$. Bands were visualized by adding 1 $\mathrm{ml}$ of enhanced chemiluminescence reagent (Millipore Corporation). Subsequently, PVDF membranes were stained for $30 \mathrm{~min}$ with Coomassie blue and destained for $\sim 10$ $\min$.

\section{RESULTS AND DISCUSSION}

\section{Regulation of $S A P K / J N K$ during dehydration}

NKs are activated by dual phosphorylation on tyrosine and threonine residues within a conserved Thr-Pro-Tyr (TPY) motif. The two known MAPKKs that are responsible for activating $\mathrm{JNKs}$ are MEK4 and MEK7; they are themselves phosphorylated by a number of MAPKKKs. The JNK family encompasses three members (JNK1, JNK2, JNK3) that exist in 10 or more different spliced forms (Roux and Blenis, 2004; Schindler et al., 2007; Krishna and Narang, 2008). A mammalian JNK antibody was used in the present study and cross-reacted well with a single protein band in $X$. laevis extracts at the expected molecular mass of $\sim 46 \mathrm{kDa}$ for JNK1. 
Dehydration stress resulted in tissue-specific responses by JNK1. Total JNK protein levels increased strongly in lung under both medium and high dehydration (Fig. 3.1A); levels rose significantly $(\mathrm{P}<0.05)$ by 2.3 and 4 -fold, respectively. Total JNK1 also increased by 1.5 -fold in skin under high dehydration conditions. Dehydration affected heart and liver differently; total $\mathrm{NK} 1$ protein decreased by $\sim 0.50$-fold in heart during medium dehydration and by $\sim 0.70$ and 0.50 -fold during medium and high dehydration in liver. The relative amount of the active phosphorylated form of JNK1 also responded to dehydration (Fig. 3.1B). Phospho-JNK thr183/tyr185 content increased significantly in skeletal muscle and lung (by 1.5- and 2.4-fold, respectively) under high dehydration. JNK1 was also activated in skin with 2.3 and 2.5 -fold increases in phospho-JNK thr183/yr185 levels in medium and high dehydrated animals, respectively. In heart, however, phosphorylated JNK1 levels fell by $\sim 0.50$-fold in dehydrated frogs. The responses of JNK1 to dehydration suggest a significant role for this transcription factor in cellular response to this stress, particularly in three organs that are likely to be most greatly affected by water loss under desiccating conditions - the two peripheral organs, skin and leg skeletal muscle, as well as the lung that can lose large amounts of water during breathing. Although the functions of JNK1-triggered gene expression responses to dehydration in $X$. laevis are not yet known, these might include actions that contribute to limiting tissue water loss and/or alleviating osmotic stress as well as contributions to dealing with collateral stresses associated with dehydration such as hypoxia or oxidative stress. Dehydration decreases blood volume and elevates blood viscosity, putting a strain on the heart and causing generalized hypoxia; indeed, dehydrational death in anurans has been linked with heart failure (Hillman, 1978). A previous study with perfused hearts of 
Rana ridibunda reported JNK activation by osmotic shock (perfusion with sorbitol) or 15 min anoxia (Aggeli et al., 2001) whereas the data presented in this chapter found reduced amounts of active $\mathrm{NK} 1$ in $X$. laevis heart under dehydration stress. The two studies differed quite substantially in both the stressor used and the in vitro versus in vivo situations making it impossible to identify a unifying principle of JNK action in the stressed frog heart at the present time.

\section{Regulation of p-38 MAPK during dehydration}

The p38 MAPK is activated by phosphorylation of a conserved Thr-Gly-Tyr (TGY) motif that is catalyzed via two upstream MAPKKs, MEK3/6, that have high specificity for p38 but do not activate other MAPK family members (Cowan and Storey, 2003; Roux and Blenis, 2004). The substrate specificity of $\mathrm{p} 38 \alpha$, studied by X-ray crystallography, was attributed to the difference in the TGY phosphorylated motif and the length of the activation loop of p38 as compared with that found in ERK2 and JNK (Roux and Blenis, 2004). The p38 family encompasses 4 different isoforms: $\alpha, \beta, \gamma$, and $\delta$ (Platanias, 2003; Krishna and Narang, 2008). These kinases are known to be activated by a number of stimuli that include hormones, osmotic shock, and heat shock (Johnson and Lapadat, 2002).

The effects of dehydration on the total p38 protein content of $X$. laevis tissues are shown Fig. 3.2A. Medium dehydration had no effect on protein levels in any tissue but high dehydration led to 1.5-, 1.7-, and 1.4-fold increases in p38 content in lung, kidney and heart, respectively. Levels of active phosphorylated p38 were also unaffected by medium dehydration (Fig. 3.2B). However, active phospho-p38 ${ }^{\text {tyr182 }}$ content was 
significantly increased in lung and kidney under high dehydration conditions with levels that were 2.15 - and 1.6-fold higher than control values, respectively. In heart, a significant decrease of $\sim 0.50$-fold was seen in phospho-p38 ${ }^{\text {tyr182 }}$ content. Phospho-p38 ${ }^{\text {tyrl } 182}$ levels were too low to measure in $X$. laevis skin. A reduction in the amount of active p38 in $X$. laevis heart under high dehydration was again contrary to results reported previously for stress effects (sorbitol perfusion, anoxia) on isolated hearts of $R$. ridibunda (Aggeli et al., 2002). Furthermore, both freezing and thawing triggered p38 activation in the freeze tolerant wood frog, Rana sylvatica (Greenway and Storey, 2000); note that extracellular freezing is effectively a dehydration stress on cells. However, the increase in phospho-p38 ${ }^{\text {tyr182 }}$ content in $X$. laevis kidney during dehydration correlates well with the similar response of $R$. sylvatica kidney to freeze/thaw (Greenway and Storey, 2000). Activation of $\mathrm{p} 38$ in the kidney could be a general response to dehydration stress arising due to either whole body water loss or water sequestration into extracellular ice. Indeed, multiple signaling and metabolic responses to freezing in $R$. sylvatica are mimicked by dehydration of the frogs and this has shown that various freeze tolerance adaptations are derived from underlying anuran responses to dehydration (Churchill and Storey, 1993; Holden and Storey, 1997). The pattern of p38 MAPK responses to dehydration in $X$. laevis appears to be independent of JNK in all tissues except for the lung suggesting that the two MAPK modules are independently triggered during dehydration and undoubtedly mediate different cellular responses to the stress.

\section{Response to dehydration by JNK and p38 downstream targets}

NKs and p38 MAPKs phosphorylate a variety of specific target proteins to affect 
functions including enzymatic activity, subcellular location, and interaction with other proteins and molecules (Johnson and Lapadat, 2002). Both MAPK members can activate cytoplasmic and nuclear substrates in response to different stressor (Roux and Blenis, 2004; Krishna and Narang, 2008). There I analyzed responses to dehydration by selected target proteins: (a) c-Jun, a known substrate of JNK1, (b) c-Myc, another substrate of JNK1, and (c) cAMP responsive element binding protein (CREB), a known substrate of p38 MAPK (Tan et al., 1996; Kultz and Burg, 1998; Noguchi et al., 1999; Krishna and Narang, 2008).

c-Jun

JNKs, originally identified as SAPKs in rats, were renamed to emphasize their role in the phosphorylation of one of their most extensively studied targets, the transcription factor, c-Jun (Krishna and Narang, 2008). JNKs phosphorylate c-Jun on two major sites, Ser63 and Ser73. The phosphorylation and activation of this protein leads to increased c-Jun dependent transcription (Roux and Blenis, 2004). As one part of the dimeric activator protein 1 (AP-1) family, c-Jun is capable of forming homo- or heterodimeric complexes with a number of the basic leucine zipper transcription factors families including c-Fos, Maf, and ATF/CREB (Ham et al., 2000; Dunn et al., 2002). In this group, c-Jun is known to exhibit the highest activation potential. Once activated the transcription factor has the ability to activate a number of genes that include cyclin D1, Bcl3, and Bim which can affect cell cycle progression, survival, and apoptosis, respectively (Shaulian and Karin, 2001; Shaulian and Karin, 2002).

Total protein levels of c-Jun were assessed in $X$. laevis tissues under medium and 
high dehydration conditions (Fig. 3.3A). Medium dehydration did not affect c-Jun protein levels in five tissues but reduced c-Jun content by $\sim 0.60$-fold in skin and also by $\sim 0.74-$ fold in skin under high dehydration conditions. Four tissues showed significantly elevated levels of c-Jun under high dehydration conditions. Total c-Jun protein increased by $1.7-$ fold in skeletal muscle and liver, 1.9-fold in heart, and 4-fold in lung. The amount of active phosphorylated c-Jun ${ }^{\text {ser73 }}$ also increased in two tissues under high dehydration conditions (Fig. 3.3B); levels rose by 1.4- and 1.9-fold in kidney and heart, respectively. Typically, two main mechanisms are responsible for regulating AP-1 activity: 1) increasing the transcription of c-fos and c-Jun, 2) the activation of c-fos and c-Jun via phosphorylation (Marshall, et al., 2000). Based on the results of the present study, AP-1 appears to play a significant role in the regulation of gene expression in all organs except skin under conditions of high dehydration in $X$. laevis as indicated by the increased levels of c-Jun protein as well as the phosphorylation activation of c-Jun in heart and kidney. The data in this chapter indicate that activated JNK does not play a role in phosphorylating c-Jun because there is no correlation between the regulation pattern of the two proteins (Fig. 3.1B and 3.3B). A number of other kinases can be responsible for c-Jun phosphorylation including protein kinase C and casein kinase (Baker et al., 1992). Previous studies using chromatin immunoprecipitation (ChIP) revealed that the activation of c-jun and ATF2 in response to genotoxic stress can lead to the induction of at least 250 genes, $\sim 10 \%$ of which are involved in DNA repair (Karin and Gallagher, 2005). For dehydrated $X$. laevis c-Jun might play a protective role via inducing pro-survival genes (Shaulian and Karin, 2002). 
$c-M y c$

Transcriptional regulation of genes by c-Myc is governed by c-Myc interaction with myc associated factor X (Max). Formation of Myc-Max heterodimers is required for the activation and binding of this transcription factor to specific DNA sequences in a diverse group of genes. One of the key biological functions of c-Myc is promotion of cell-cycle progression (Pelengaris et al., 2002). c-Myc is also known to play a role in sensitizing cells to apoptotic stimuli; that is achieved via direct phosphorylation of c-Myc at Ser-62 and Ser-71 by JNK leading to enhanced apoptosis promoting activities (Noguchi et al., 1999). Total cMyc antibody did not crossreact with $X$. laevis tissue extracts, so in this study I analyzed only the phosphorylated active form of the transcription factor, phospho-cMyc ${ }^{\text {thr58/ser62 }}$ (Fig. 3.4). Medium and high dehydration had

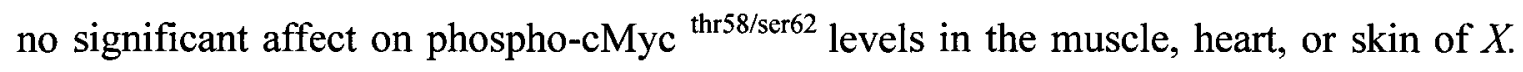
laevis. However, medium dehydration resulted in a 0.24 -fold decrease in phospho-cMyc thr58/ser62 in lung but levels returned to control values during high dehydration. Kidney was the only tissue that showed a strong significant increase in phospho-cMyc ${ }^{\text {thr58/ser62 }}$ content in response to dehydration with a 2.4-fold increase seen under high dehydration conditions. However, this result did not correlate with the response of phospho-JNK1 in kidney (Fig. 3.1B). Other MAPK family members and other kinases such as GSK3 can also activate c-Myc (Alarcon-Vargas and Ronai, 2004). However, both c-Jun and c-Myc were activated in kidney indicating they may be part of the general stress response in kidney. Significant decreases in kidney water contents, measured as a change in protein concentration, was reported in wood frogs in response to either freezing or dehydration stresses (Churchill and Storey, 1993; Holden and Storey, 1997). C-Myc is also known to 
enhance cellular response to oxidative stress (Benassi et al., 2006), another side effect of dehydration. Oxidative stress in spadefoot toads seems to occur due to an overall decrease in antioxidant capacity during dehydration stress, a result of estivation (Grundy and Storey, 1998).

\section{CREB}

The name CREB was given to this transcription factor because it was first identified as a cAMP signaling pathway target. Subsequent studies showed that CREB is activated by a diverse array of stimuli that result in phosphorylation on serine 133 . To achieve further specificity, CREB can be phosphorylated on additional sites. Furthermore, phosphorylation of CREB associated proteins also plays a role in modulating the activity and specificity of this transcription factor (Shaywitz and Greenberg, 1999). Both total CREB protein and phosphorylated CREB ${ }^{\text {serl } 133}$ content were widely affected by dehydration in X. laevis organs (Fig. 3.5). Total CREB protein levels increased significantly ( 2 -fold) during medium dehydration in skeletal muscle; levels also rose in by 0.40 -fold in skin and increased further to 0.60 -fold above control levels under high dehydration (Fig. 3.5A). In lung, however, total CREB protein levels decreased significantly by $\sim 0.40$ and 0.60 -fold under medium and high dehydration conditions, respectively. Heart also showed $\mathbf{a} \sim 0.50$-fold decrease in total CREB protein level under high dehydration. Liver showed the strongest response to dehydration with a significant 3.5-fold increase in CREB levels during high dehydration.

Unlike the somewhat variable tissue-specific response by total CREB to dehydration, the amount of active phosphorylated $\mathrm{CREB}{ }^{\text {ser133 }}$ showed a uniform increase 
in response to dehydration in five out of the six tissues tested (Fig. 3.5B). In muscle, high dehydration led to a strong 3.5 -fold increase in phospho-CREB ${ }^{\text {ser133 }}$ content; skin responded similarly with a 2.6 fold increase in CREB ${ }^{\text {ser133 }}$ under high dehydration. Lung, liver and heart showed significant increases in CREB ${ }^{\text {serl } 133}$ under both medium and high dehydration; compared with control values, levels rose by 2.3 and 2.6-fold in lung, 2 and 1.9-fold in liver, and 1.3 and 1.2-fold in heart under medium and high dehydration conditions, respectively. Hence, CREB-mediated gene expression would appear to have a significant and broad-based role in X. laevis tissues under dehydration stress, perhaps mediating adaptive functions that promote cell survival. Indeed, CREB is known to play a critical role in cell survival by increasing the transcription of pro-survival proteins including Bcl-2 family members (Bcl-2 and Bcl- $\mathrm{X}_{\mathrm{L}}$ ) and Mcl-1 (Ballif and Blenis, 2001). Furthermore, a recent study linked CREB action to regulating one of the major mucins in the human airway submucosl glands (Choi et al., 2009). Although this remains to be experimentally tested, one can speculate that the activation of CREB during medium and high dehydration in $X$. laevis lung might play a role in limiting respiratory water loss by this organ by changing the amount or type of mucins in the lung epithelia. 
Figure 3.1. Effect of medium and high dehydration on the protein expression of JNK in six tissues of $X$. laevis. (A) Relative levels of total JNK protein. (B) Relative levels of active phosphorylated JNK ${ }^{\text {thr183/tyr185 }}$. Representative western blots show JNK expression under control (C), medium dehydration (MD), and high dehydration (HD) conditions. Histograms show mean \pm SEM, $n=3-6$ independent trials on tissue samples from different animals. Letters that differ are significantly different from each other, $\mathrm{P}<0.05$. 
Figure 3.1

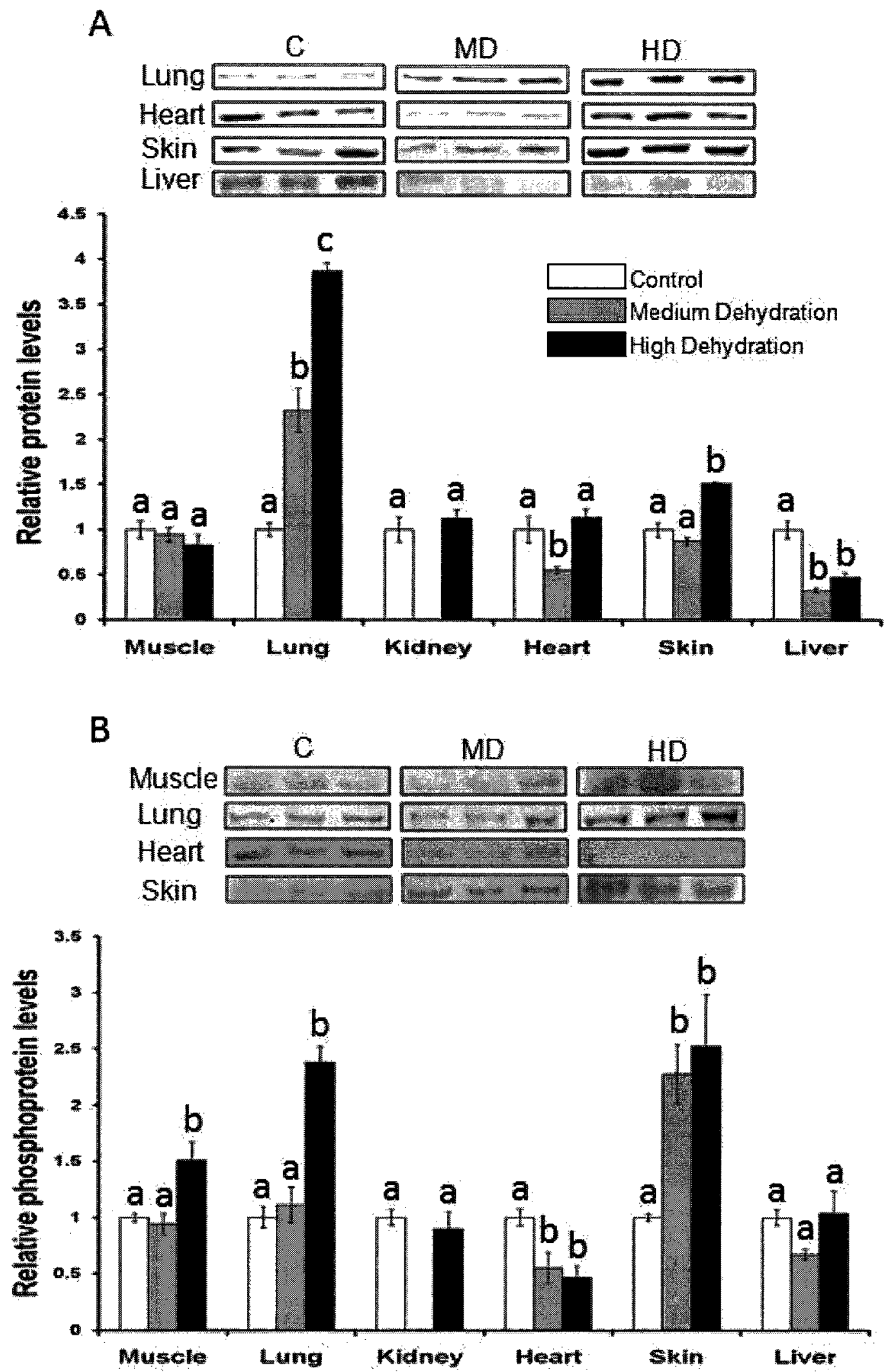


Figure 3.2. Effect of medium and high dehydration on the protein levels of (A) p38 MAPK, and (B) phosphorylated $\mathrm{p} 38^{\text {tyr } 182}$ in six tissues of $X$. laevis. The antibodies used crossreacted with single bands at the expected molecular mass of $\sim 40 \mathrm{kDa}$. Other information as in Figure 3.1. 
Figure 3.2
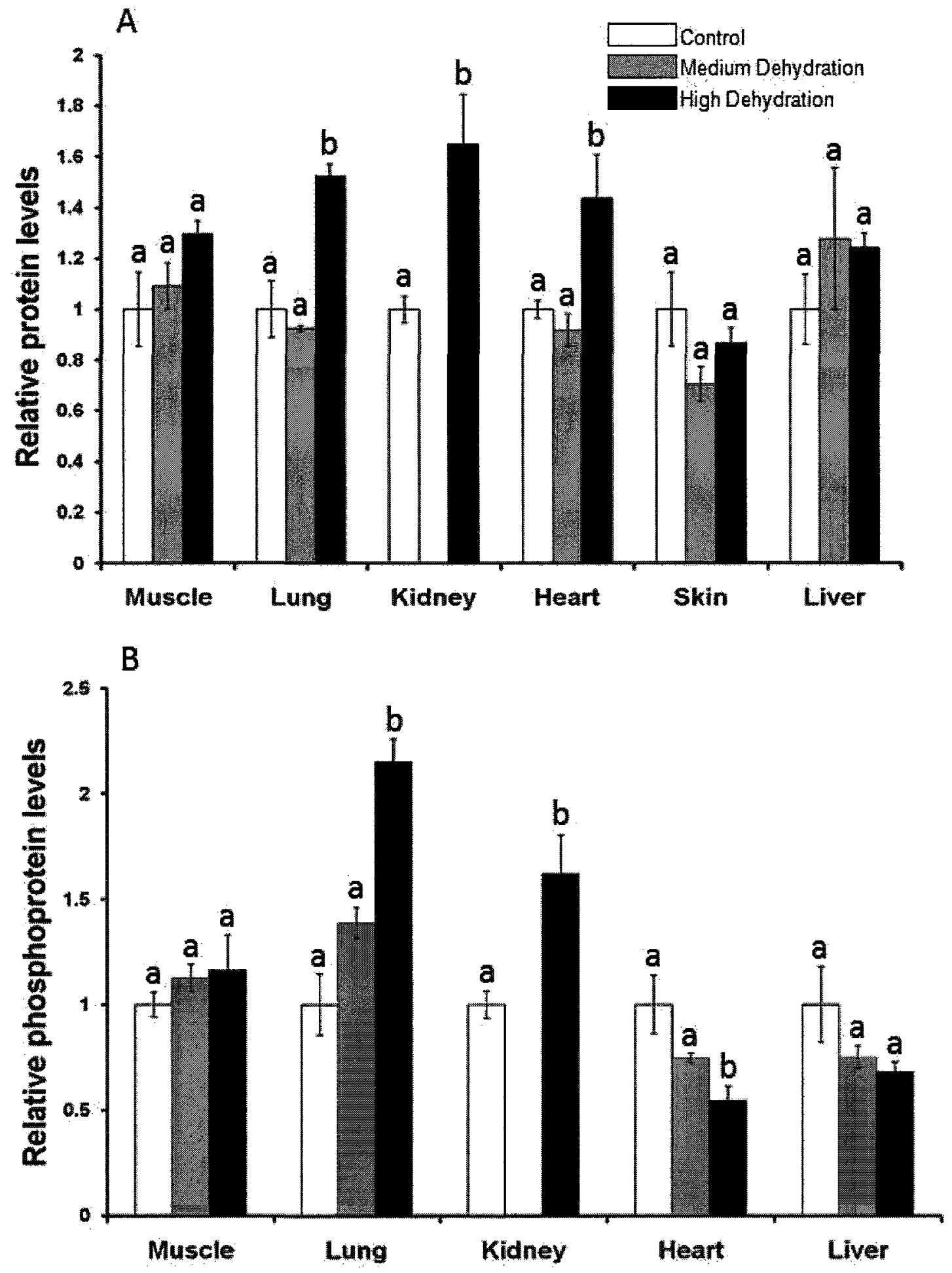
Figure 3.3. Effect of medium and high dehydration on the protein expression of (A) c-

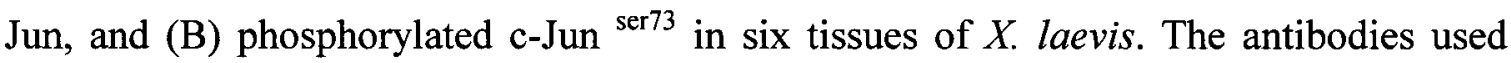
crossreacted with single bands at the expected molecular mass of $\sim 48 \mathrm{kDa}$. Other information as in Figure 3.1. 
Figure 3.3
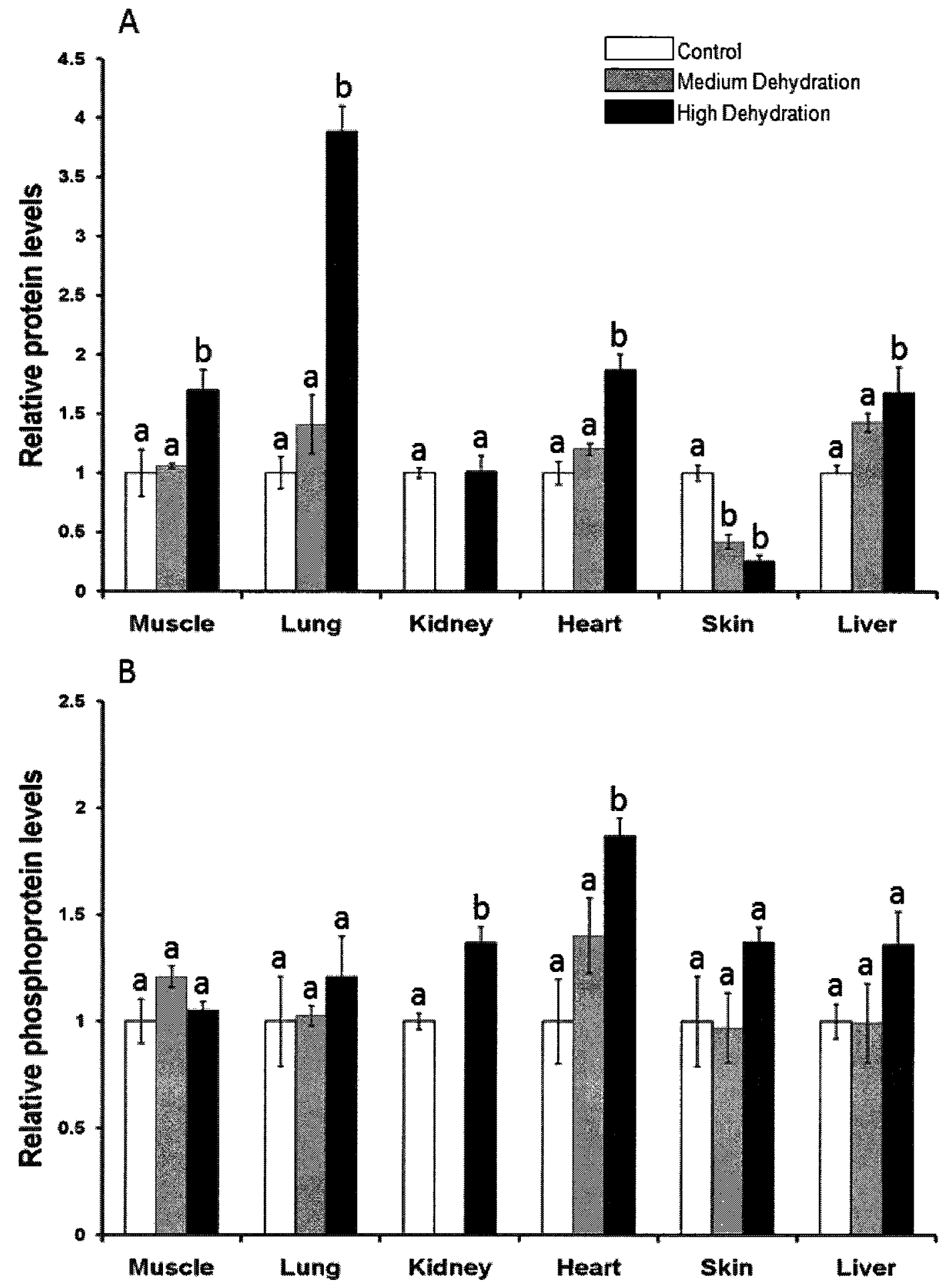
Figure 3.4. Effect of medium and high dehydration on phosphorylated c-Myc ${ }^{\text {thr } 58 / \mathrm{ser} 62}$ protein expression in five tissues of $X$. laevis. The antibodies used crossreacted with single bands at the expected molecular mass of $\sim 67 \mathrm{kDa}$. Other information as in Figure 3.1 . 
Figure 3.4

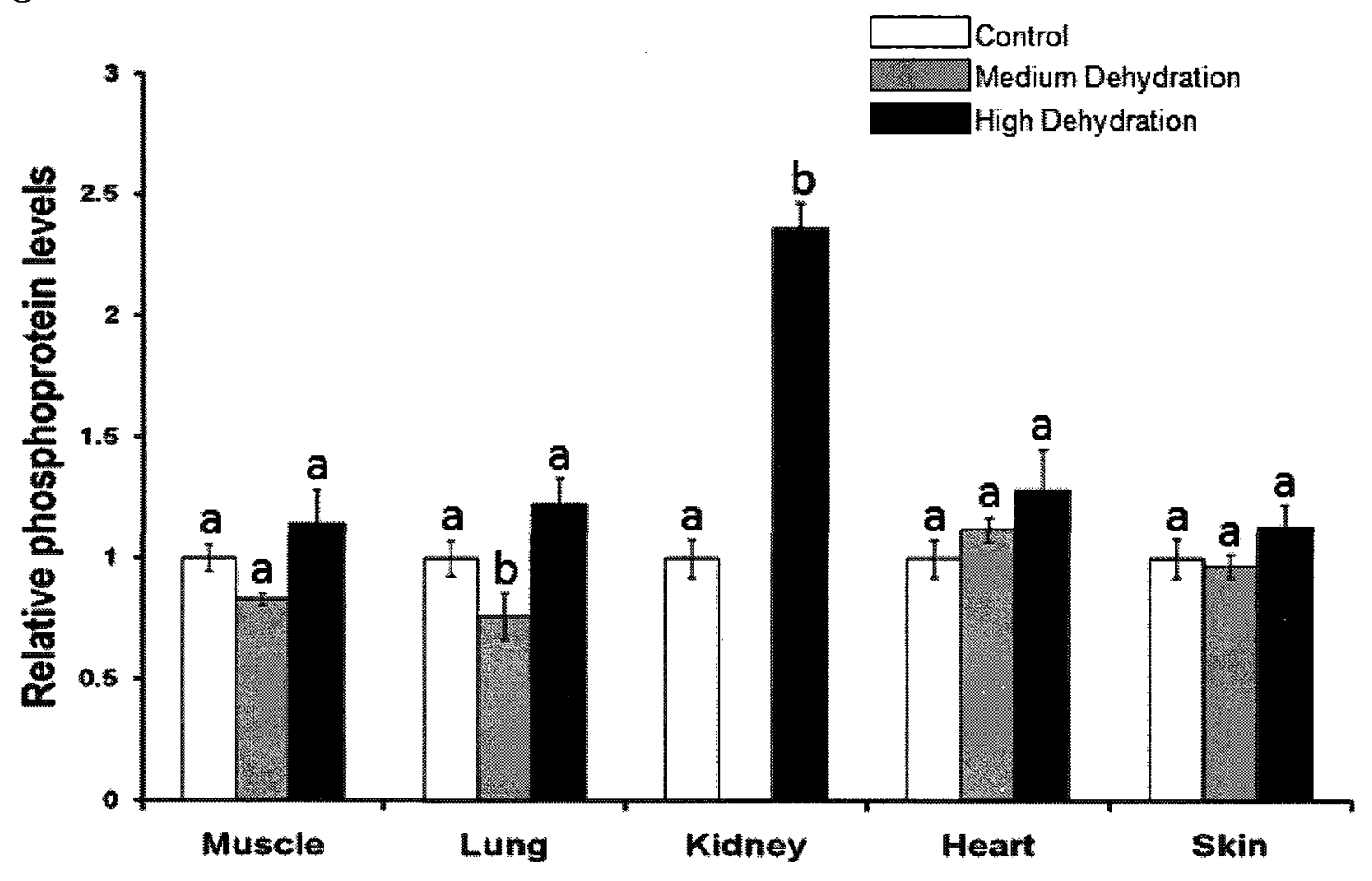


Figure 3.5. Effect of medium and high dehydration on the protein expression of (A)

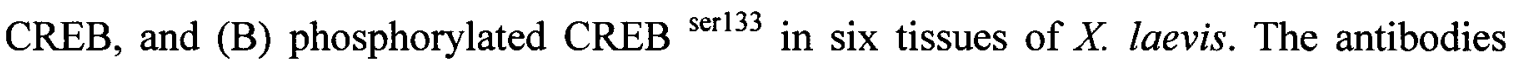
used crossreacted with single bands at the expected molecular mass of $\sim 40 \mathrm{kDa}$. Other information as in Figure 3.1. 
Figure 3.5
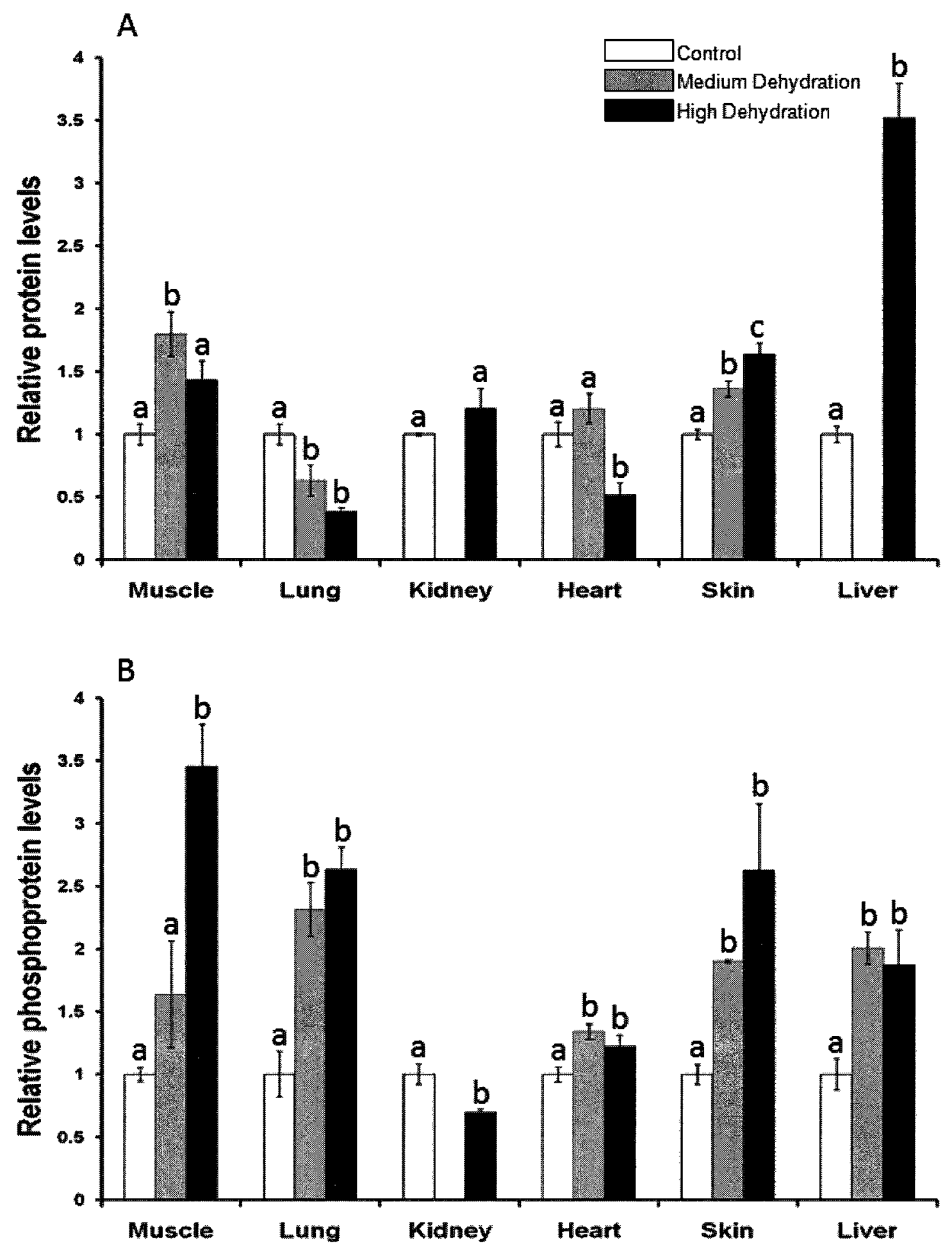


\section{CHAPTER 4}

\section{Activation of antioxidant defense via Nrf2 transcription factor in the dehydrated African clawed frog}




\section{INTRODUCTION}

Exposure to a variety of environmental factors can induce oxidative stress in living organisms, triggering the over-production of ROS. These include UV radiation, pathogen invasion and oxygen shortage (reviewed in Blokhina et al., 2003). Various natural reactions in cells also produce ROS including superoxide radical and hydrogen

peroxide. These are relatively unreactive but can undergo reactions, catalyzed by $\mathrm{Fe}^{2+}$ or $\mathrm{Cu}^{+}$, that produce highly reactive hydroxyl radicals that can cause severe damage to biological macromolecules including proteins, lipids, and DNA (Hermes-Lima, 2004; Halliwell and Gutteridge, 2007). Because of this, many organisms have a range of antioxidant defences involving metabolites, peptides and enzymes and manage these in both constitutive and inducible forms. Constitutive defences provide a "housekeeping" response that is present in all cells whereas inducible defences are enhanced in response to specific stress conditions that over-produce ROS.

The expression of antioxidant genes is under the control of selected transcription factors, key ones being members of the NF-E2-related factor (Nrf) family of basic leucine zipper transcription factors. Nrf2 is of particular interest because it mainly regulates the inducible response (Cullinan and Diehl, 2006). Nrf2 normally resides in the cytoplasm where it is bound to a repressor protein, Keap1. Oxidative stress triggers Nrf2 release from Keap1, followed by Nrf2 translocation to the nucleus. There it forms heterodimers with other proteins, including small Mafs, and activates transcription by binding to the antioxidant response element (ARE) in the promoter region of genes that code for antioxidant and detoxifying proteins (Shih et al., 2005; Cullinan and Diehl, 2006). 
Nrf2 regulates a number of genes but, as mentioned before, the present chapter focuses on the expression of two families of enzymes: the GSTs and the AKRs. Soluble GSTs belong to four main classes: alpha, mu, pi, and theta. A mitochondrial GST, kappa, has also been identified. Sequence identity is about $40-50 \%$ for GSTs in the same class and $25-30 \%$ between GSTs from different classes. In mammals soluble GSTs are collectively expressed in rather large amounts, constituting as much as $4 \%$ of total soluble protein in liver (Eaton and Bammler, 1999). Enzymes in the AKR superfamily perform oxidoreduction reactions on a huge variety of natural and foreign substrates. They are divided into 14 families (AKR1-AKR14) with a total of 114 members (http://www.med.upenn.edu/akr). The present study focuses on members of the AKR1 and AKR7 families. The AKR1 family includes aldehyde reductases (AKR1A group), aldose reductases (AKR1B group) and other groups such as hydroxysteroid dehydrogenases and steroid $5 \beta$-reductases. The AKR7 family members are aflatoxin aldehyde reductases (also known as AFARs) that catalyse the reduction of dicarbonyl containing compounds (Hyndman et al., 2003; Ellis and Hayes, 1995).

This chapter investigates responses by antioxidant systems to the stress of dehydration in $X$. laevis. The skin of frogs is highly water-permeable and, hence, water balance is a major physiological imperative for all species. Frogs display a wide variety of adaptive strategies to acquire and retain water, deal with desiccating environmental conditions, and endure a wide range of osmolality of body fluids (Hillman et al., 2009). As mentioned before, $X$. laevis is primarily an aquatic frog but in its native environment in southern Africa can experience seasonal drying out of ponds that imposes dehydration stress and stimulates overland migration of frogs to find new ponds. One effect of 
dehydration is an increase in blood viscosity and a decrease in blood volume that impairs proper oxygen delivery to tissues and causes hypoxia. Indeed, Hillman (1978) showed a strong decrease in maximal oxygen consumption rates and circulatory oxygen delivery capabilities during dehydration stress in $X$. laevis leading to hypoxia/anoxia and ultimately dehydrational death. However, if dehydration is not lethal, the process of rehydration is also stressful for it produces a quick reoxygenation of tissues that results in a rapid increase in the generation of ROS (Hermes-Lima and Storey, 1998; Hermes-Lima and Zenteno-Savin, 2002). Hence, defences against oxidative stress are needed. In this study I hypothesized that $X$. laevis up-regulates its antioxidant defences under dehydration stress to avoid oxidative injuries as a result of dehydration/rehydration episodes.

\section{MATERIAL AND METHODS}

\section{Animals}

Dehydration experiments for $X$. laevis were conducted as described in chapter 2 .

\section{Preparation of crude extracts and Western blot analysis}

Preparation of crude extracts was conducted as described in chapter 2 with minor changes. Antibodies were a gift from Dr. John Hayes (Biomedical Research Centre, University of Dundee) and were raised against rat proteins except for Nrf2 which was purchased from Santa Cruz Biotechnology. For nuclear extracts, only samples of skeletal muscle and liver were analyzed. Extracts were prepared essentially as described by Mamady and Storey (2006) with minor changes. Samples (0.5-1.0 g) was homogenized 
in a Douce homogenizer using 1-2 ml of homogenization buffer containing $10 \mathrm{mM}$ Hepes at pH 7.9, $10 \mathrm{mM} \mathrm{KCL}, 10 \mathrm{mM}$ EDTA and $1 \mathrm{mM}$ DTT, with $1 \mu \mathrm{l}$ per ml protease inhibitor cocktail (Sigma). After centrifugation for $10 \mathrm{~min}$ at 10,000 rpm, supernatants (cytoplasmic extract) were removed and then pellets were resuspended in $150 \mu \mathrm{l}$ of extraction buffer containing $10 \mathrm{mM}$ Hepes at $\mathrm{pH} 7.9,400 \mathrm{mM} \mathrm{NaCl}, 1 \mathrm{mM}$ EDTA, 1 mM DTT, 10\% v:v glycerol, and 1-2 $\mu$ l protease inhibitor cocktail. The pellets and extraction buffer were mixed at room temperature for $1 \mathrm{~h}$ by gently shaking the sample every $10 \mathrm{~min}$. Samples were then centrifuged again and nuclear extracts (supernatant) were collected. Soluble protein concentration was quantified in whole tissue extracts and nuclear fractions as described in chapter 2. Sample preparation, western blotting, and visualization were conducted as described in chapter 2 .

\section{Total RNA extraction}

Total RNA was prepared from $\sim 100 \mathrm{mg}$ of muscle and liver samples. Diethylpyrocarbonate (DEPC; $0.1 \% \mathrm{v} / \mathrm{v})$ was used to treat all materials and solutions used in this procedure. Tissue was homogenized in $1 \mathrm{ml}$ of Trizol ${ }^{\mathrm{TM}}$ reagent (Invitrogen) using a Polytron homogenizer and then $200 \mu 1$ chloroform was added followed by centrifugation at $10,000 \mathrm{rpm}$ for $15 \mathrm{~min}$. The upper aqueous phase that contained RNA was removed to a fresh tube and the RNA was precipitated by adding $500 \mu \mathrm{l}$ isopropanol. After centrifugation at $10,000 \mathrm{rpm}$ for $10 \mathrm{~min}$ and washing with $1 \mathrm{ml} 70 \%$ ethanol, the total RNA pellet was resuspended in 50-100 $\mu$ l DEPC-treated water. RNA concentration was determined by absorbance at $260 \mathrm{~nm}$ and the quality of total RNA was assessed by the integrity of $28 \mathrm{~S}$ and $18 \mathrm{~S}$ ribosomal RNA bands. 


\section{$R T-P C R$}

RT-PCR was conducted essentially as described by Mamady and Storey (2006) with minor alterations. Briefly, 10-15 $\mu \mathrm{g}$ total RNA was reverse transcribed into cDNA using the reverse transcriptase enzyme Superscript II (Invitrogen) and an oligo-dT primer (Sigma Genosys). The resulting cDNA was serially diluted $\left(10^{-1}-10^{-5}\right)$ and PCR was conducted using primers designed from $X$. laevis $n r f 2$ using the Primer Designer program version 3.0 (Scientific and Educational Software). The forward and reverse primers used for $n r f 2$ were 5'-CATGGTGGAGCAGAGCATGT-3' and 5'GGAGAGTCGTGGGCTTTAAC-3', respectively. The housekeeping gene ( $\alpha$-tubulin) was also amplified with forward and reverse primers being 5'AAGGAAGATGCTGCCAATAA-3' and 5'-GGTCACATTTCACCATCTG-3', respectively. PCR was performed by mixing $5 \mu$ l diluted cDNA with $15.5 \mu$ DEPCtreated water, $1.25 \mu \mathrm{l}$ primer mixture, $0.5 \mu \mathrm{l} 10 \mathrm{X}$ PCR buffer (Invitrogen), $1.25 \mu 150$ $\mathrm{mM} \mathrm{MgCl}_{2}, 0.5 \mu 110 \mathrm{mM}$ dNTPs, and $0.5 \mu 1$ Taq Polymerase. PCR amplification cycles started with an initial step of $2 \min$ at $94^{\circ} \mathrm{C}$, followed by $1 \mathrm{~min}$ at $95^{\circ} \mathrm{C}, 1 \mathrm{~min}$ at $62.5^{\circ} \mathrm{C}$, $1 \mathrm{~min}$ at $72^{\circ} \mathrm{C}$, repeated 36 times; the final step was 6 min at $72^{\circ} \mathrm{C}$. PCR products were separated on a $1 \%$ agarose gel, stained with ethidium bromide, and the intensity of the cDNA band of interest (the most dilute sample that was visible) was scanned and quantified.

\section{Sequencing}


RT-PCR products were sequenced by the Ontario Health Research Institute (OHRI) using the dideoxy method. The sequence retrieved was 566 base pairs and was verified as encoding $X$. laevis $\mathrm{Nrf2}$, also known as nuclear factor (erythroid-derived 2)like 2 (NFE2L2) protein (accession number BC082631.1) using the program BLAST at http://blast.ncbi.nlm.nih.gov/Blast.cgi.

\section{Normalization and Statistics}

Normalization and statistics were conducted as described in chapter 2. For RTPCR, detection of gel bands was done using the ChemiGenius Bio-Imaging System (Syngene, Frederick, MD, USA) and densitometric analysis was performed with the associated Gene Tools software. Band intensity of $n r f 2$ was normalized against the corresponding intensity of the house keeping gene band amplified from the same sample. Mean normalized band densities \pm SEM for control and dehydrated samples were calculated and significance testing used the Student t-test. Data are derived from multiple independent extracts from different animals with a minimum of $n=3$.

\section{RESULTS}

\section{Nrf2 total protein, nuclear localization, and $m R N A$ levels}

The Nrf2 antibody crossreacted with a single band on the immunoblots at the expected molecular mass of $\sim 57 \mathrm{kDa}$. Nrf2 protein expression was assessed in six tissues of $X$. laevis comparing control frogs with dehydrated animals that had lost $28.8 \pm 1.6 \%$ $(n=8)$ of total body water (Fig. 4.1); this level of dehydration is a high but survivable stress that is near the lethal limit $(\sim 32 \%)$ for this species (Malik and Storey, 2009). 
Dehydration resulted in a strong significant increase $(\mathrm{P}<0.05)$ in Nrf2 protein levels in four tissues; levels rose by 1.7-, 2.8-, 3- and 4-fold in heart, abdominal skin, lung and liver, respectively (Fig. 4.1A). However, Nrf2 protein content did not change in skeletal muscle or kidney. To determine if the increases in Nrf2 protein derived from activation of $n r f 2$ gene expression, PCR was used to amplify $n r f 2 \mathrm{mRNA}$ from liver and skeletal muscle. Fig. 4.1B shows that $n r f 2$ transcript levels increased 2 -fold $(\mathrm{P}<0.05)$ in liver during dehydration, similar to the rise in Nrf2 protein in the organ whereas $n r f 2$ transcript levels did not change in muscle. To activate gene expression, transcription factors must migrate to the nucleus and hence, the distribution of $\mathrm{Nrf} 2$ between cytoplasmic and nuclear compartments is instructive. Fig. $4.1 \mathrm{C}$ shows the nuclear localization of $\mathrm{Nrf} 2$ in muscle and liver. In liver, the amount of Nrf2 protein in the nucleus did not change in dehydrated frogs but in muscle strong nuclear translocation was seen with nuclear $\mathrm{Nrf} 2$ levels being 4.3 -fold higher $(\mathrm{P}<0.05)$ in muscle from control versus dehydrated frogs. The elevated levels of Nrf2 protein in $X$. laevis organs suggest that downstream genes under Nrf2 control may be up-regulated under dehydration stress. To assess this, I next quantified protein levels from two families of genes under Nrf2 control: glutathione $S$ transferases and aldo-keto reductases.

\section{GST family of proteins}

Figures 4.2 and 4.3 show the responses by six GST family members to dehydration in $X$. laevis tissues. GST levels were assessed by immunoblotting and, for all six proteins, the antibody used cross-reacted with a single strong band of frog protein at the expected GST molecular weight of $\sim 28 \mathrm{kDa}$. Protein levels of the GST P isozyme 1 
are shown in Fig. 4.2A. Strong significant increases in GSTP1 occurred in heart, skin and liver; levels were 2.6-, 1.7-, and 9-fold $(\mathrm{P}<0.05)$ higher in dehydrated frogs as compared with controls. However, GSTP1 content did not change in muscle and lung and decreased significantly by 0.50 -fold in kidney. Two GST Mu isozymes were assessed. Levels of the GSTM1 isoform increased significantly $(\mathrm{P}<0.05)$ by 2.1 -fold in muscle during dehydration and by 3- and 2-fold in lung and skin, respectively (Fig. 4.2B). GSTM1 levels did not change in kidney and liver and decreased significantly by 0.40 -fold in heart. GSTM3 levels showed a similar tissue-specific pattern of expression. Levels of GSTM3 rose significantly by $2-, 1.4-$, and $1.9-$ fold $(\mathrm{P}<0.05)$ in the muscle, lung, and skin respectively, and were unaffected in the other three tissues. A GST kappa 1 isozyme was assessed in five tissues of $X$. laevis (Fig. 4.3A). In muscle and kidney of dehydrated frogs, levels of GSTK1 protein increased significantly by 1.8 - and 1.5 -fold $(\mathrm{P}<0.05)$, respectively, compared with control values but levels were unchanged in heart, skin and liver. Dehydrated frogs showed enhanced levels of GST alpha 3 protein (GSTA3) in kidney (2-fold) and lung $(3.9$-fold $)(\mathrm{P}<0.05)$ but levels were unchanged in muscle and heart and decreased significantly by 0.70 -fold in liver (Fig. 4.3B). The last member of the GST family studied was a theta isozyme, GSTT1 (Fig. 4.3C). Protein levels rose by 2.3 and 1.7-fold $(\mathrm{P}<0.05)$ in muscle and kidney, respectively, of dehydrated frogs, but were reduced by 0.60 and 0.70 -fold in lung and skin, respectively, and were unchanged in muscle, heart, and liver.

\section{AKR family of proteins}


The responses to dehydration by three members of the AKR family were analyzed using antibodies that recognized the rat isozymes that are named AFAR1 (or AKR7A1), AKR1B4, and AKR1A3 (http://www.med.upenn.edu/akr). Each of the three antibodies crossreacted with single bands of protein on the frog blots at the expected molecular mass of $\sim 37 \mathrm{kDa}$ for AKR members. AFAR1 protein increased in muscle, kidney, and skin of dehydrated frogs by 1.3-, 1.5-, and 1.7-fold $(\mathrm{P}<0.05)$, respectively (Fig. 4.4A). However, levels fell by 0.20 -fold in liver of dehydrated frogs. The second member studied was an aldose reductase, using the antibody against the rat protein (AKR1B4). Levels increased significantly in four tissues, rising 1.4-fold in lung, 1.8-fold in muscle and 2-fold in heart and skin $(\mathrm{P}<0.05)$ (Fig. 4.4B) but did not change in kidney and liver of dehydrated frogs. The AKR1A enzyme subfamily contains aldehyde reductases and levels in $X$. laevis were assessed using antibodies raised against rat AKR1A3. Levels increased significantly in three tissues of dehydrated frogs by $1.9-, 2-$ and 2.2 -fold in muscle, liver and skin, respectively $(\mathrm{P}<0.05)$ but were unchanged in the other tissues (Fig. 4.4C).

\section{DISCUSSION}

The role of Nrf2, a member of the Cap ' $n$ ' Collar (CNC) family of basic leucine zipper (bZip) transcription factors, in promoting the expression of genes involved in cell growth, protein folding, antioxidant defence, and detoxifying reactions is well-established (Cullinan and Diehl, 2006; Thimmulappa et al., 2002). The present study examined the expression of $\mathrm{Nrf} 2$ in response to whole body dehydration in $X$. laevis. The results in this chapter show a strong elevation of $\mathrm{Nrf} 2$ protein levels in lung, heart, skin and liver during 
dehydration which suggests that Nrf2 mediated gene expression has a significant role to play in the responses of frog tissues to dehydration stress. $X$. laevis rely mainly on their lungs for gas exchange (Feder and Burggren, 1992), but their skin also plays a central role in this process according to Emilio and Shelton (1974) who reported that $X$. laevis skin accounts for $30 \%$ of $\mathrm{O}_{2}$ uptake and $80 \%$ of $\mathrm{CO}_{2}$ elimination. Under dehydration conditions, the lungs have to take over the skin's role which might explain the increase in the lung antioxidants defenses during dehydration. In the muscle and kidney no significant changes in Nrf2 total protein levels were recorded. The 2-fold increase in $n r f 2$ mRNA transcripts in the liver suggests that the regulation of Nrf2 total protein levels in this organ is linked with transcriptional control of $n r f 2$ expression. This is also supported by the data for skeletal muscle where both $n r f 2$ mRNA and Nrf2 protein levels were unchanged under dehydration stress. The up-regulation of Nrf2 protein and mRNA levels in a detoxifying organ like the liver during dehydration is consistent with a role for $\mathrm{Nrf} 2$ in regulating genes involved in detoxification reactions. However, the nuclear translocation data for $\mathrm{Nrf} 2$ in liver showed no significant increase in the relative amount of Nrf2 present in the nucleus in dehydrated animals whereas Nrf2 presence in the nuclear fraction of muscle rose strongly by 4.3 -fold during dehydration.

Both the changes in total Nrf2 protein levels in four tissues and the nuclear translocation of $\mathrm{Nrf2}$ in muscle suggest an enhanced antioxidant response in $X$. laevis during dehydration. To assess this, the expression of selected proteins from two families (GSTs and AKRs) that are known to be transcriptionally activated by Nrf2 were assessed (Chanas et al., 2002; Jowsey et al., 2003; Kang et al., 2007, Nishinaka and Nishimur, 2005; Ellis et al., 2003). The multiclass family of GST enzymes functions to detoxify 
xenobiotic compounds. Each subunit of these dimeric enzymes has an active site that is composed of 2 distinct functional regions. The first is the hydrophilic G-site that binds glutathione (GSH); this site is highly conserved among all GSTs. The second is the adjacent $\mathrm{H}$-site that binds structurally diverse electrophilic substrates by providing a hydrophobic environment. The H-site is less conserved between GST family members because of the broad range of substrates that must be handled (Eaton and Bammler, 1999). GSTs catalyze reactions by binding both GSH and the electrophilic substrate into the active site followed by a nucleophilic attachment of GSH onto the electrophilic substrate by activating the sulfhydryl group on GSH. The electrophilic functional center of the substrate can be a carbon, nitrogen, or sulphur. Generally, GSTs catalyze detoxification reactions with the general formula: $\mathrm{GSH}+\mathrm{R}-\mathrm{X} \rightarrow \mathrm{GSR}+\mathrm{HX}$, where $\mathrm{R}-\mathrm{X}$ is the electrophile. The cysteine residue of GSH and the electrophile form a thioether bond producing a product that is usually less reactive with cellular macromolecules and more water soluble (reviewed in Armstrong, 1997). Unlike mammalian GSTs, little is known about this family of proteins in amphibians. A few studies identified and characterized the different classes of GSTs present in $X$. laevis and mu, alpha, sigma, and pi classes have been found (Angelucci et al., 2002; De Luca et al., 2002; De Luca et al., 2003). However, the responses and regulation of these different classes of GSTs with respect to environmental stress in $X$. laevis has not previously been examined.

Organ-specific patterns were seen in GST responses to dehydration. Significant increases in the protein levels of GSTM1, GSTM3 and GSTA3 all occurred in lung correlated with elevated lung Nrf2 content. Similarly, skin showed increased levels of GSTM1, GSTM3 and GSTP1 (by 1.7-, 3- and 3.9-fold, respectively), again correlated 
with high Nrf2 levels in skin of dehydrated frogs. High Nrf2 in heart and liver of dehydrated frogs also correlated with strong elevations of GSTP1 protein in these organs. The response of the Pi class isoenzyme in liver was unexpected since this mRNA for this isozyme was reported to be present only in $X$. laevis embryos but not adult tissue (De Luca et al., 2003). However, the present data would argue that expression of GSTP1 is minimal (or trace) in liver of control adult frogs in an aquatic environment but is markedly induced ( $\sim 9$-fold) by dehydration stress. Furthermore, although $n r f 2$ mRNA increased in liver, giving rise to strong increases in $\mathrm{Nrf} 2$ protein, $\mathrm{Nrf} 2$ translocation to the nucleus did not change in liver (Fig. 4.1). Perhaps, then, changes in the levels of a Nrf2 binding partner are an important determinant for the Nrf2-mediated up-regulation of GSTP1 in liver, or perhaps other response elements are involved in up-regulating liver GSTP1 during dehydration; candidates could include the xenobiotic response element (XRE), glucocorticoid response element (GRE), or GST P enhancer 1 (GPE). In skeletal muscle, however, the responses to dehydration were different. Total $n r f 2 \mathrm{mRNA}$ and Nrf2 protein did not change in muscle of dehydrated frogs but the nuclear content of $\mathrm{Nrf} 2$ rose by 4.3 -fold. This correlated with the up-regulation of multiple antioxidant enzymes in muscle including 3 GST isozymes (M1, M3, K1) and all 3 AKR isozymes.

The second family of proteins studied was the AKRs. These enzymes are generally involved in the detoxification of a wide range of environmental and endogenously generated aldehydes and diketones to alcohols (Spite et al., 2007; Ellis and Hayes, 1995). AKRs also catalyze the reduction of carbonyl compounds such as sugars, steroids hormones, and ketones in an NADPH-dependent manner (Seery et al., 1998). A variety of tissue specific roles of these enzymes have been identified that range from 
glucose reduction to steroid metabolism (Spite et al., 2007). AKR1 family members are known to be regulated by a variety of stimuli including osmotic stress, oxidative stress, and ROS (Hsu et al., 1997; Nishinaka and Nishimura, 2001, 2005; Seo et al., 2000); in kidney, for example, aldose reductase acts to reduce glucose to sorbitol, an organic osmolyte that is important in kidney osmoregulation (Hsu et al., 1997). However, in this study only AFAR1, an AKR7 family member, showed enhanced expression in the kidney. The present data found a significant consistent elevation of AFAR1, AKR1B4 and AKR1A3 in muscle and skin of $X$. laevis under dehydration stress; this suggests a common need by these two peripheral tissues for AKR actions under situations of tissue water loss. AKR1B4 was also elevated in lung and AKR1A3 also increased in liver of $X$. laevis during dehydration. Enhanced levels of the AKR1A type protein in X. laevis tissues is interesting because AKR1A group members reduce aldehydes including malondialdehyde (MDA) which is an end product of ROS attack on polyunsaturated fatty acids (Hjelle and Petersen, 1983). Hence, AKR1A group members can make a defined contribution to antioxidant metabolism. 
Figure 4.1. Effect of dehydration on X. laevis Nrf2. (A) Representative western blots show Nrf2 protein expression under control (C) and dehydrated (D) conditions in four tissues with two independent samples shown per tissue. Histogram shows normalized protein levels in six tissues. (B) Representative bands on agarose gels show PCR product levels of amplified $n r f 2$ and $\alpha$-tubulin for two preparations from liver. Histogram shows normalized $n r f 2$ mRNA levels in the muscle and liver. (C) Representative western blots show levels of Nrf2 protein in nuclear extracts. Histogram shows relative protein distribution of $\mathrm{Nrf} 2$ in nuclear extracts of muscle and liver from control versus dehydrated frogs. Data are means \pm S.E.M., $n=3-5$ independent trials on tissue from different animals. $\star$ : Significantly different from the corresponding control, as determined by the Student's t-test, $\mathrm{P}<0.05$. 
Figure 4.1
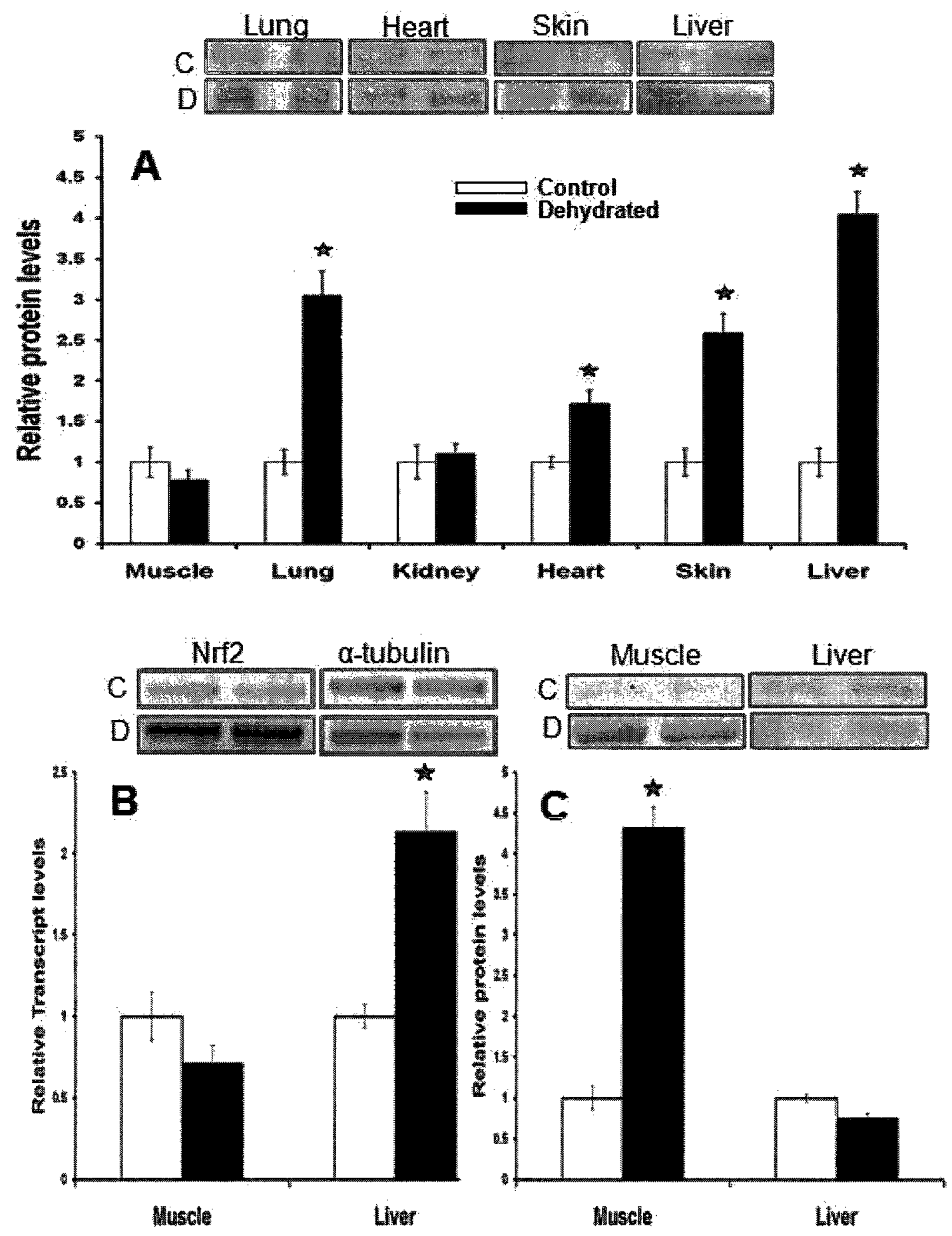
Figure 4.2. Effect of dehydration on the protein levels of GST pi and mu family members in six tissues of $X$. laevis: (A) GSTP1, (B) GSTM1, (C) GSTM3. In all panels, representative bands show western blots of protein levels in tissues from control (C) and dehydrated (D) conditions; bands for two independent samples are shown per tissue. Histograms show normalized protein levels for control versus dehydrated conditions; data are means \pm S.E.M., $\mathrm{n}=3-5$ independent trials on tissue from different animals. $\star$ : Significantly different from the corresponding control, $\mathrm{P}<0.05$. 
Figure 4.2
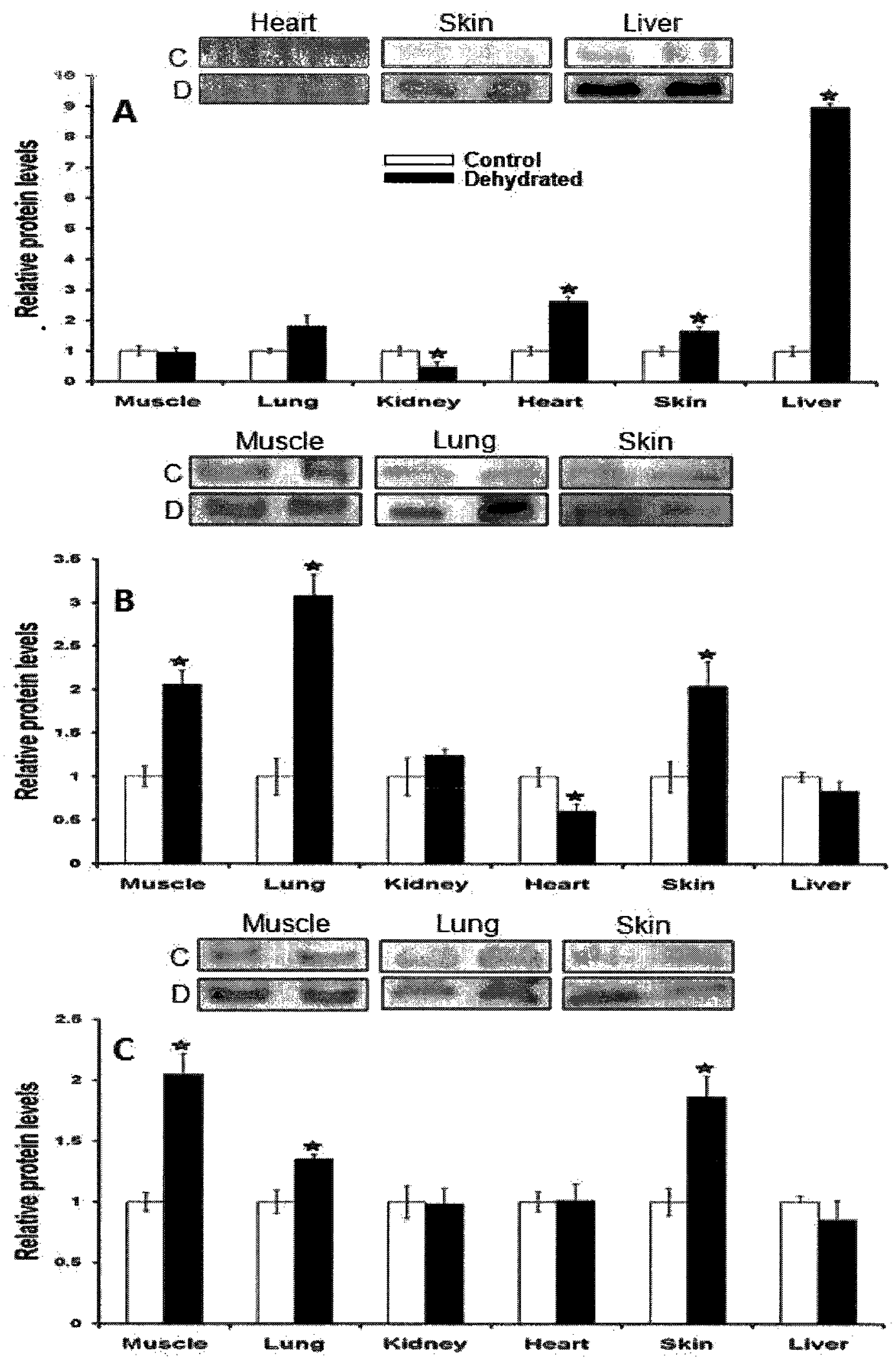
Figure 4.3. Effect of dehydration on the protein levels of GST kappa, alpha and theta family members in tissues of $X$. laevis: (A) GSTK1, (B) GSTA3, (C) GSTT1. Other information as in Figure 4.2. 
Figure 4.3
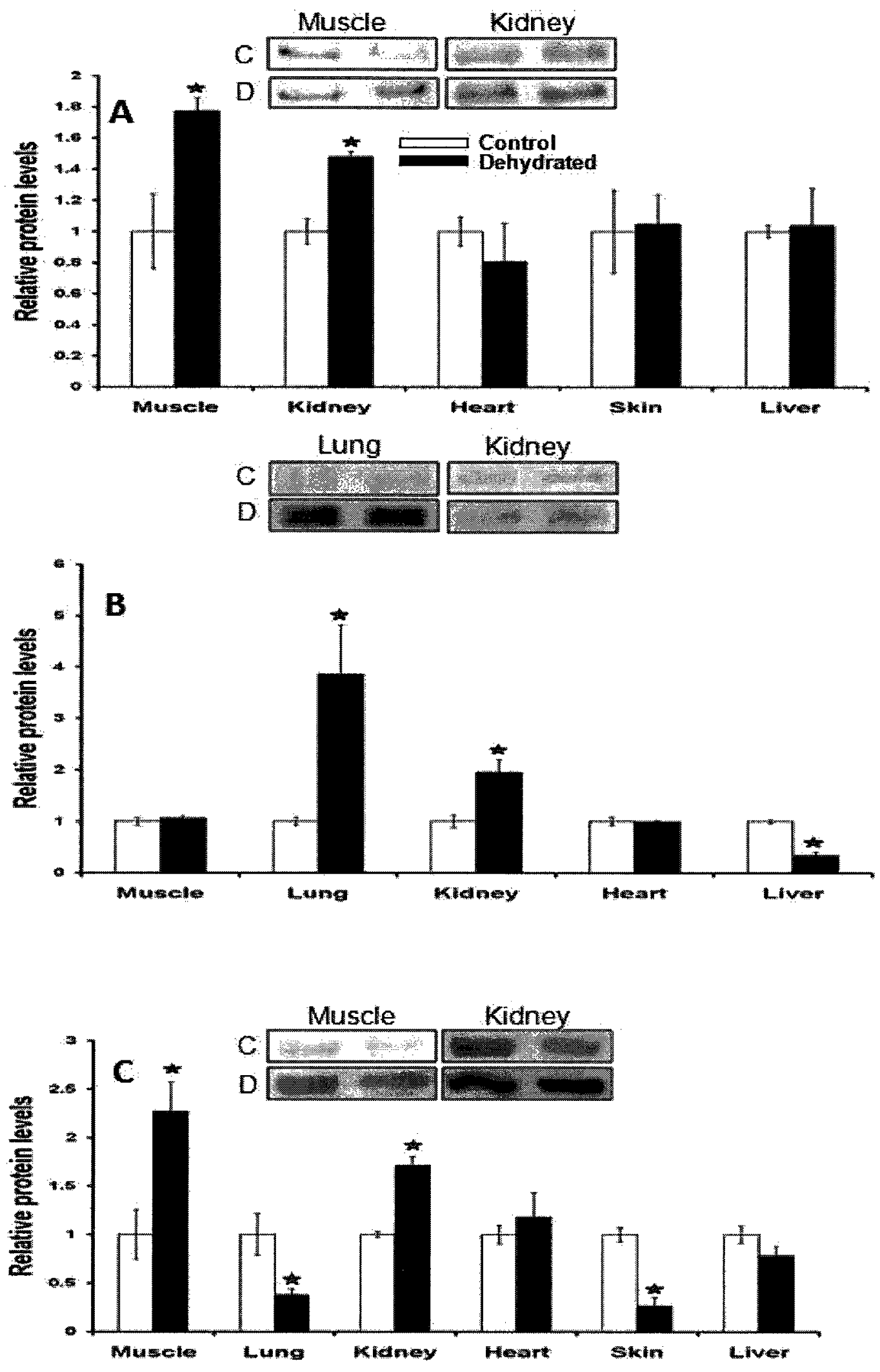
Figure 4.4. Effect of dehydration on the protein levels of AKR family members in $X$. laevis: (A) AFAR1, (B) AKR1B4, (C) AKR1A3. Other information as in Figure 4.2. 
Figure 4.4
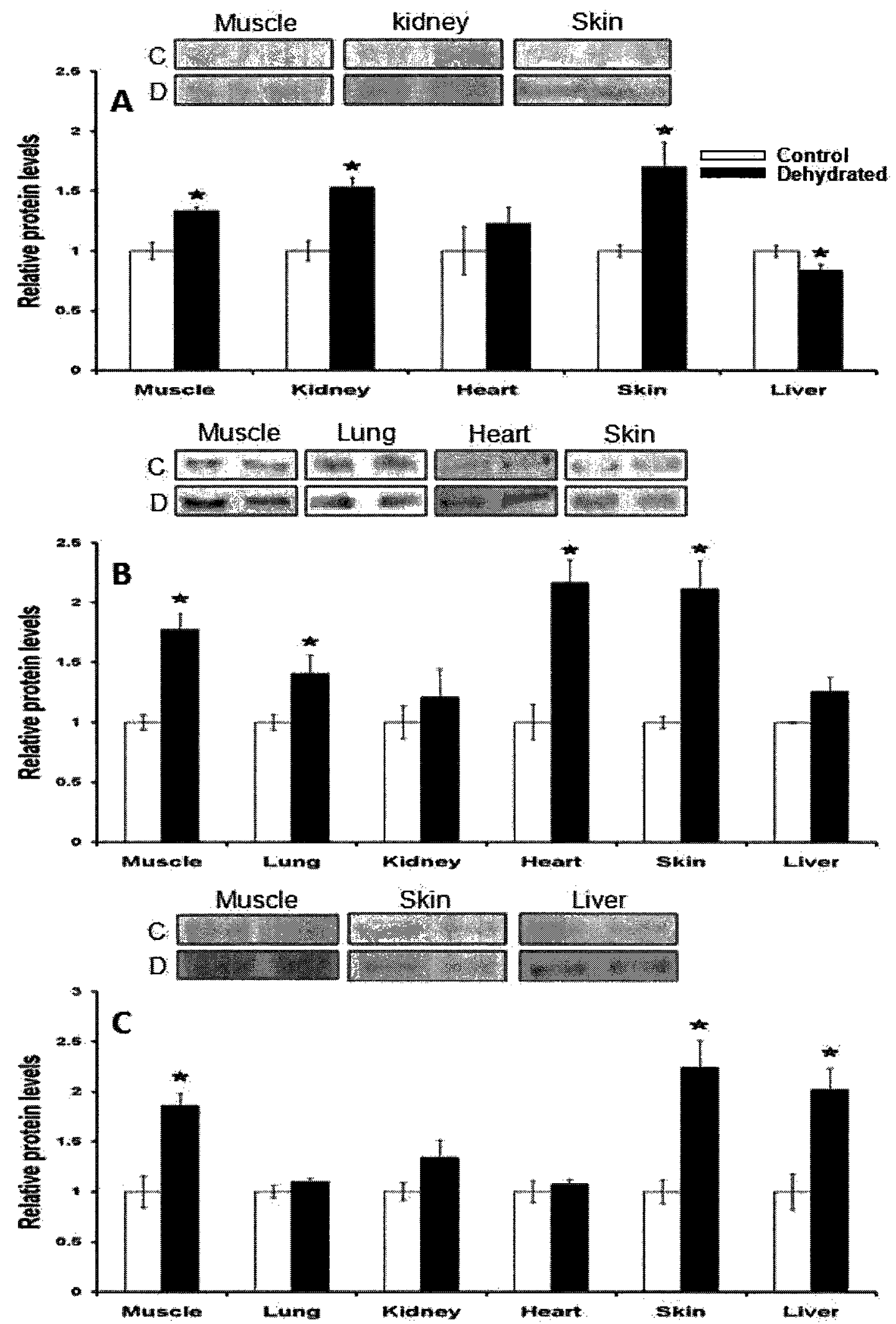


\section{CHAPTER 5}

\section{Transcriptional regulation of antioxidant enzymes by FoxO1 in dehydrated Xenopus laevis}




\section{INTRODUCTION}

FoxO transcription factors are considered to be key regulators of cell fate; they control fundamental cellular processes like metabolism, cell cycle, stress response, and apoptosis (Glauser and Schlegel, 2007; Horst and Burgering, 2007; Lam et al., 2006; Salih and Brunet, 2008). In mammals four FoxO isoforms have been identified to date: FoxO1, FoxO3, FoxO4 (previously known as FKHR, FKHRL1, and Afx, respectively) and FoxO6 (Glauser and Schlegel, 2007; Lam et al., 2006). The first three (FoxO1, 3, 4) are major substrates of Akt (protein kinase B) and serum and glucocorticoid induced protein kinase (SGK). Akt-dependent phosphorylation in response to growth factor and insulin stimulation reduces the DNA-binding ability of FoxO, promotes FoxO export from the nucleus to the cytoplasm, and enhances its degradation (Lam et al., 2006; Salih and Brunet, 2008). The newly identified FoxO member, FoxO6, is not tightly controlled by Akt posttranslational modification because it lacks the C-terminal AKT consensus phosphorylation motif and is constitutively located in the nucleus (Lam et al., 2006). In addition to phosphorylation, FoxO family members can also be regulated by acetylation and ubiquitylation (Horst and Burgering, 2007).

Dehydrational death in anurans is believed to be the result of circulatory collapse resulting from a rapid fall in the frogs' blood pressure due to the significantly increased blood viscosity near their tolerance limit. In $X$. laevis viscosity does play a role in dehydration death by intensifying the effects of non-permeant solutes present in the plasma, which when exceeded lead to the debilitation of the cardiovascular system. That debilitation results in reduced oxygen delivery capabilities and a generalized tissue hypoxia/anoxia due to the increase in blood oxygen arterio-venous difference, which is 
caused by the decrease in venous oxygen concentration with dehydration. To compensate for the high arterial blood oxygen capacity (BOC) and the low venous BOC, frogs increase their heart rate to be able to deliver the same amount of oxygen to tissues. That was proven when it was shown that $X$. laevis resting heart rate (RHR) increased significantly with dehydration. At $25 \%$ of original body weight the RHR value was similar to that of the active heart rate. Dehydration stress also causes a significant decline in active metabolic rate which was reduced to values similar to resting metabolic rate when frogs reached $30 \%$ water loss (Hillman, 1978). The decrease in tissue oxygen levels during dehydration makes $X$. laevis organs susceptible to oxidative injury similar to that seen in postischemic mammals (Echenhoff et al., 1992). I have already shown in chapter 4 that $X$. laevis regulates its antioxidant defence through increasing the production of antioxidant enzymes when facing dehydration stress (Malik and Storey, 2009). This chapter further investigate $X$. laevis antioxidant regulation by measuring the total protein levels and activation status of one member of the FoxO subfamily, the FoxO1 transcription factor. I hypothesize that dehydration stress in $X$. laevis will lead to the activation of FoxO1 transcription factor and that this will result in an increase in oxidative stress resistance by $X$. laevis organs by up-regulating two antioxidant enzymes, catalase and $\mathrm{Mn}^{2+}$-dependent superoxide dismutase (MnSOD), both known to be FoxO1 downstream targets (Venkatesan et al., 2006; Van der Horst and Burgering, 2007; Birkenkamp and Coffer, 2003; Salih and Brunet, 2008). 


\section{MATERIAL AND METHODS}

\section{Animals}

Dehydration experiments were conducted as described in chapter 2. Two groups were compared: control frogs and those from the high dehydrated group $(28.0 \pm 1.6 \%$ of total body water lost).

\section{Preparation of crude tissue extracts, Western blots, and RT-PCR}

All procedures were performed as described in chapters 2 and 3, except for minor changes. For western blots, antibodies were purchased from Cell Signalling Technology except for catalase which was from GenScript Corporation; all were used according to manufacturer's instructions. For RT-PCR, primers were designed for MnSOD and catalase using the Primer Designer program version 3.0 (Scientific and Educational Software). The forward and reverse primers used for MnSOD were 5'GTWCCAGCSTTGGSCTACTC-3' and 5'-CTCCCAGTTGATMACATTCC -3 ', respectively, where $\mathrm{W}=\mathrm{A} / \mathrm{T}, \mathrm{S}=\mathrm{G} / \mathrm{C}$ and $\mathrm{M}=\mathrm{A} / \mathrm{C}$. The forward and reverse primers used for Catalase were 5'-GTGAGAACATTGCTGGACAC-3' and 5'GTGGCGTAAGAGGAATGCTG-3', respectively. The housekeeping gene ( $\alpha$-actin) was also amplified with forward and reverse primers being 5'TGCTCCRAGRGCAGTATTCC-3' and 5'- AAGACGCATGATKGCATGAG -3', respectively.

\section{DNA binding assay}

Liver nuclear extracts were prepared as described previously. Aliquots containing 
an equal amount of protein from control and dehydrated samples (skeletal muscle and liver) were used to assess the amount of binding by FoxO1 to its response element using an ELISA type assay from Panomics Corp. There are two parts to this assay: 1) the activated FoxO1 in $X$. laevis nuclear extracts binds to a FoxO1 probe on a biotinylated oligonucleotide forming the TF-DNA complex, and 2) this is then immobilized and captured on a 96-well streptavidin coated assay plate. The binding assay was performed according to manufacturer's instructions. Briefly, FoxO1-DNA complex binding was carried out by incubating the nuclear extracts with the FoxO1 specific probe for 30 minutes. The samples were then transferred to the assay plate where they were incubated for 1 hour. The wells were washed three times prior to adding FoxO1 primary antibody $(1: 200 \mathrm{v} / \mathrm{v}$ diluted in antibody dilution buffer). The primary antibody was incubated at room temperature for 1 hour followed by washing each well three times using washing buffer. A secondary antibody, HRP linked anti-rabbit IgG, was added (1:200 v/v) to each well and the plate was incubated for 1 hour. The wells were washed three times prior to adding the substrate solution. After developing for 15 minutes, the stop solution was added and the developed color was immediately quantified by reading the absorbance at $450 \mathrm{~nm}$. All incubation steps were performed at room temperature with mild agitation on a rocking platform at $150 \mathrm{rpm}$.

\section{Sequencing}

RT-PCR products were sequenced by the Ontario Health Research Institute (OHRI) using the dideoxy method. The sequence retrieved for $X$. laevis MnSOD, also known as SOD2, was 538 base pairs; the sequence retrieved for catalase was 116 base 
pairs. Both sequences were verified (MnSOD accession number AY362041, catalase accession number NM001087075) using the program BLAST at http://blast.ncbi.nlm.nih.gov/Blast.cgi.

\section{RESULTS}

\section{FoxO1 total protein, nuclear localization, and DNA binding assay}

The anti-rabbit FoxO1 cross reacted with a single band at the expected molecular weight of $\sim 78 \mathrm{kDa}$. Total FoxO1 protein levels remained unchanged during dehydration stress in X. laevis muscle and liver. Activated FoxO1 translocates to the nucleus, where an increase in DNA binding activity follows. Hence, FoxO1 content in nuclear and cytoplasm extracts of skeletal muscle and liver from control versus dehydrated frogs was assessed. FoxO1 levels in nuclear extracts of muscle from dehydrated frogs were significantly reduced by 0.40 -fold as compared with controls (Fig. 5.1A). By contrast, the opposite was seen in liver where FoxO1 showed a significant increase of 1.8 -fold in nuclear extracts from dehydrated frogs and a 0.60 -fold decrease in the cytoplasm.

Next, FoxO1 DNA binding activity was assessed in nuclear extracts from $X$. laevis muscle and liver using the Panomics commercial kit and a correlation was found with FoxO1 nuclear translocation. Relative FoxO1 DNA binding activity was $1 \pm 0.18$ SEM in control muscle and $0.88 \pm 0.18$ SEM in dehydrated muscle $(n=4$ independent trials). In the liver relative FoxO1 DNA binding activity showed an increase from $1 \pm$ 0.11 SEM in nuclear extracts from control frogs to $1.57 \pm 0.13 \mathrm{SEM}$ in $(\mathrm{n}=3$ independent trials) in extracts from dehydrated frogs. 


\section{FoxO1 posttranslational modification}

FoxO1 transcription factor can be regulated via protein phosphorylation. Mammalian FoxO1 can be phosphorylated at serine and threonine residues in response to insulin signaling: these sites are T24, S256, S319, and S329. An examination of the $X$. laevis FoxO1 sequence identified the comparable residues as T28, S245, S308, and S318 (Pohl et al., 2004). FoxOl phosphorylation status in response to dehydration in $X$. laevis was examined using a FoxO1 ${ }^{\mathrm{ser} 256}$ anti-rabbit antibody that should recognize the homologous Ser245 site in the frog protein. This crossreacted with a single protein band in frog liver at the expected molecular weight of $\sim 82 \mathrm{kDa}$; however, the antibody did not crossreact on blots with $X$. laevis muscle extracts. Total phospho-protein level was significantly reduced in liver from dehydrated X. laevis, as compared with controls (Fig.

5.1B). Furthermore, when nuclear extracts were assessed, FoxO $1^{\text {ser245 }}$ phosphoprotein content was also significantly reduced in liver of dehydrated $X$. laevis implying reduced nuclear translocation of FoxO1 in the dehydrated state.

\section{MnSOD}

MnSOD levels were assessed by immunoblotting and the antibody used crossreacted with a single strong band of frog protein at the expected molecular weight of $\sim 25$ $\mathrm{kDa}$ (Fig. 5.2A). Protein levels of MnSOD showed no significant changes in $X$. laevis skeletal muscle, lung, heart, and skin in response to dehydration. However, in kidney and liver significant increases of $1.4-$ and 1.5 fold were seen, respectively, in tissue from dehydrated frogs as compared to controls. To determine if the increases in MnSOD protein derived from activation of $M n S O D$ gene expression, RT-PCR was used to 
amplify $M n S O D$ mRNA transcripts from skeletal muscle and liver of $X$. laevis. Fig. 5.2B shows that $M n S O D$ transcript levels did not change in muscle, but increased 1.5 -fold in the liver in response to dehydration, similar to the rise in MnSOD protein in the organ.

\section{Catalase}

Catalase protein expression was also assessed in six tissues of $X$. laevis (Fig. 5.3A). The antibody crossreacted with a single band on the immunoblots at the expected molecular weight of $\sim 65 \mathrm{kDa}$. Significant increases in catalase content of 1.8-fold, 1.9fold, and 1.4-fold were seen in response to dehydration in muscle, lung and liver, respectively. However, in kidney, catalase protein level decreased significantly (0.50fold) during dehydration. No significant change occurred in heart and skin. Fig. 5.3B shows comparable results for catalase mRNA levels in $X$. laevis muscle and liver. A significant increase of 2.2-fold was seen for catalase mRNA levels in liver during dehydration stress but muscle mRNA levels remains constant.

\section{DISCUSSION}

This chapter focuses on the role of FoxO1 in the $X$. laevis response to dehydration. As mentioned earlier, transcriptional activation of FoxO family members is controlled at multiple levels that include: initiation of gene expression, subcellular localization, posttranslational modification, and degradation (Lam et al., 2006). Posttranslational modification plays an essential role in FoxO1 nuclear translocation and DNA binding ability. The phosphorylation of FoxOs inhibits their ability to activate gene expression by disrupting FoxO interactions with co-activator proteins and facilitating 
exclusion from the nucleus (Glauser and Schlegel, 2007). It is proposed that FoxO phosphorylation leads to its binding to $14-3-3$ proteins, which cause its translocation into the cytoplasm where FoxO is targeted for proteosomal degradation (Kirkenkamp and Coffer, 2003; Lam et al., 2006). In this study, FoxO1 total protein levels showed no significant change in response to dehydration stress in $X$. laevis muscle and liver suggesting that FoxO1 protein is not actively manipulated by differential transcription or translation in response to dehydration stress in this frog. However, the activity of FoxO1 as a transcription factor appears to change significantly in response to dehydration, at least in $X$. laevis liver (Fig. 5.1). In response to dehydration, FoxO1 protein showed movement into the nucleus (ie. protein content increased significantly in nuclear extracts of liver) as well as a decrease in phospho-FoxO1 ${ }^{\text {ser245 }}$ content both in whole liver and nuclear extracts of dehydrated frogs, changes that would facilitate nuclear retention and/or translocation into the nucleus by FoxO1. Furthermore, the DNA binding assay found a 1.6-fold increase in relative binding activity by FoxO1 in nuclear extracts from dehydrated versus control frogs. All of these indicate that FoxO1 transcriptional activity is enhanced during dehydration stress in $X$. laevis liver and suggest that genes under FoxO1 control would be up-regulated in response to dehydration stress.

Activated FoxO transcription factors play important roles in gene expression in response to a wide range of cellular processes such as cell death, differentiation, cycle progression, and resistance to stress (Glauser and Schlegel, 2007; Salih and Brunet, 2008). This chapter focused on the role of FoxO1 in cellular resistance to oxidative stress showing an up-regulation of key antioxidant targets of FoxO1, MnSOD and catalase, in response to dehydration. Superoxide radicals are mainly produced in the mitochondria as 
a result of a "leaky" electron transport system (ETS). Spontaneous or catalyzed dismutation of superoxide radicals via MnSOD leads to the production of hydrogen peroxide $\left(\mathrm{H}_{2} \mathrm{O}_{2}\right)$ (Storey, 2004). There are three structurally distinct SOD families: 1) copper/zinc containing SODs, found in both eukaryotes and bacteria, 2) iron/manganese containing SODs, and 3) nickel containing SOD found in bacteria (Fridovich, 1995; Wuerges et al., 2004). The iron containing SODs are found in prokaryotes, chloroplasts and protozoans, whereas the manganese containing SODs are found in prokaryotes and mitochondrial matrices. Purrello et al. (2004) cloned $X$. laevis SOD2 (MnSOD) cDNA and compared its amino acid sequence to other eukaryotes and prokaryotes. Their results demonstrated a very high conservation of $X$. laevis SOD2 amino acid sequence during evolution. To better understand the protective role of MnSOD during dehydration stress, I analyzed total protein and mRNA levels in $X$. laevis tissues. A significant increase in MnSOD protein levels was seen in kidney and liver of dehydrated $X$. laevis as compared with controls suggesting that the enzyme plays a key role in antioxidant defense against harmful superoxide radicals when the frog is under dehydration stress. A similar result was reported for estivating land snails, Otala lactea, where the activity of hepatopancreas SOD was significantly higher in estivating groups compared to aroused snails. The activity of SOD was also significantly elevated in garter snake liver after $10 \mathrm{~h}$ of anoxia (Hermes-Lima et al., 1998). The protein content of MnSOD remained stable in four tissues of $X$. laevis (Fig. 5.2A) showing that defense against superoxide radicals is held intact during the stress period in those tissues and possibly implicates tissues such as liver and kidney as being particularly susceptible to oxidative stress caused by dehydration. A similar result was reported for Rana pipiens, where SOD activity remained stable in these 
frog tissues after $30 \mathrm{~h}$ of anoxia (Hermes-Lima and Storey, 1996). The data for MnSOD mRNA transcripts correlate well with the total MnSOD protein levels in $X$. laevis muscle and liver and indicated that the significant increase in total MnSOD protein in the liver during dehydration is a result of enhanced $M n S O D$ gene transcription.

Even though $\mathrm{H}_{2} \mathrm{O}_{2}$ is a poor oxidizing agent, its ability to easily cross biological membranes and its high stability make it potentially dangerous. Also, the interaction of $\mathrm{H}_{2} \mathrm{O}_{2}$ with transition metals leads to the production of the most reactive species known, hydroxyl radicals ( $\left.{ }^{\circ} \mathrm{OH}\right)$. Hence, it is important to destroy $\mathrm{H}_{2} \mathrm{O}_{2}$ that is produced from the SOD reaction. Catalase is a heme enzyme that is present in almost all aerobic organisms (Prakash et al., 2009); its main role is to detoxify $\mathrm{H}_{2} \mathrm{O}_{2}$ by reducing it to water and oxygen (Storey, 2004). The results in this chapter show that elevated levels of catalase protein are a common response to dehydration in $X$. laevis muscle, lung, and liver and thereby suggest the importance of $\mathrm{H}_{2} \mathrm{O}_{2}$ detoxification to survival of this stress. Catalase gene expression has been linked to several FoxO family members (Lam et al., 2006; Van der Horst and Burgering, 2007). The correlation between FoxO1 activation in liver and catalase gene and protein up-regulation in this organ implicates FoxO1 in the catalase response to dehydration in liver. However, the evidence indicates that catalase upregulation in skeletal muscle would not be under FoxO1. Furthermore, although catalase protein level increased significantly during dehydration in $X$. laevis muscle, catalase mRNA levels did not, so this may indicate that controls other than gene transcription contribute to determining net muscle catalase protein levels; this could include controls at the levels of translation by ribosomes or degradation by the proteolytic apparatus. It is also possible that catalase mRNA up-regulation and catalase protein synthesis are early 
events in $X$. laevis muscle when animals start to dehydrate with the result that mRNA levels had returned to baseline in highly dehydrated frogs whereas catalase protein remained elevated. Indeed, catalase mRNA half-life is known to be about $7 \mathrm{~h}$ (Clerch et al., 1991). In other models, where animals experienced variation in oxygen availability, catalase was reported to limit cellular oxidative stress by lowering $\mathrm{OH}$ production (Hermes-Lima and Storey, 1998). For example, a significant increase in catalase activity was seen after $30 \mathrm{~h}$ of anoxia exposure in $R$. pipiens muscle (Hermes-Lima and Storey, 1996). Also, catalase activity was elevated in land snails after 30 days of estivation (Hermes-Lima and Storey, 1995).

During early development, $X$. laevis rely on MnSOD and catalase activities for antioxidant defense (Rizzo et al., 2007). The present chapter shows for the first time that the same enzymes play a protective role during dehydration stress in the adult frog. The expression of FoxO regulated genes seem to be controlled by any of the FoxO transcription factors because the DNA-binding domain of all FoxO isoforms binds to the same consensus sequence motif on target genes. Therefore, the specificity of the members of this transcription factor family is obtained by isoform specific regulation or specific expression pattern (Horst and Burgering, 2007). In this study, FoxO1 translocation to the nucleus, and the increase in FoxO1 DNA binding activity in $X$. laevis liver strongly correlate with the up-regulation of MnSOD and catalase mRNA and protein and mRNA levels in this organ. This strongly supports the proposal that FoxO1 is responsible for the increased production of MnSOD and catalase during dehydration stress in $X$. laevis liver. This is not surprising since the results presented in chapter 4 showed that organ-specific up-regulation of other antioxidant enzymes occurs in response 
to dehydration stress in $X$. laevis, and MnSOD and catalase represent the first line of defense in ROS detoxification. 
Figure 5.1. Effect of dehydration on $X$. laevis FoxO1. (A) Representative western blots showing levels of FoxO1 protein in nuclear and cytoplasm extracts under control (C) and dehydrated (D) conditions in skeletal muscle and liver of $X$. laevis (3 independent samples are shown for each condition). Histogram summarizes the mean data. (B) Representative western blots and summary histogram showing the expression of phosphorylated FoxO1 ${ }^{\text {ser245 }}$ in whole liver extracts and liver nuclear extracts from control versus dehydrated frogs. Data are means \pm S.E.M., $n=3-5$ independent trials on tissue from different animals. Significantly different from the corresponding control, $\mathrm{P}<0.05$. 
Figure 5.1

A

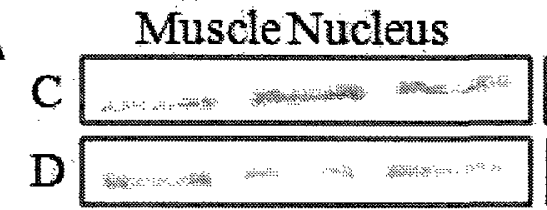

Liver Nucleus

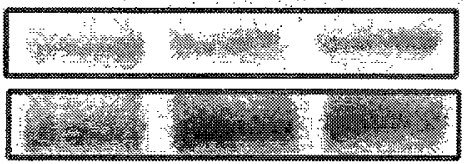

c Muscle Cytoplasm

D

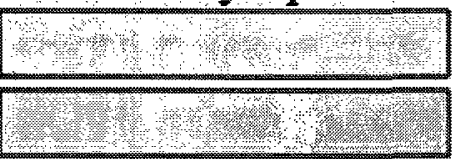

Liver Cytoplasm
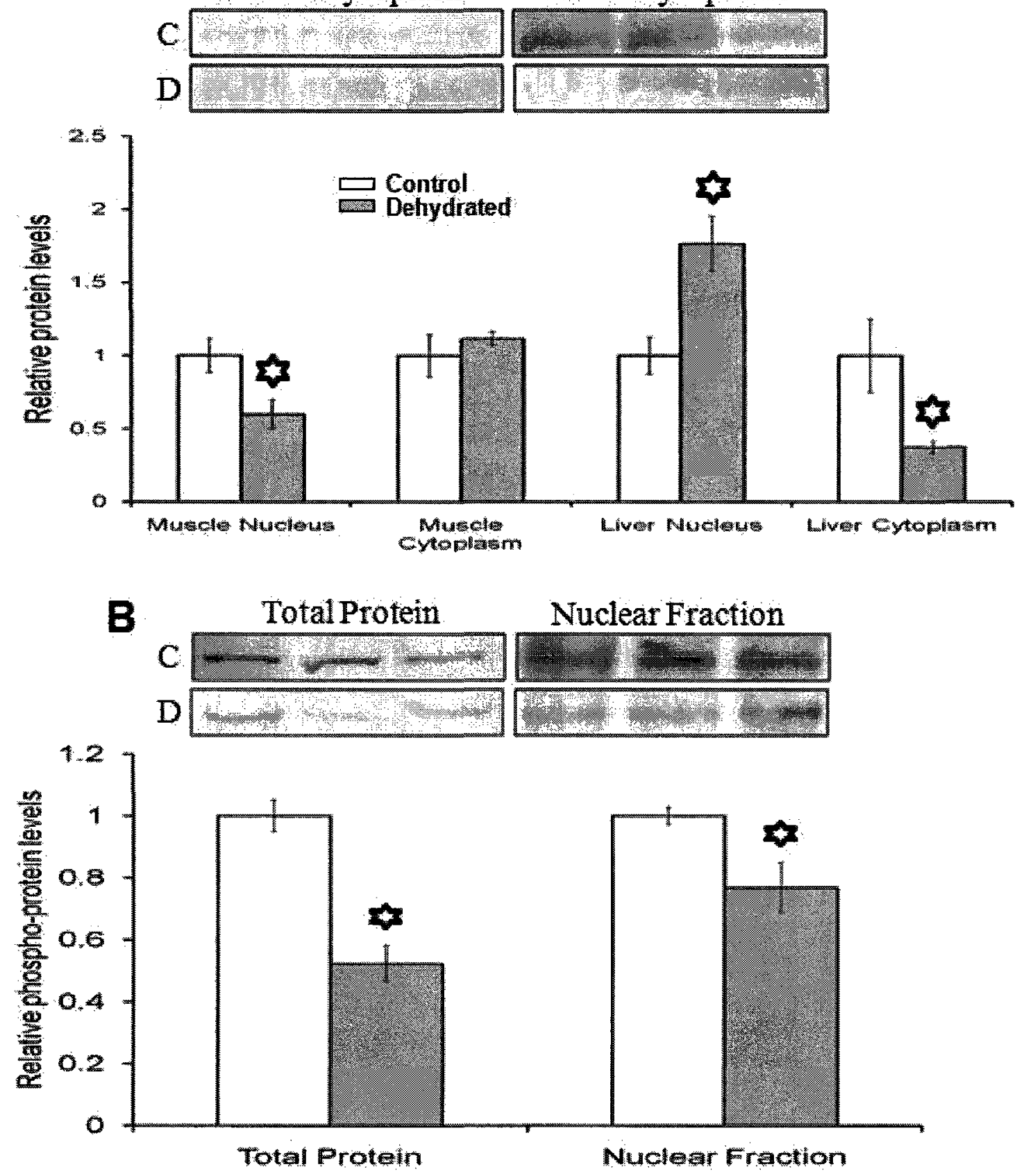
Figure 5.2. Effect of dehydration on the expression of MnSOD protein and mRNA in $X$. laevis tissues. (A) Representative western blots of MnSOD protein levels in six tissues from control (C) and dehydrated (D) frogs; immunoblot images for three independent samples are shown per tissue. Histogram shows normalized protein levels for control versus dehydrated conditions. (B) Representative bands on agarose gels showing PCR product levels of amplified $M n S O D$ and actin mRNA for three preparations from $X$. laevis muscle and liver. Band intensities for MnSOD PCR product were normalized against the corresponding intensities of the $\alpha$-actin band amplified from the same sample. Histogram shows normalized mRNA levels in muscle and liver. Data are means \pm S.E.M., $\mathrm{n}=3-5$ independent trials on tissue from different animals. Significantly different from the corresponding control, $\mathrm{P}<0.05$. 
Figure 5.2
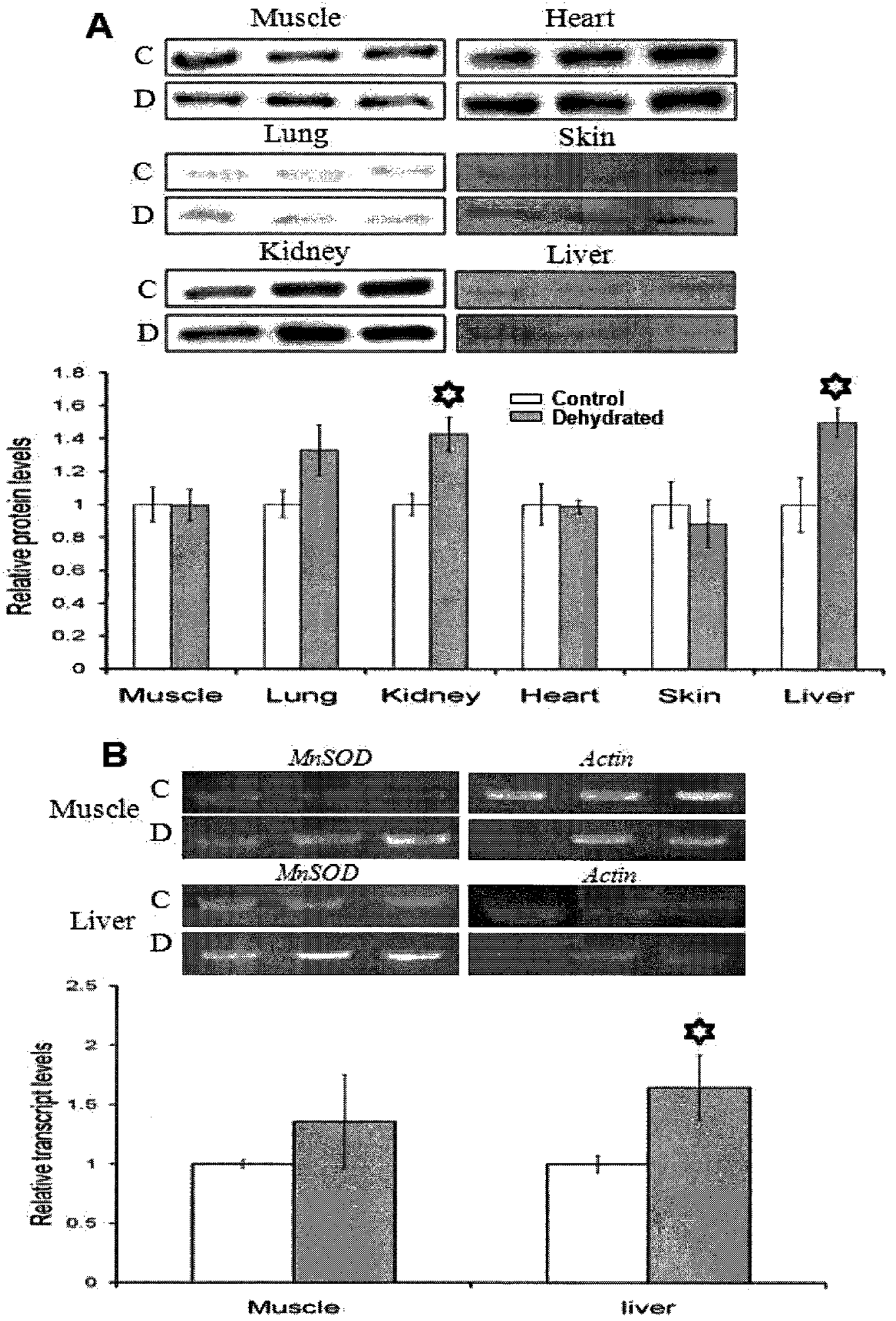
Figure 5.3. Effect of dehydration on the expression of catalase in $X$. laevis muscle and liver. (A) Representative western blots and summary histogram of catalase protein levels in six tissues. (B) Representative bands on agarose gels show PCR product levels of amplified catalase and $\alpha$-actin for three preparations from $X$. laevis muscle and liver. Histogram shows normalized catalase mRNA levels. Other information as in Figure 2. 
Fingurpe 5.3
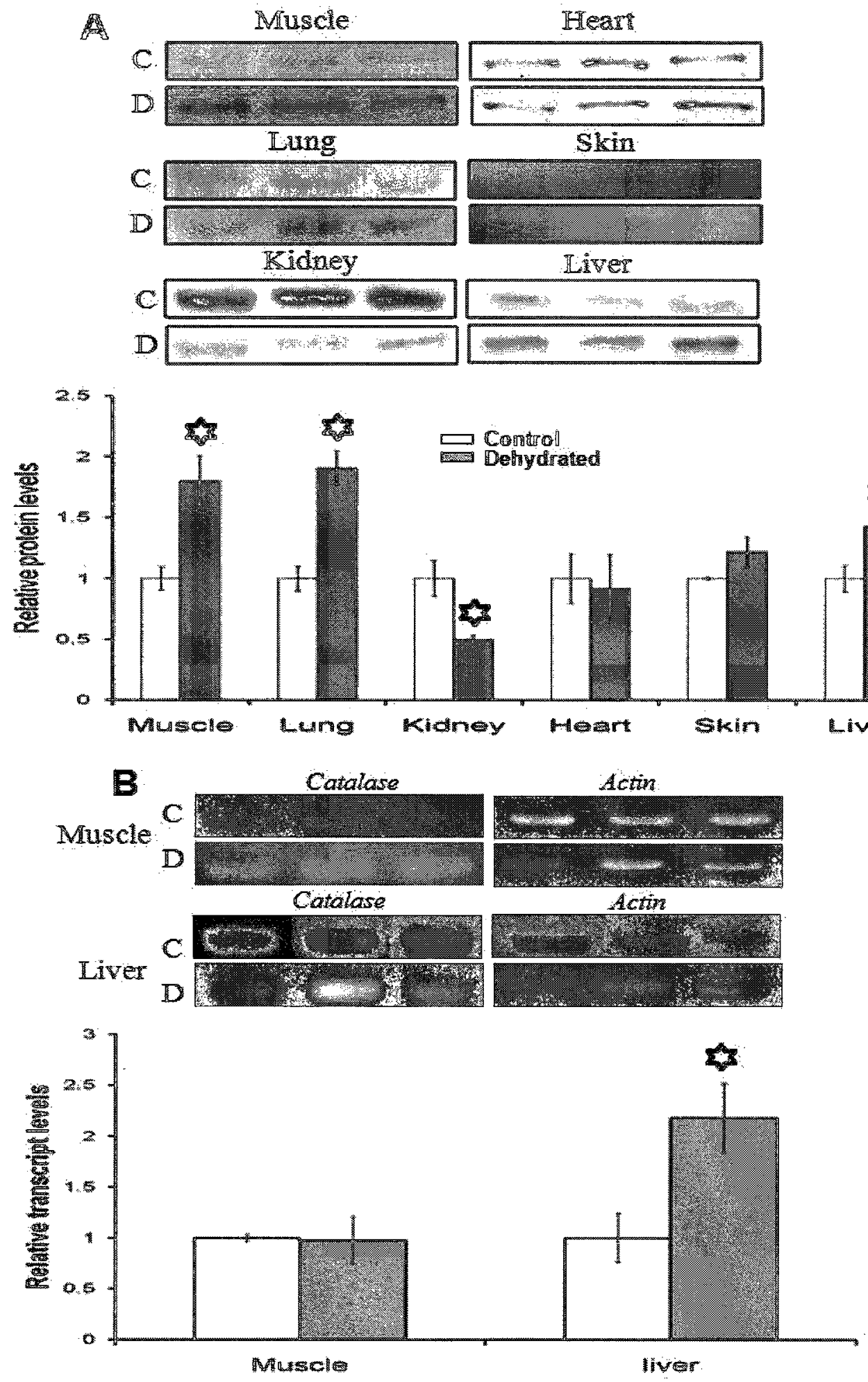


\section{CHAPTER 6}

\section{General Discussion}


The focus of this thesis was to characterize two aspects of dehydration stress protective responses in $X$. laevis. The first one was the activation of signal transduction, which was achieved by examining total protein levels and phosphorylation status of three members of the MAPK superfamily, as well as a number of their downstream targets. The second was the activation of antioxidant defenses during dehydration stress, which was achieved by examining the regulation states of Nrf2 and FoxO1 transcription factors and a number of their downstream antioxidant proteins that play roles in ROS detoxification. The thesis focused on conserved MAPKs and transcription factors and looked at different levels of regulation including: 1) posttranslational modification, 2) transcriptional control, and 3) translational control.

Dehydration stress in $X$. laevis leads to a number of physiological reorganizations that were well characterized by Hillman (1978). They included: 1) an increase in blood viscosity, 2) a decrease in maximum oxygen consumption, 3) an increase in resting heart rate, and finally 4) an increase in whole animal lactate concentration at the critical activity point (CAP, inability of the frog to right itself). In an effort to minimize water loss, Xenopi are also capable of producing osmolytes like urea (Balinsky et al., 1961). $X$. laevis held out of water for 1-3 weeks showed increased urea levels in blood, liver and muscle. Balinsky et al. (1961) stated that urea accumulation was a metabolic response and showed that the amount of urea accumulated is proportional to the extent of water shortage. That was also evident in the present study, the frogs show significant urea accumulation in response to both medium and high dehydration, with urea levels being markedly greater in the high dehydration group (Table 2.1). Furthermore, an increase in plasma glucose level also occurred during high dehydration in X. laevis (Table 2.1) 
indicating that the frogs were experiencing some level of hypoxia that triggered the mobilization of liver glycogen. To better understand the molecular mechanisms underlying dehydration tolerance in $X$. laevis, I used techniques that included western blotting and RT-PCR to analyze the molecular organization of known stress-induced transcription factors and proteins.

\section{ACTIVATION OF MAPKS FAMILY MEMBERS}

Chapters 2 and 3 analyzed the involvement of three MAPK family members and a number of their downstream targets in the response to dehydration by X. laevis organs. Posttranslational modification via reversible protein phosphorylation represents a powerful tool for triggering and coordinating cellular responses to stress because it is a regulatory mechanism that can control the activity of many enzymes and functional proteins (Storey, 2004). Western blotting was used to measure the total protein level and activation statues of the three MAPK family members (Fig. 2.5, 3.1, 3.2). Each family member showed a tissue specific response to dehydration stress in X. laevis. The pattern of ERK2 responses to dehydration appeared to be independent to that of JNK1 and p38 in heart, skin and liver. In the muscle, ERK2 and JNK1 were activated in response to high dehydration. Similarly, high dehydration caused the activation of ERK2 and p38 in $X$. laevis kidney. Activation of MAPK family members was particularly apparent in lung during high dehydration, which is an organ that is highly susceptible to water loss during breathing. Perhaps MAPK signaling might trigger early protective measures by lung to help limit respiratory water loss under desiccating conditions. 
Chapter 2 showed the activation of some or all of the components of the ERK2 cascade (c-Raf, MEKK, MEK1/2, and ERK1/2) in response to high dehydration which demonstrated that ERK signaling is important to cellular defense in X. laevis when water loss becomes severe. Two well-known downstream targets, STAT3 and RSK1, were also phosphorylated and activated in some $X$. laevis tissues in response to dehydration, as was the RSK target, the S6 ribosomal protein. This suggests that these targets contribute to dehydration defense and further confirms the importance of ERK signaling. Some organs (e.g. heart) showed clear activation of the ERK cascade but no change in the downstream targets that were assessed. However, there are a large number of downstream targets of ERK2 so this argues that dehydration-stimulated ERK signaling is focused on alternative targets in heart. Skin showed a strong increase in c-Raf and phospho-MEK1/2 but not in other cascade components which suggests that skin responses to dehydration are not directed by ERK2 but are likely accomplished by another ERK member, such as ERK1. Overall, chapter 2 provides strong evidence of a role for ERK signaling in dehydration defense in X. laevis organs, documents activation or up-regulation of well-known ERK targets, and directs our attention to detailed studies of ERK-mediated responses to uncover all of the metabolic adaptations that are coordinated by ERK signaling in response to dehydration.

Chapter 3 analyzed the regulation pattern of a number of JNK and p38 MAPK downstream targets showing that each had one or more protective functions during dehydration stress. In particular, the CREB transcription factors appeared to have a key protective role to play being activated in five tissues during high dehydration. Activation of this transcription factor could enhance the expression of pro-survival genes (Ballif and 
Blenis, 2001). CREB can also play a role in limiting respiratory water loss in $X$. laevis by changing the amount or composition of mucins in the airway epithelia of this frog (Choi et al., 2009). Another important transcription factor studied was c-Myc. Western blotting showed a significant increase in active phospho-c-Myc content during high dehydration in X. laevis lung and kidney. A key function of c-Myc is its ability to promote cell cycle progression by affecting production of the rate-limiting translation initiation factors (eIF) $2 \alpha$ and 4E (Pelengaris et al., 2002). From studies conducted in different stress models, protein synthesis is known to be one of the ATP-expensive cell functions that is typically strongly suppressed because of its high energy requirement (Storey, 2004). Even though cells can respond by totally shutting down the synthesis of most proteins during stress, they tend to increase the production of a small number of proteins that protect and stabilize other macromolecules during the stress period (Hightower and Hendershot, 1997). C-Myc can play a regulatory role through increasing the production of eIFs in $X$. laevis lung and kidney in order to increase the production of desired proteins.

Chapters 2 and 3 clearly showed that the MAPK signal transduction cascades are activated in $X$. laevis tissues in response to dehydration. Activation was particularly pronounced under high dehydration conditions whereas fewer and less pronounced effects were seen in response to medium dehydration. This suggests that responses regulated by MAPK may be defensive actions to deal with severe dehydration and some of its consequences such as hypoxia due to elevated blood viscosity. Given that all anurans have wide tolerances for changes in body hydration and osmolality, it appears probable that the stress represented by medium dehydration could be dealt with largely without the intervention of MAPK-mediated responses. 


\section{ACTIVATION OF ANTIOXIDANTS}

Chapters 4 and 5 focused on the regulation of two of the main antioxidant transcription factors. Western blotting was used to analyze their activation status via measuring their nuclear translocation and posttranslation modification (e.g. phosphoFoxO1). The chapters further investigated the transcriptional control of selected proteins using RT-PCR and showed tissue specific modification of antioxidant transcription factors and proteins in response to dehydration stress in X. laevis.

Chapter 4 demonstrated an increase in Nrf2 protein levels in four tissues of $X$. laevis (Fig. 4.1A) indicating that this transcription factor has a protective role during dehydration stress in this frog. The increase in Nrf2 protein levels was determined to be the result of the active production of this protein (Fig. 4.1B). Chapter 4 further investigated the role of Nrf2 in ROS detoxification by measuring the protein expression of two families of enzymes, that are known Nrf2 targets. Western blotting showed an increase in the production of AKR family members (10 cases) versus 1 case of suppression in frog organs in response to dehydration (Fig. 4.4). The six GST family members assessed showed similar responses to dehydration stress being more frequently elevated (14 cases) in frog organs versus suppressed (5 cases) (Fig. 4.2 and 4.3). This argues that selective elevation of GST isozymes is beneficial for dealing with the effects of dehydration on tissues. Predictably, these responses by GSTs could deal with oxidative stress occurring under the dehydrated state or provide an anticipatory response that precedes oxidative stress associated with rehydration and recovery from dehydrationassociated hypoxia. Such anticipatory responses to environmental stresses that alter tissue 
oxygenation are well-characterized in amphibians and other species (Hermes-Lima and Storey, 1998; Hermes-Lima and Zenteno-Savin, 2002). Four of the six GSTs tested showed increased protein levels in $X$. laevis muscle. The same GSTs showed no significant change in their protein level in X. laevis liver during dehydration stress. That result correlated positively with $\mathrm{Nrf2}$ nuclear translocation in $X$. laevis muscle, where a 4.3-fold increase in Nrf2 levels was seen during dehydration stress.

Chapter 5 showed an increase in FoxO1 nuclear translocation during high dehydration in $X$. laevis liver. Western blotting also showed a significant decrease in the nuclear amount of the phosphorylated inactive form of FoxOlin liver (Fig. 5.1B). To confirm an activation of FoxO1 in $X$. laevis liver, an ELISA was used. A significant increase of $\sim 1.5$ fold was seen in high dehydrated liver compared to that of control. The chapter further investigated FoxO1 role in ROS detoxification via measuring the protein expression and mRNA levels of two FoxO1 downstream targets. Western blotting showed significant increases in MnSOD and catalase protein levels in X. laevis liver during high dehydration. RT-PCR confirmed that the increase was due to elevated mRNA levels of MnSOD and catalase in X. laevis liver under high dehydration.

Chapters 4 and 5 provide the first demonstration in an important model species (X. laevis) of a transcriptional response by antioxidant systems, regulated by $\mathrm{Nrf} 2$ and FoxO1, to dehydration stress in amphibians. Although more details of this response to dehydration remain to be explored, these data suggest that modification of antioxidant defenses may be an integral part of amphibian management of natural cycles of dehydration and rehydration, perhaps particularly so for species inhabiting ephemeral waters. As such, the expression of antioxidant genes might be developed into a useful 
marker of environmental stress among sentinel species. The relationship between antioxidant defense and dehydration stress is also supported by previous work that shows that oxidative stress is an element of natural estivation in anurans, a state of hypometabolism that typically includes severe dehydration. Thus, spadefoot toads (Scaphiopus couchii), that estivate underground for 9-10 months of the year and can lose up to $60 \%$ of total body water, showed decreased levels of reduced glutathione and accumulation of products of lipid peroxidation (conjugated dienes, lipid hydroperoxides) in tissues during estivation (Grundy and Storey, 1998). Hence, I conclude that dehydration stress in amphibians stimulates enhancement of antioxidant defenses in an organ-specific manner regulated, at least in part, by transcriptional control of antioxidant genes under the regulation of the $\mathrm{Nrf} 2$ and FoxO1 transcription factors.

\section{OUTLOOK}

This thesis answered many questions about the molecular mechanisms underlining dehydration survival of $X$. laevis. However, many of the answers have created new and more complicated questions. This thesis showed that survival of dehydration stress in $X$. laevis requires major biochemical reorganization in the frogs' organs. Chapters 2 and 3 explored the activation of MAPKs family members. Chapter 2 showed ERK2 role in the activation of STAT3, RSK, and S6RP, but further investigation is still need to determine their specific protective actions in dehydrated X. laevis. STAT3 could affect the expression of a number of genes including antiapoptotic genes. To determine if that is the case in X. laevis western blotting could be used to assess STAT3 
movement into the nucleus as well as ELISA to analyze DNA binding activity. Once STAT3 activation is confirmed, RT-PCR could be applied to determine which Bcl-2 family member is up-regulated by dehydration stress in X. laevis. Chapter 2 also showed the activation of S6RP, but further investigation is needed to define its protective role during dehydration stress in $X$. laevis. The S6RP is well-studied and its role during dehydration stress in X. laevis could be to determine cell size, regulated protein synthesis, or maintain glucose homeostasis (Ruvinsky and Meyuhas, 2006). Chapter 3 showed tissue specific activation of SAPK and p-38 MAPK family members. The chapter also assessed the activation status of three downstream targets: c-Jun, c-Myc, and CREB. The p38 MAPK is known to play a role in translation regulation. As mentioned before, protein synthesis is one of the ATP-expensive cell functions that is known to be regulated (typically strongly suppressed) under different stress conditions due to its high energy requirement (Storey, 2003). A major mechanism of translation regulation is the reversible phosphorylation of selected eukaryotic initiation factors (eIFs). EIF4E for example is a known target of p38 MAPK. Western blotting could be used to determine the activation status of eIF4E and other family members. The transcription regulation of eIF4E and eIF2 $\alpha$ is also controlled by c-Myc, one of the p38 MAPK downstream targets studied. Once activated c-Myc can influence cell growth via increasing the production of eIF4E and eIF2 $\alpha$ (Pelengaris et al., 2002). The three transcription factors studied in chapter 3 all play an essential role in cell cycle progression, survival, and apoptosis (Pelengaris et al., 2002; Shaulian and Karin, 2001; Shaulian and Karin, 2002; Ballif and Blenis, 2001). To determine which of these is the main target, western blotting could be used to assess nuclear translocation and RT-PCR can be used to analyze mRNA transcript levels of 
specific downstream targets such as $\mathrm{Bcl} 2, \mathrm{Bcl} \mathrm{xl}, \mathrm{Bcl} 3, \mathrm{Bim}$, cyclin D1 and cyclin D2. Chapters 4 and 5 mapped the regulation patterns of GSTs, AKRs, MnSOD, and catalase in $X$. laevis tissues during dehydration stress. All of these antioxidant enzymes showed tissue specific regulation in response to dehydration stress. However, further studies are needed to examine different time points of dehydration to determine if antioxidant defenses are activated throughout the stress period or only when dehydration becomes severe. In addition, a number of other antioxidant enzymes and TFs could contribute to ROS detoxification in $X$. laevis tissues. To test that theory a number of studies can be proposed. Western blotting could be used to assess the regulation status of glutathione peroxidase (GPx) family members, which can play major roles in $\mathrm{H}_{2} \mathrm{O}_{2}$ decomposition. GPx family members can also catalyze the destruction of organic hydroperoxides using the tripeptide glutathione in its reduced form (GSH) as a cosubstrate (Storey, 2004). As mentioned before dehydration causes an increase in blood viscosity and a decrease in blood volume that impairs proper oxygen delivery to tissues, leading to hypoxia. The role of dehydration-related hypoxia can be investigated by examining the expression of the hypoxia inducible factor 1 (HIF-1). HIF-1 mediated expression of selected genes under desiccation stress could trigger compensatory strategies that either (a) enhance non- $\mathrm{O}_{2}$ dependent pathways of energy production, or (b) enhance oxygen delivery to tissues. The role for HIF-1 in desiccation stress has never before been studied in animal systems. HIF-1 is a heterodimer composed of HIF-1 $\beta$ which is located in the nucleus and is not affected by oxygen levels and HIF-1 $\alpha$ which is located in the cytoplasm and is oxygen dependent. When oxygen is abundant in the cell HIF-1 $\alpha$ is degraded continuously by the ubiquitin proteasome system. However, under 
hypoxic conditions HIF-1 $\alpha$ is stabilized and translocated into the nucleus where it heterodimerizes with HIF-1 $\beta$ to produce the active HIF-1 protein that acts as a transcription factor to activate a number of target genes (Vaupel, 2004; Morin and Storey, 2005). Western blotting can be used to determine the regulation and nuclear translocation of HIF-1 $\alpha$ and DNA binding assay could be used to determine the activation status of HIF during dehydration in X. laevis.

In conclusion, this thesis examined posttranslational modification and transcription control during dehydration stress in X. laevis. One MAPK family member that showed a major increase in all tissues was identified (ERK2), and tissue specific regulation of the other two MAPK members was also reported. Differential expression of antioxidant enzymes was identified, and increases in antioxidant proteins in the muscle and liver were shown to be regulated mainly by the Nrf2 and FoxO1 transcription factors, respectively. This might not reflect an identical response to that seen in nature because the frogs are forced to dehydrated suddenly and give only about a week to reach their lethal limit. 
PUBLICATION LIST 


\section{PUBLISHED RESEARCH ARTICAL}

Malik, A. I. and Storey, K. B. 2009. Activation of antioxidant defense during dehydration stress in the African clawed frog. Gene. 442, 99-107.

\section{RESEARCH ARTICLE IN PRESS}

Malik, A. I. and Storey, K. B. 2009. Activation of extracellular signal-regulated kinases during dehydration in the African clawed frog, Xenopus laevis. J. Exp. Biol.

\section{RESEARCH ARTICLE IN PREPARATION}

Malik, A. I. and Storey, K.B. Transcription regulation via the activation of mitogenactivated protein kinases during dehydration in the African clawed frog, Xenopus laevis.

Malik, A.I. and Storey, K.B. Transcriptional regulation of antioxidant enzymes by FoxO1 in the dehydrated Xenopus laevis.

Malik, A. I. and Storey, K.B. Expression of heat shock proteins and heat shock factor1 in response to dehydration in Xenopus laevis.

Malik, A. I. and Storey, K.B. Regulation of unfolded protein response during dehydration stress in the African clawed frog.

\section{COMMUNICATIONS AT SCIENTIFIC MEETINGS}

Malik, A. and Storey, K.B. "Expression of heat shock proteins and heat shock factor1 in response to dehydration in Xenopus laevis". Chemistry and Biochemistry Graduate Research Conference. Montreal, Quebec, November 25, 2006.

Malik, A. and Storey, K.B. "Expression of antioxidant proteins and NF-E2-related factor in response to dehydration in Xenopus laevis". Canadian Oxidative Stress Consortium, $5^{\text {th }}$ Meeting. Montreal, Quebec, May 3-6, 2007.

Malik, A. and Storey, K.B. "Expression of antioxidant proteins and NF-E2-related factor in response to dehydration in Xenopus laevis". Chemistry and Biochemistry Graduate Research Conference. Montreal, Quebec, November 24, 2007. 
Malik, A. and Storey, K.B. "Expression of antioxidant proteins and NF-E2-related factor in response to dehydration in Xenopus laevis". Comparative Biology of Aging, Round Top, Texas, March 6-8, 2008.

Malik, A. and Storey, K.B. "Expression of antioxidant proteins and NF-E2-related factor in response to dehydration in Xenopus laevis". $5^{\text {th }}$ annual Ottawa-Carleton Institute of Biology Symposium, Ottawa, April 28-29, 2008.

Malik, A. and Storey, K.B. "Expression of heat shock proteins and heat shock factor1 in response to dehydration in Xenopus laevis". Joint meeting of Ichthyologists and Herpetologists, Montreal, Quebec, July 23-28, 2008.

Malik, A. and Storey, K.B. "Expression of Antioxidant Proteins and NF-E2-related Factor in Response to Dehydration in Xenopus laevis". 13th International Hibernation Symposium, Swakopmund, Namibia, August 6-12, 2008.

Malik, A. and Storey, K.B. "Activation of extracellular signal-regulated kinases during dehydration in the African clawed frog, Xenopus laevis". $6^{\text {th }}$ annual OttawaCarleton Institute of Biology Symposium, Ottawa, April 30- May1, 2008.

Malik, A. and Storey, K.B. Expression of antioxidant proteins and NF-E2-related factor in response to dehydration in Xenopus laevis". Canadian Oxidative Stress Consortium, 6th Canadian Oxidative Stress Conference, Winnipeg, Manitoba, May 7-10, 2009.

Malik, A. and Storey, K.B. "Activation of extracellular signal-regulated kinases during dehydration in the African clawed frog, Xenopus laevis". $48^{\text {th }}$ annual Canadian Society of Zoologists, Toronto, May 12-16, 2009.

Malik, A. and Storey, K.B. "Expression of heat shock proteins and heat shock factor1 in response to dehydration in Xenopus laevis". $34^{\text {th }}$ annual APICS/CIC Student Chemistry Conference, Antigonish, N.S., May $14^{\text {th }}-16^{\text {th }}, 2009$.

Malik, A. and Storey, K.B. "Activation of extracellular signal-regulated kinases during dehydration in the African clawed frog, Xenopus laevis". $52^{\text {nd }}$ annual meeting of the Canadian Society for Biochemistry, Molecular and Cellular Biology, Niagara, June 1-5, 2009. 


\section{REFERENCES}


Aggeli, I.S., Gaitanaki, C., Lazou, A. and Beis, I. 2001. Activation of multiple MAPK pathways (ERKs, JNKs, p38-MAPK) by diverse stimuli in amphibian heart. Mol. Cell. Biochem. 221, 63-69.

Alarcon-Vargas, D. and Ronai, Z. 2004. C-Jun-NH2 kinase (JNK) contributes to the regulation of c-Myc protein stability. J. Biol. Chem. 279(6), 5008-5016.

Angelucci, S., Sacchetta, P., De Luca, A., Moio P., Amicarelli, F. and Di Ilio, C. 2002. Glutathione transferase isoenzymes from frog (Xenopus laevis) liver and embryo. Biochim. Biophys. Acta. 1569, 81-85.

Anjum, R. and Blenis, J. 2008. The RSK family of kinases: emerging role in cellular signaling. Nat. Rev. Mol. Cell Biol. 9(10), 747-758.

Armstrong, R.N. 1997. Structure, catalytic mechanism, and evolution of the glutathione transferases. Chem. Res. Toxicol. 10, 2-18.

Baker, S.J., Kerppola, T.K., Luk, D., Vandenberg, M.T., Marshak, D.R., Curran, T. and Abate, C. 1992. Jun is phosporylated by several protein kinases at the same sites that are modified in serum-stimulated fibroblasts. Mol. Cell Biol. 12(10), 4694-4705.

Balinsky, J.B., Choritz, E.L., Coe, C.G.L. and Van Der Schans, G.S. 1967. Amino acid metabolism and urea synthesis in naturally aestivating Xenopus laevis. Comp. Biochem. Physiol. 22, 59-68.

Balinsky, J.B., Cragg, M.M. and Baldwin, E. 1961. The adaptation of amphibian waste nitrogen excretion to dehydration. Comp. Biochem. Physiol. 3, 236-244.

Ballif, B.A. and Blenis, J. 2001. Molecular mechanisms mediating mammalian mitogenactivated protein kinase (MAPK) kinase (MEK)-MAPK cell survival signals. Cell Growth Differ. 12(8), 397-408.

Beck, C.W. and Slack, J.M. 2001. An amphibian with ambition: a new role for Xenopus in the $21^{\text {st }}$ century. Genome Biol. 2, 1029.1-1029.5.

Benassi, B., Fanciulli, M., Fiorentino, F., Porrello, A., Chiorino, G., Loda, M., Zupi, G. and Biroccio, A. 2006. c-Myc phosphorylation is required for cellular response to oxidative stress. Mol. Cell. 21(4), 509-519.

Benekli, M., Baer, M.R., Baumann, H. and Wetzler, M. 2003. Signal transducer and activator of transcription protein in leukemias. Blood 101, 2940-2954.

Biondi, R.M. and Nebreda, A.R. 2003. Signalling specificity of Ser/Thr protein kinases through decking-site-mediated interactions. Biochem. J. 372 (1), 1-13.

Birkenkamp, K.U. and Coffer, P.J. 2003. Regulation of cell survival and proliferation by the FOXO (Forkhead box, class $\mathrm{O}$ ) subfamily of forkhead transcription factors. Biochem. Soc. Trans. 31, 292-297. 
Blokhina, O., Virolainen, E. and Fagersted, K.V. 2003. Antioxidants, oxidative damage and oxygen deprivation stress: a review. Ann. Bot. 91, 179-194.

Cannatella, D. 2008. Version 11 January 2008, http:tolweb.org/Anura/16963/2008.01.11 in The tree of life web project, http://tolweb.org/.

Cannatella, D.C. and De Sa, R.O. 1993. Xenopus laevis as a model organism. Syst. Biol. 42(4), 476-507.

Chanas, S.A., Jiang, Q., McMahon, M., McWalter, G.K., McLellan, L.I., Elcombe, C.R., Henderson, C.J., Wolf, C.R., Moffat, G.J., Itoh, K., Yamamoto, M. and Hayes, J.D. 2002. Loss of the Nrf2 transcription factor causes a marked reduction in constitutive and inducible expression of the glutathione S-transferase Gsta1, Gsta2, Gstm1, Gstm2, Gstm3 and Gstm4 genes in the livers of male and female mice. Biochem. J. 365, 405-416.

Choi, H.J., Chung, Y.S., Kim, H.J., Moon, U.Y., Choi, Y.H., Van Seuningen, I., Baek, S.J., Yoon, H.G. and Yoon, J.H. 2009. Signal pathway of 17 betaestradiol-induced MUC5B expression in human airway epithelial cells. Am. J. Respir. Cell Mol. Biol. 40, 168-178.

Chung, J., Uchida, E., Grammer, T.C. and Blenis, J. 1997. Stat3 serine phosphorylation by ERK-dependent and independent pathways negatively modulates its tyrosine phosphorylation. Mol. Cell. Biol. 17, 6508-6516.

Churchill, T.A. and Storey, K.B. 1993. Dehydration tolerance in wood frogs: a new perspective on the development of amphibian freeze tolerance. Am. J. Physiol. 265, 1324-1332.

Clerch, L.B., Iqbal, J. and Massaro, D. 1991. Perinatal rat lung catalase gene expression: influence of corticosteroid and hyperoxia. Am. J. Physiol. 260(6-1), 428-433.

Cowan, K.J. and Storey, K.B. 2003. Mitogen-activated protein kinases: new signaling pathways functioning in cellular responses to environmental stress. J. Exp. Biol. 206, 1107-1115.

Cullinan, S.B. and Diehl, J.A. 2006. Coordination of ER and oxidative stress signaling: the PERK/Nrf2 signaling pathway. Int. J. Biochem. Cell Biol. 38, 317-332.

De Luca, A., Favaloro, B., Angelucci, S., Sacchetta, P. and Di Ilio, C. 2002. Mu-class glutathione transferase from Xenopus laevis: molecular cloning, expression and site-directed mutagenesis. Biochem. J. 365, 685-691.

De Luca, A., Favaloro, B., Carletti, E., Sacchetta, P. and Di Ilio, C. 2003. A novel amphibian pi-class glutathione transferase isoenzyme from Xenopus laevis: importance of phenylalanine 111 in the H-site. Biochem. J. 373, 539-545.

Deuchar, E.M. 1975. Xenopus: the South African Clawed Frog. John Wiley \& Sons. Inc. 
London.

Dos Santos Ferreira da Silva, G., Giusti, H., Sanchez, A.P., Do Carmo, J.M. and Glass, M.L. 2008. Aestivation in the South American lungfish, lepidosiren paradoxa: effects on cardiovascular function, blood gases, osmolality and leptin levels. Respir. Physiol. Neurobiol. 164(3), 380-385.

Dunn, C., Wiltshire, C., MacLaren, A. and Gillespie, D.A.F. 2002. Molecular mechanism and biological function of c-Jun N-termianl kinase signaling via the cJun transcription factor. Cell. Signal. 14(7), 585-593.

Dunn, J.F., Hochachka, P.W., Davison, W. and Guppy, M. 1983. Metabolic adjustments to diving and recovery in the African lungfish. Am. J. Physiol. 245, 651-657.

Eaton, D.L. and Bammler, T.K. 1999. Concise review of the glutathione s-transferases and their significance to toxicology. Toxicol. Sci. 49, 156-164.

Eckenhoff, R.G, Dodia, C., Tan, Z. and Fischer, A.B. 1992. Oxygen-dependent reperfusion injury in the isolated rat lung. J. Appl. Physiol. 72, 1454-1460.

Ellis, E.M. and Hayes, J.D. 1995. Substrate specificity of an aflatoxin-metabolizing aldehyde reductase. Biochem. J. 312, 535-541.

Ellis, E.M., Slattery, C.M. and Hayes, J.D. 2003. Characterization of the rat aflatoxin B1 aldehyde reductase gene, AKR7A1. Structure and chromosomal localization of AKR7A1 as well as identification of antioxidant response elements in the gene promoter. Carcinogenesis 24, 727-737.

Emilio, M.G. and Shelton, G. 1974. Gas exchange and its effect on blood gas concentrations in the amphibian, Xenopus laevis. J. Exp. Biol. 60, 567-579.

English, J., Pearson, G., Wilsbacher, J., Swantek, J., Karandikar, M., Xu., S. and Cobb, M.H. 1999. New insights into the control of MAP kinase pathway. Exp. Cell Res. 253, 255-270.

Feder, M.E. and Burggren, W.W. 1992. Environmental physiology of amphibians. University of Chicago press, Ltd., Chicago.

Fishman, A.P., Galante, R.J., Winokur, A. and Pack, A.I. 1992. Estivation in the African lungfish. APS. 136(1), 61-70.

Frick, N.T. Bystriansky, J.S., IP, Y.K, Chew, S.F. and Ballantyne, J.S. 2008. Carbohydrate and amino acid metabolism in fasting and aestivating African lungfish (protopterus dolloi). Comp. Biochem. Physiol. A. Mol. Integr. Physiol. 151(1), 85-92. 
Fridovich, I. 1995. Superoxide radical and superoxide dismutases. Annu. Rev. Biochem. 64, 97-112.

Gaitanaki, C., Konstantina, S., Chrysa, S. and Beis, I. 2003. Oxidative stress stimulates multiple MAPK signalling pathways and phosphorylation of the small HSP27 in the perfused amphibian heart. J. Exp. Biol. 206, 2759-2769.

Glauser, D.A. and Schlegel, W. 2007. The emerging role of FOXO transcription factors in pancreatic beta cells. J. Endocrinol. 193(2), 195-207.

Greenway, S.C. and Storey, K.B. 2000a. Activation of mitogen-activated protein kinases during natural freezing and thawing in the wood frog. Mol. Cell. Biochem. 209, 29-37.

Greenway, S.C. and Storey, K.B. 2000b. Mitogen-activated protein kinases and anoxia tolerance in turtles. J. Exp. Zool. 287, 477-484.

Grundy, J.E. and Storey, K.B. 1998. Antioxidant defenses and lipid peroxidation damage in estivating toads, Scaphiopus couchii. J. Comp. Physiol. B 168, 132142.

Halliwell, B. and Gutteridge, M.C. 2007. Free radicals in biology and medicine, $4^{\text {th }}$ edition. Oxford University Press, Oxford.

Ham, J., Eilers, A., Whitfield, J., Neame, S.J. and Shah, B. 2000. C-Jun and transcriptional control of neuronal apoptosis. Biochem. Pharmacol. 60(8), 10151021.

Hermes-Lima M. and Storey K.B. 1995. Antioxidant defenses and metabolic depression in a pulmonate snail. Am. J. Physiol. 268, 1386-1393.

Hermes-Lima M. and Storey K.B. 1996. Relationship between anoxia exposure and antioxidant status in the frog Rana Pipiens. Am. J. Physiol. 271, 918-925.

Hermes-Lima M. and Storey K.B. 1998. Role of antioxidant defenses in the tolerance of severe dehydration by anurans. The case of the leopard frog Rana pipiens. Mol Cell Biochem. 189(1-2), 79-89.

Hermes-Lima M. and Zenteno-Savin, T. 2002. Animal response to drastic changes in oxygen availability and physiological oxidative stress. Comp. Biochem. Physiol. 133, 537-556.

Hermes-Lima M., Storey J.M. and Storey K.B. 1998. Antioxidant defenses and metabolic depression. The hypothesis of preparation for oxidative stress in land snails. Comp. Biochem. Physiol. B. Biochem. Mol. Biol. 120(3), 437-448. 
Hermes-Lima, M. 2004. Oxygen in biology and biochemistry: role of free radicals. In: Functional Metabolism: Regulation and Adaptation. In Storey, K.B. (Ed.), WileyLiss, Hoboken, New Jersey.

Hermes-Lima, M. and Storey, K.B. 1993a. In vitro oxidative inactivation of GST from freezing tolerant reptile. Mol. Cell. Biochem. 124, 149-158.

Hermes-Lima, M. and Storey, K.B. 1993b. Antioxidant defenses in the tolerance of freezing and anoxia by garter snakes. Am. J. Physiol. 265, 646-652.

Hillman, S.S. 1978. Some effects of dehydration on internal distribution of water and solutes in Xenopus laevis. Comp. Biochem. Physiol. 61(A), 303-307.

Hillman, S.S. 1978. The role of oxygen delivery and electrolyte levels in the dehydrational death of Xenopus laevis. J. Comp. Physiol. 128, 169-175.

Hillman, S.S., Withers, P.K., Drewes, R.C. and Hillyard, S.D. 2009. Ecological and Environmental Physiology of Amphibians. Oxford University Press, Oxford.

Hjelle, J.J. and Petersen, D.R. 1983. Metabolism of malondialdehyde by rat liver aldehyde dehydrogenase. Toxicol. Appl. Pharmacol. 70, 57-66.

Hohmann, S. Krantz, M. and Nordlander, B. 2007. Yeast osmoregulation. Methods Enzymol. 428, 29-45.

Holden, C.P. and Storey, K.B. 1997. Second messenger and cAMP-dependent protein kinase responses to dehydration and anoxia stresses in frogs. J. Comp. Physiol. B 167, 305-312.

Horton, H.R., Moran, L.A., Ochs, R.S., Rawn, J.D. and Scrimgeour, K.G. 1996. Principles of Biochemistry $2^{\text {nd }}$ addition. Simon \& Schuster. Inc. New Jersey.

Hsu, D.K.W., Guo, Y., Peifley, K.A. and Winkles, J.A. 1997. Differential control of murine aldose reductase and fibroblast growth factor (FGF)-regulated-1 gene expression in NIH $3 \mathrm{~T} 3$ cells by FGF-1 treatment and hyperosmotic stress. Biochem. J. 328, 593-598.

Huang, Z. and Tunnacliffe, A. 2004. Response of human cells to desiccation: comparison with hyperosmotic stress response. J. Physiol. 558 (1), 181-191.

Hyndman, D., Bauman, D.R., Heredia, V.V. and Penning, T.M. 2003. The aldo-keto reductase superfamily homepage. Chem. Biol. Interact. 144, 621-631.

Iliodromitis, E.K., Gaitanaki, C., Lazou, A., Aggeli, I., Gizas, V., Bofilis, E., Zoga, A., Beis, I. and Kremastinos, D.T. 2006. Differential activation of mitogenactivated protein kinases in ischemic and nitroglycerin-induced preconditioning. Basic Res. Cardiol. 101, 327-335.

Jacobs, D., Glossip, D., Xing, H. Muslin, A.J. and Kornfeld, K. 1999. Multiple docking sites on substrate proteins form a modular system that mediates 
recognition by ERK MAP kinase. Genes Dev. 13(2), 163-175.

Janssens, P.A. 1964. Urea production and transaminase activity in Xenopus laevis (Daudin). Comp. Biochem. Physiol. 13, 217-224.

Ji, R.R., Gereau, R.W., Malcangio, M., Strichartz, and G.R. 2009. MAP kinase and pain. Brain Res. Rev. 60(1), 135-148.

Joanisse, D.R. and Storey, K.B. 1996. Oxidative damage and antioxidant in Rana sylvatica, the freeze tolerant wood frog. Am. J. Physiol. 271,545-553.

Johnson, G.L. and Lapadat, R. 2002. Mitogen-activated protein kinase pathways mediated by ERK, JNK, and P38 protein kinases. Science. 298, 1911-1912.

Jones, R.M. 1980. Metabolic consequences of accelerated urea synthesis during seasonal dormancy of spadefoot toads, Scaphiopus couchii and Scaphiopus multiplicatus. J. Exp. Zool. 212, 255-267.

Jowsey, I.R., Jiang, Q., Itoh, K., Yamamoto, M. and Hayes, J.D. 2003. Expression of the Aflatoxin B1-8-9-epoxide-metabolizing murine glutathione S-transferase A3 subunit is regulated by the Nrf2 transcription factor through an antioxidant response element. Mol. Pharmacol. 64, 1018-1028.

Kang, E.S., Woo, I.S., Kim, H.J., Eun, S.Y., Paek, K.S., Kim, H.J., Chang, K.C., Lee, J.H., Lee, H.T., Kim, J., Nishinaka, T., Yabe-Nishimura, C. and Seo, H.G. 2007. Up-regulation of aldose reductase expression mediated by phosphatidylinositol 3-kinase/Akt and Nrf2 is involved in the protective effect of curcumin against oxidative damage. Free Radic. Biol. Med. 43, 535-545.

Karin, M. and Gallagher, E. 2005. From JNK to pay dirt: Jun kinases, their biochemistry, physiology and clinical importance. IUBMB Life. 57(4-5), 283295.

Krishna, M. and Narang, H. 2008. The complexity of mitogen-activated protein kinases (MAPKs) made simple. Cell Mol. Life Sci. 65, 3525-3544.

Kultz, D. and Burg, M. 1998. Evolution of osmotic stress signaling via MAP kinase cascades. J. Exp. Biol. 201, 3015-3021.

Lam, E.W. Francis, R.E. and Petkovic, M. 2006. FOXO transcription factors: key regulators of cell fate. Biochem. Soc. Trans. 34, 722-726.

Larade, K. and Storey, K.B. 2006. Analysis of signal transduction pathways during anoxia exposure in a marine snail: A role for p38 MAP Kinase and downstream signaling cascades. Comp. Biochem. Physiol. B 143, 85-91.

MacDonald, J.A. and Storey, K.B. 2004. Tyrosine phosphorylation and the control of cellular information. In Functional Metabolism: Regulation and Adaptation (ed. K. B. Storey), Wiley-Liss, Hoboken, NJ. 
MacDonald, J.A. and Storey, K.B. 2005. Mitogen-activated protein kinase and selected downstream targets display organ-specific responses in the hibernating ground squirrel. Int. J. Biochem. Cell Biol. 37, 679-691.

Malik, A.I. and Storey, K.B. 2009. Activation of extracellular signal-regulated kinases during dehydration in the African clawed frog, Xenopus laevis. J. Exp. Biol. submitted.

Mamady, H. and Storey, K.B. 2006. Up-regulation of the endoplasmic reticulum molecular chaperone GRP78 during hibernation in thirteen-lined ground squirrels. Mol. Cell. Biochem. 292, 89-98.

Marshall, H.E., Merchant, K. and Stamler, J.S. 2000. Nitrosation and oxidation in the regulation of gene expression. FASEB J. 14(13), 1889-1900.

Matsuda, S., Kawasaki, H., Moriguchi, T., Gotoh, Y. and Nishida, E. 1995. Activation of protein kinase cascades by osmotic shock. J. Biol. Chem. 270, 12781-12786.

May, L.T. and Hill, S.J. 2008. ERK phosphorylation: spatial and temporal regulation by G protein-coupled receptors. Int. J. Biochem. Cell Biol. 40, 2013-2017.

Merkle, S. and Hanke, W. 1988a. Long-term starvation in Xenopus laevis (Daudin) - I. Effects on general metabolism. Comp. Biochem. Physiol. 89(4), 719-730.

Merkle, S. and Hanke, W. 1988b. Long-term starvation in Xenopus laevis (Daudin) - II. Effects on several organs. Comp. Biochem. Physiol. 90(3), 491-495.

Morin, P.J. and Storey, K.B. 2005. Cloning and expression of hypoxia-inducible factor $1 \alpha$ from the hibernating ground squirrel, Spermophilus tridecemlineatus. Biochim. Biophys. Acta. 1729: 32-40.

Ning, Z-Q., Li, J. and Arceci, R.J. 2001. Signal transducer and activator of transcription 3 activation is required for Asp816 mutant c-Kit-mediated cytokine-independent survival and proliferation in human leukemia cells. Blood 97, 3559-3567.

Nishinaka, T. and Yabe-Nishimura, C. 2001. EGF receptor-ERK pathway is a major signaling pathway that mediates upregulation of aldose reductase expression under oxidative stress. Free Radic. Biol. Med. 31, 205-216.

Nishinaka, T. and Yabe-Nishimura, C. 2005. Transcription factor Nrf2 regulates promoter activity of mouse aldose reductase (AKR1B3) gene. J. Pharmacol. Sci. 97, 43-51.

Noguchi, K., Kitanaka, C., Yamana, H., Kokubu, A., Mochizuki, T. and Kuchino, Y. 1999. Regulation of c-Myc through phosphorylation at Ser-62 and Ser-71 by c-jun N-terminal kinase. J. Biol. Chem. 274(46), 32580-32587.

Pelengaris, S., Khan, M. and Evan, G. 2002. C-MYC: more than just a matter of life and death. Nat. Rev. Cancer 2(10), 764-776. 
Platanias, L.C. 2003. Map kinase signaling pathway and hematologic malignancies. Blood 101(12), 4667-4679.

Pohl, B.S., Schön, C., Rössner, A. and Knöchel, W. 2004. The FoxO-subclass in Xenopus laevis development. Gene Expr. Patterns. 5(2), 187-192.

Prakash, P.A., Yogeswaran, U. and Chen, S.M. 2009. A review on direct electrochemistry of catalase for electrochemical sensors. Sensors. 9(3), 18211844.

Price, N.M. and Harrison, P.J. 1987. Comparison of methods for the analysis of dissolved urea in seawater. Marine Biol. 94, 907-317.

Purrello, M., Di Pietro, C., Ragusa, M., Pulvirenti, A., Giugno, R., Di Pietro, V., Emmanuele, G., Travali, S., Scalia, M., Shasha, D. and Ferro, A. 2005. In vitro and in silico cloning of Xenopus laevis SOD2 cDNA and its phylogenetic analysis. DNA cell Biol. 24(2), 111-116.

Ramos J.W. 2008. The regulation of extracellular signal-regulated kinase (ERK) in mammalian cells. Int. J. Biochem. Cell Biol. 40, 2707-2719.

Richards, S.A., Dreisbach, V.C., Murphy, L.O. and Blenis, J. 2001. Characterization of regulatory events associated with membrane targeting of p90 ribosomal S6 kinase 1. Mol. Cell. Biol. 21, 7470-7480.

Rizzo, A.M., Adorni, L., Montorfano, G., Rossi, F. and Berra, B. 2007. Antioxidant metabolism of Xenopus laevis embryos during the first days of development. Comp. Biochem. Physiol. B. Biochem. Mol. Biol. 146(1), 94-100.

Roux, P.P. and Blenis, J. 2004. ERK and p38 MAPK-activated protein kinases: a family of protein kinases with diverse biological functions. Microbiol. Mol. Biol. Rev. $68,320-344$.

Ruvinsky, I. and Meyuhas, O. 2006. Ribosomal protein S6 phosphorylation: from protein synthesis to cell size. Trends Biochem. Sci. 31, 342-348.

Salih, D.A. and Brunet, A. 2008. FoxO transcription factors in the maintenance of cellular homeostasis during aging. Curr. Opin. Cell Biol. 20(2), 126-136.

Schaeffer, H.J. and Weber, M.J. 1999. Mitogen-activated protein kinases: specific messages from ubiquitous messengers. Mol. Cell Biol. 19, 2435-2444.

Schindler, J.F., Monahan, J.B. and Smith, W.G. 2007. P38 pathway kinases as antiinflammatory drug targets. J. Dent. Res. 86, 800-811.

Schwab, M.S., Kim, S.H., Terada, N., Edfjall, C., Kozma, S.C., Thomas, G. and Maller, J.L. 1999. P70s6k Controls selective mRNA translation during oocyte maturation and early embryogenesis in Xenopus laevis. Mol. Cell. Biol. 19, $2485-$ 
2494.

Seery, L.T., Nestor, P.V. and FitzGerald, G.A. 1998. Molecular evolution of the aldoketo reductase gene superfamily. J. Mol. Evol. 46, 139-146.

Seiter, P., Schultheiss, H. and Hanke, W. 1978. Osmotic stress and excretion of ammonia and urea in Xenopus laevis. Comp. Biochem. Physiol. A 61, 571-576.

Seo, H.G., Nishinaka, T. and Yabe-Nishimura, C. 2000. Nitric oxide up-regulates aldose reductase expression in rat vascular smooth muscle cells: a potential role for aldose reductase in vascular remodeling. Mol. Pharmacol. 57, 709-717.

Shaulian, E. and Karin, M. 2001. AP-1 in cell proliferation and survival. Oncogene. 20(19), 2390-2400.

Shaulian, E. and Karin, M. 2002. AP-1 as a regulator of cell life and death. Nat. Cell Biol. 4(5), E131-E136.

Shaywitz, A.J. and Greenberg, M.E. 1999. CREB: A stimulus-induced transcription factor activated by a diverse array of extracellular signals. Annu. Rev. Biochem. $68,821-861$.

Shih, A.Y., Imbeault, S., Barakauskas, V., Erb, H., Jiang, L., Li, P. and Murphy, T.H. 2005. Induction of Nrf2 driven antioxidant response confers neuroprotection during mitochondrial stress in vivo. J. Biol. Chem. 280, 22925-22936.

Spite, M., Baba, S.P., Ahmed, Y., Barski, O.A., Nijhawan, K., Petrash, J.M., Bhatnagar, A. and Srivastava, S. 2007. Substrate specificity and catalytic efficiency of aldo-keto reductases with phospholipid aldehydes. Biochem. J. 405, 95-105.

Sridhar, S.S., Hedley, D. and Sit, L.L. 2005. Raf kinase as a target for anticancer therapeutics. Mol. Cancer. Ther. 4, 677-685.

Storey, K.B. 1996. Oxidative stress: animal adaptations in nature. Braz. J. Med. Biol. Res. 29, 1715-1733.

Storey, K.B. 2002. Life in the slow lane: molecular mechanisms of estivation. Comp. Biochem. Physiol. 133(A), 733-754.

Storey, K.B. 2004. Functional Metabolism Regulation and Adaptation. John Wiley \& Sons. Inc. New Jersey.

Storey, K.B. and Storey, J.M. 1990. Metabolic rate depression and biochemical adaptation in anaerobiosis, hibernation and estivation. Quart. Rev. Biol. 65(2), 145-174.

Storey, K.B. and Storey, J.M. 2004. Metabolic rate depression in animals: transcriptional and translational controls. Biol. Rev. 79, 207-233.

Tan, Y., Rouse, J., Zhang, A., Cariati, S., Cohen, P. and Comb, M.J. 1996. FGF and 
stress regulate CREB and ATF-1 via a pathway involving p38 MAP kinase and MAPKAP kinase-2. EMBO J. 15(17), 4629-4642.

Thimmulappa, R.K., Mai, K.H., Srisuma, S., Kensler, T.W., Yamamoto, M. and Biswal, S. 2002. Identification of Nrf2-regulated genes induced by the chemopreventative agent sulforaphane by oligonucleotide microarray. Cancer Research 62, 5196-5203.

Tinsley, R.C. and Kobel, H.R. 1996. The biology of Xenopus. Zoolgical Society of London, Clarendon Press, Oxford.

Tsai, T.T., Guttapalli, A. Agrawal, A. Albert, T.J., Shapiro, I.M. and Risbud, M.V. 2007. MEK/ERK signaling controls osmoregulation of nucleus pulposus cells of the interverteb ral disc by transactivation of TonEBP/OREBP. J.Bone Miner. Res. 22(7), 965-974.

Van der Horst, A. and Burgering, B.M. 2007. Stressing the role of FoxO proteins in lifespan and disease. Nat. Rev. Mol. Cell Biol. 8(6), 440-450.

Vaupel, P. 2004. The role of hypoxia-induced factors in tumor progression. Oncologist 9: $10-17$.

Venkatesan, B., Mahimainathan, L. Das, F., Ghosh-Choudhury, N. and Ghosh Choudhury, G. 2007. Downregulation of catalase by reactive oxygen species via PI 3 kinase/Akt signaling in mesangial cells. J. Cell Physiol. 211(2), 457-467.

Willmore, W.G. and Storey, K.B. 1997a. Antioxidant systems and anoxia tolerance in a freshwater turtle Trachemys scripta elegans. Mol. Cell. Biochem. 170,177-185.

Willmore, W.G. and Storey, K.B. 1997b. Glutathione systems and anoxia tolerance in turtles. Am. J. Physiol. 273, 219-225.

Wu, X., Noh, S.J., Zhou, G., Dixon, J.E. and Guan, K. 1996. Selective activation of MEK1 but not MEK2 by A-Raf from epidermal growth factor-stimulated Hela cells. J. Biol. Chem. 271, 3265-3271.

Wuerges, J., Lee, J.W., Yim, Y.I., Yim, H.S., Kang, S.O. and Djinovic Carugo, K. 2004. Crystal structure of nickel-containing superoxide dismutase reveals another type of active site. Proc. Natl. Acad. Sci. USA. 101(23), 8569-8574. 


\section{Appendix 1}

\begin{tabular}{|c|c|c|c|}
\hline Antibody used & Source & Company & Product number \\
\hline c-Raf & Rabbit & Cell Signaling Technology & 9427 \\
\hline MEKK & Rabbit & Transduction Laboratories & M17230/L5 \\
\hline MEK1/2 & Rabitt & Transduction Laboratories & M17030/L9 \\
\hline Phospho-MEK1/2 & Rabbit & Cell Signaling Technology & 9121 \\
\hline ERK1/2 & Rabbit & Cell Signaling Technology & 9102 \\
\hline Phospho-ERK1/2 & Rabitt & Cell Signaling Technology & 9101 \\
\hline RSK & Rabbit & Cell Signaling Technology & 9341 \\
\hline RIS6 & Rabbit & Cell Signaling Technology & 2212 \\
\hline Phospho-RIS6 & Rabbit & Cell Signaling Technology & 2211 \\
\hline STAT3 & Rabitt & Cell Signaling Technology & 9134 \\
\hline JNK & Rabbit & Cell Signaling Technology & 9252 \\
\hline Phospho-JNK & Rabbit & Cell Signaling Technology & 9251 \\
\hline p-38 & Rabitt & New England Biolabs & 9212 \\
\hline Phospho-p-38 & Rabbit & New England Biolabs & $9211 \mathrm{~S}$ \\
\hline c-Jun & Rabbit & Santa Cruz Biotechnology & $\mathrm{SC} 045$ \\
\hline Phospho-c-Jun & Rabitt & \begin{tabular}{|l|l|} 
Cell Signaling Technology \\
\end{tabular} & $9164 \mathrm{~S}$ \\
\hline Phospho-c-Myc & Rabbit & Santa Cruz Biotechnology & J1906 \\
\hline CREB & Rabbit & Santa Cruz Biotechnology & SC186 \\
\hline Phospho-CREB & Rabitt & Santa Cruz Biotechnology & SC101663 \\
\hline Nrf2 & Rabbit & Santa Cruz Biotechnology & SC722 \\
\hline FoxO1 & Rabbit & Cell Signaling Technology & 2880 \\
\hline Phospho-FoxO1 & Rabitt & Cell Signaling Technology & 9461 \\
\hline MnSOD & Rabbit & Stressgen Biotechnologies & SOD110D \\
\hline Catalase & Rabbit & GenScript & A011881 \\
\hline
\end{tabular}


Appendix 2
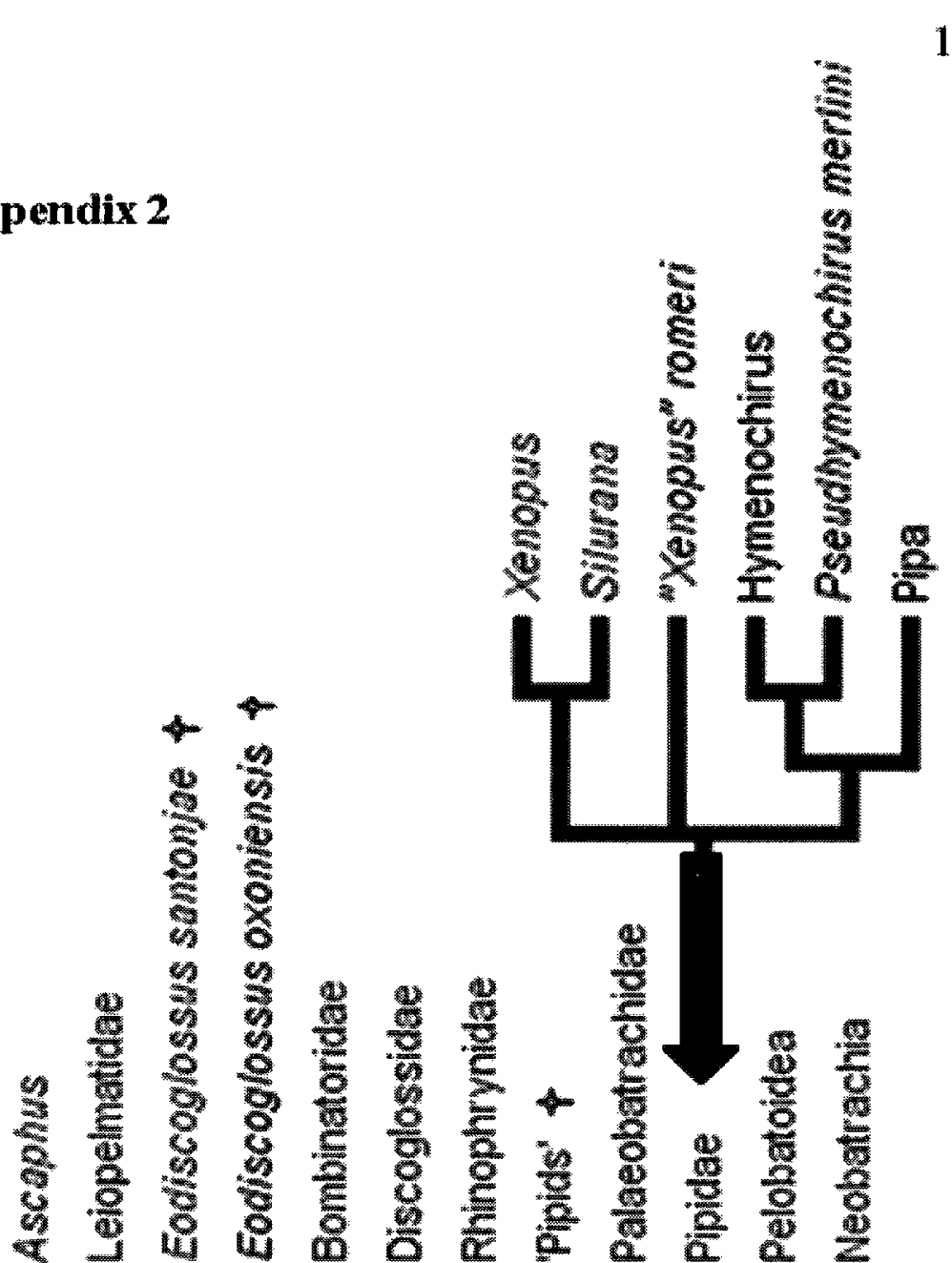

95

$\frac{8}{\frac{8}{6}} \frac{9}{8}$
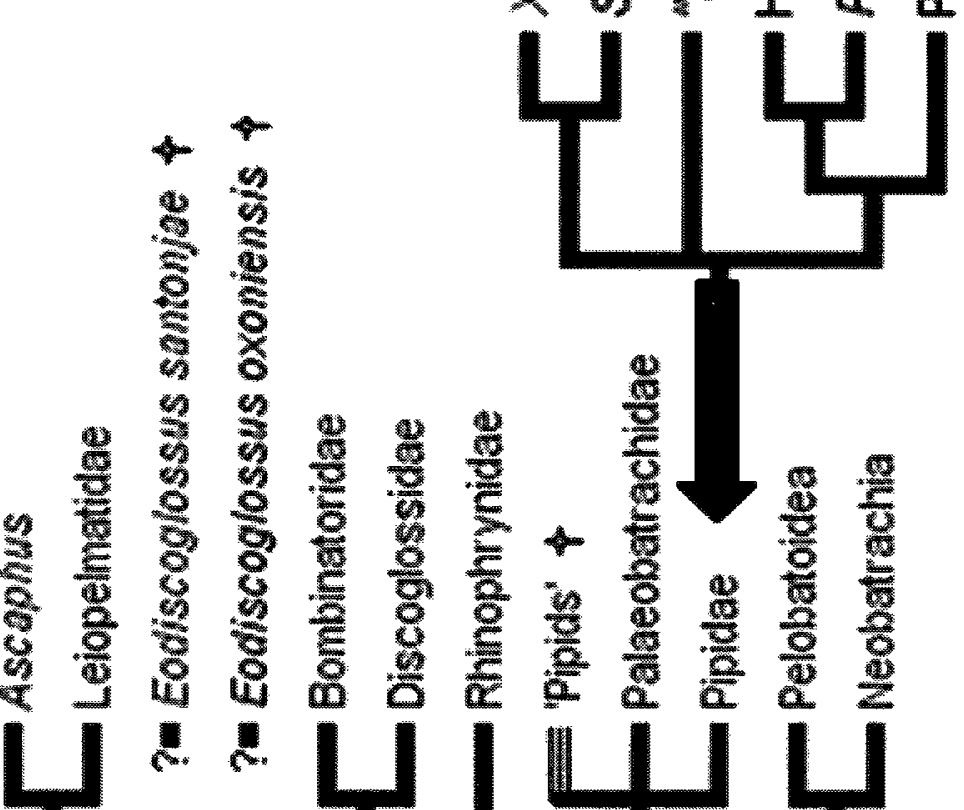

‥
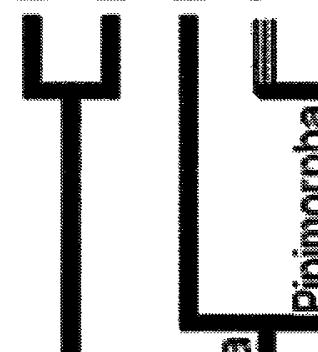